\title{
\begin{tabular}{llllllllll}
\hline & U & P & L & E & M & E & V & T & O
\end{tabular}
}

Fundada en 1911

 M É D I C A}

w w w a c t u a lid a d medica.e s
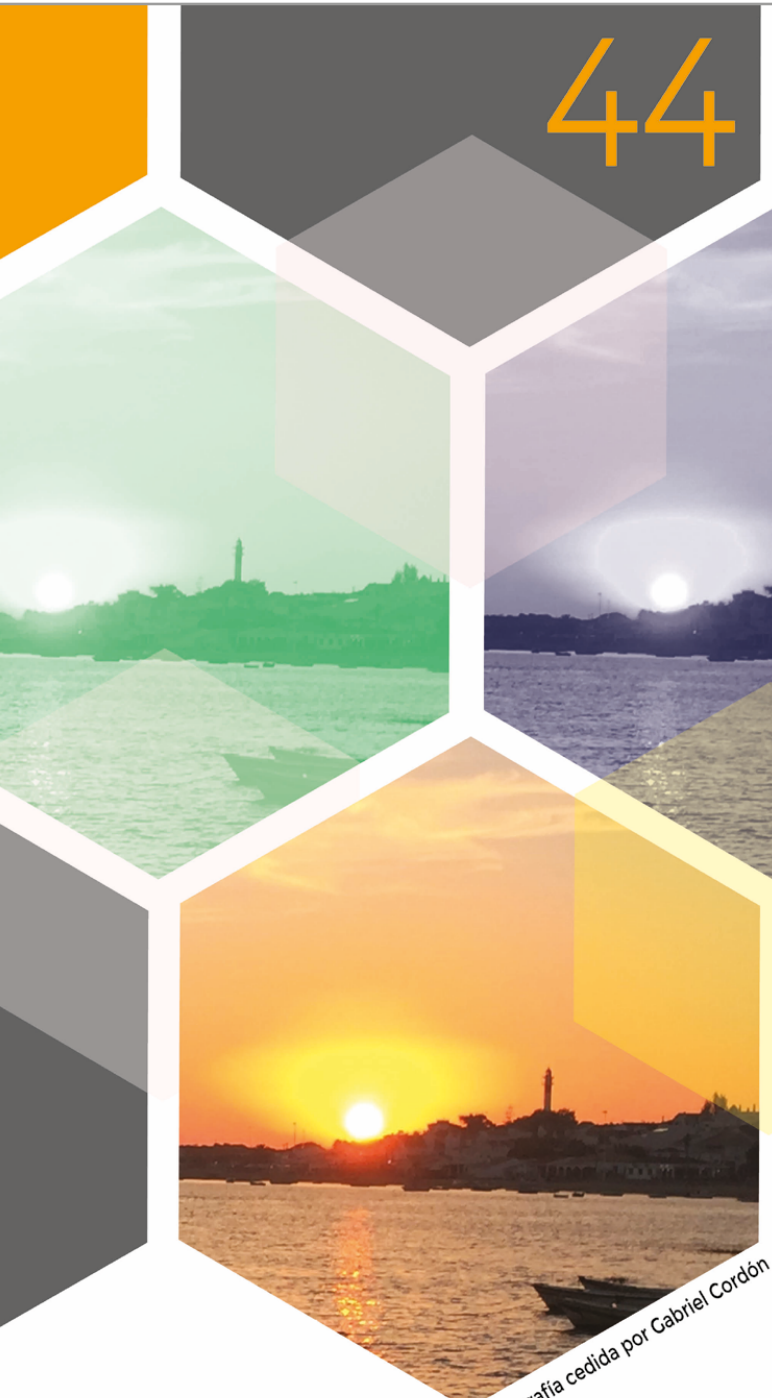

\section{Congreso de la Sociedad} Andaluza de Endocrinología, Diabetes y Nutrición

\section{Formato híbrido \\ (PRESENCIAL Y STREAMING)}
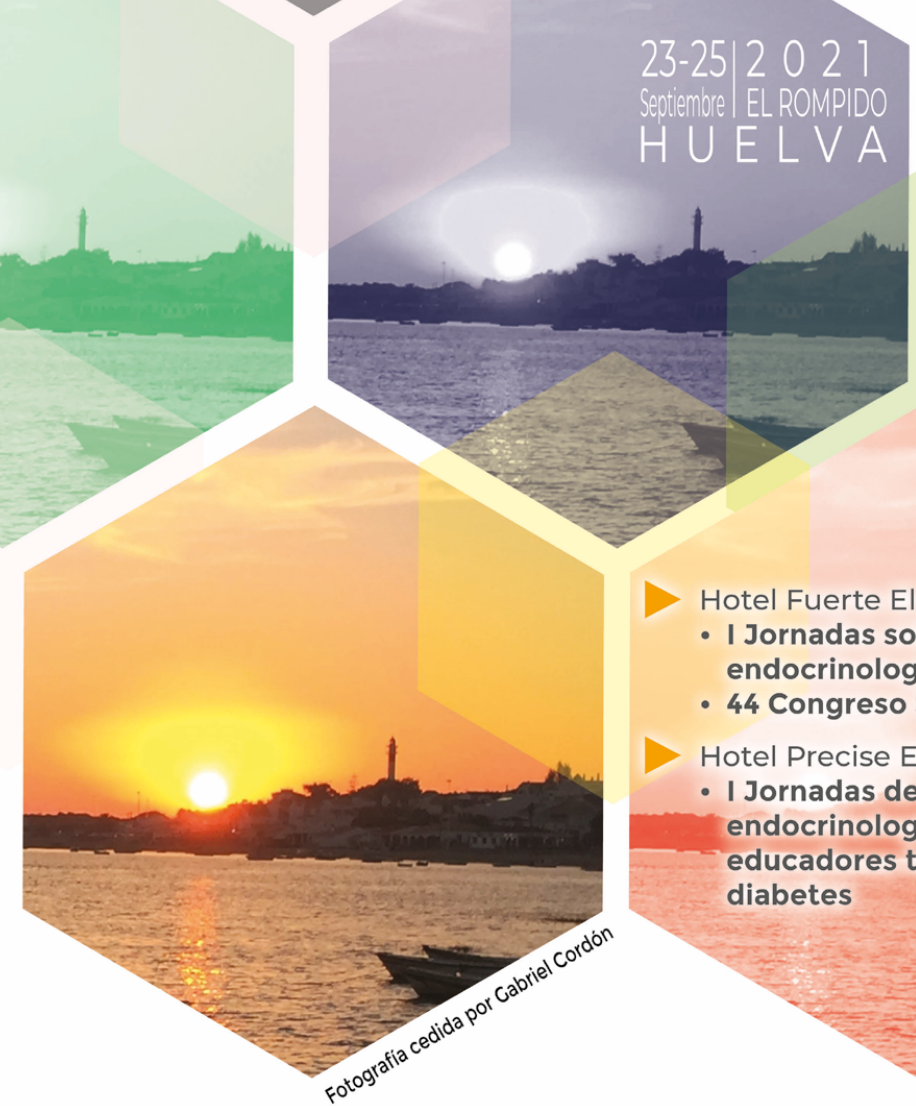

Hotel Fuerte El Rompido:

- I Jornadas sobre técnicas en endocrinología y nutrición

- 44 Congreso SAEDYN

Hotel Precise El Rompido:

- I Jornadas de enfermería en endocrinología, nutrición y educadores terapéuticos en diabetes

La SAEDYN añadiendo Luz a las controversias en Endocrinología, Nutrición y Diabetes

\section{saedyn}

Sociedad Andaluza de

Endocrinologia, Diabetes y Nutrición

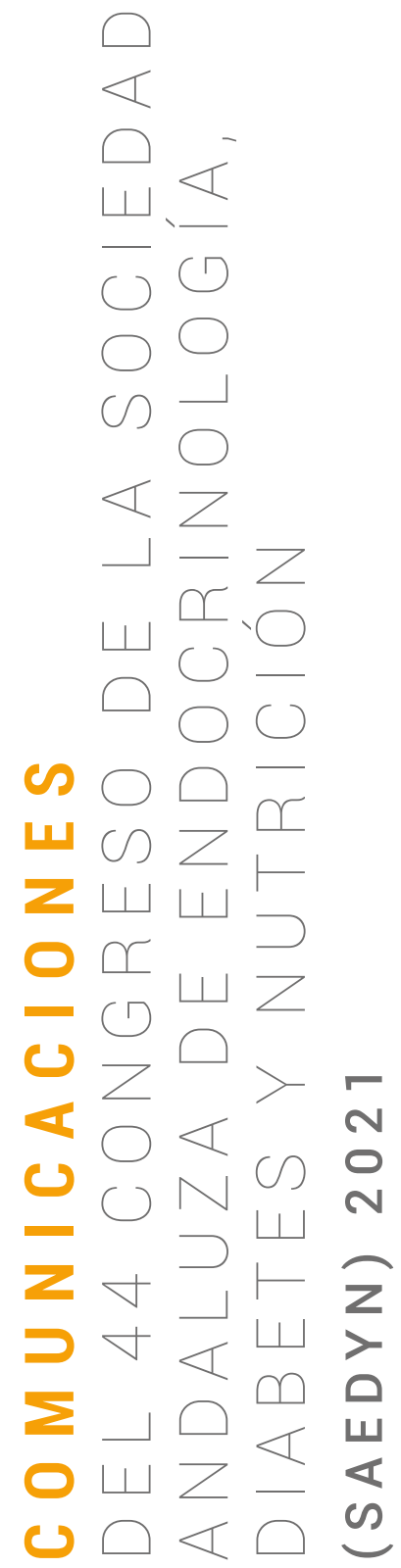




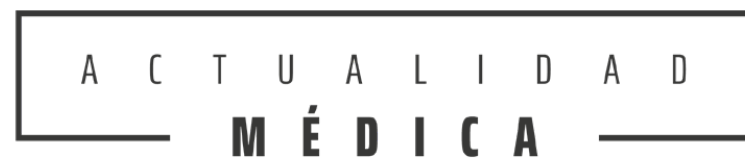

www. actualidad medica.es

\section{Publicación cuatrimestral}

(3 números al año)

\section{() 2021. Actualidad Médica}

Reservados todos los derechos. El contenido de la presente publicación no puede ser reproducido, ni transmitido por ningún procedimiento electrónico o mecánico, incluyendo fotocopia, grabación magnética, ni registrado por ningún sistema de recuperación de información, en ninguna forma, ni por ningún medio, sin la previa autorización por escrito del titular de los derechos de explotación de la misma.

Actualidad Médica, a los efectos previstos en el artículo 32.1 párrafo segundo del vigente TRLPI, se opone de forma expresa al uso parcial o total de las páginas de Actualidad Médica con el propósito de elaborar resúmenes de prensa con fines comerciales.

Cualquier forma de reproducción, distribución, comunicación pública o transformación de esta obra sólo puede ser realizada con la autorización de sus titulares, salvo excepción prevista por la ley.

\section{Disponible en internet:}

Revista editada por:

www.actualidadmedica.es

Atención al lector:

infoam@actualidadmedica.es

Actualidad Médica.

Avda. Madrid 11. 18012 Granada · España.

Protección de datos: Actualidad Médica declara cumplir lo dispuesto por la Ley Orgánica 15/1999 de Protección de Datos de Carácter Personal. Papel ecológico libre de cloro. Esta publicación se imprime en papel no ácido. This publication is printed in acid-free paper. Impreso en Europa.

Depósito Legal: GR-14-1958

ISSN: 0365-7965

DOI: $10.15568 / \mathrm{am}$

Actualidad Médica incluída en Latindex , Índices CSIC y Google Scholar

Para la redacción de los manuscritos y una correcta definición de los términos médicos, Actualidad Médica recomienda consultar el Diccionario de Términos Médicos de la Real Academia Nacional de Medicina

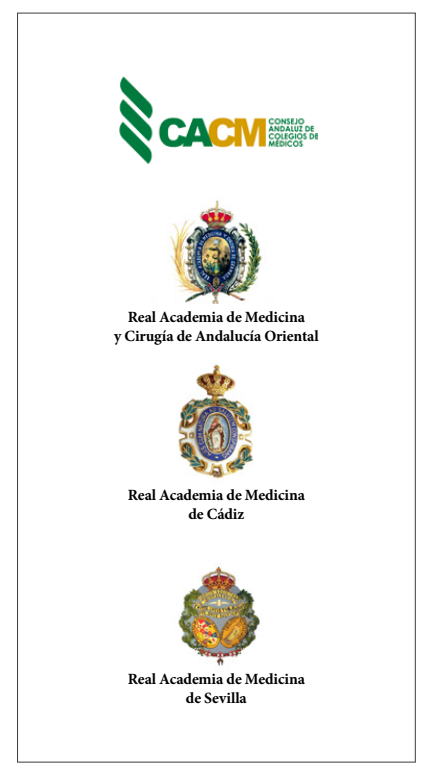




\section{Editores}

Miguel Ángel Martín Piedra. Facultad de Medicina de Granada. España

Antonio Cárdenas Cruz. Hospital de Poniente de Almería. España

\section{Editores adjuntos}

Fernando Leiva Cepas. Facultad de Medicina de Córdoba. España

Antonio Santisteban Espejo. Hospital Universitario Puerta del Mar, Cádiz. España

Miguel Sola García. Hospital Alta Resolución Alcalá la Real, Jaén. España

David González Quevedo. Hospital Regional Universitario de Málaga. España

\section{COMITÉ RECTOR}

\section{Editores}

Miguel Ángel Martín Piedra

Facultad de Medicina de Granada. España

Dr. Emilio García de la Torre

Presidente del Consejo Andaluz del Colegios de Médicos

Prof. Antonio Campos Muñoz

Presidente de la Real Academia de Medicina y Cirugía de Andalucía Oriental

Prof. José Antonio Girón González

Presidente de la Real Academia de Medicina de Cádiz

Prof. Jesús Castiñeiras Fernández

Presidente de la Real Academia de Medicina de Sevilla

\section{COMITÉ CIENTÍFICO Y ASESOR}

Manuel Díaz-Rubio. Real Academia Nacional de Medicina de España. Madrid. España Jorge Alvar Ezquerra. OMS. Ginebra. Suiza

Manuel L. Martí. Academia Nacional de Medicina. Buenos Aires. Argentina

Pasquale Quattrone. Istituto Nazionale dei Tumori. Milán. Italia

Ismael Ángel Rodríguez. Universidad Nacional de Córdoba. Argentina

Antonio Rendas. Universidade Nova de Lisboa. Portugal

Duarte Nuno Vieira. Universidade de Coímbra. Coímbra. Portugal

Alice Warley. King's College. Londres. Reino Unido

Sebastián San Martín. Universidad de Valparaiso. Valparaíso. Chile

Antonio Alcaraz Asensio. Hospital Clinic. Barcelona. España

Francisco Gómez Rodríguez. Universidad de Cádiz. H. U. de Puerto Real. España

Andrés M. Lozano. University of Toronto. Toronto Western Hospital. EEUU

Eduardo Vázquez Ruiz de Castroviejo. Especialista en Cardiología en Jaén. España

Francisco Gómez Rodríguez. Universidad de Cádiz H. U. de Puerto Real. Españal. Cádiz. España

Andrés M. Lozano. Toronto Western Hospital. University of Toronto. Canadá

José Antonio Castilla Alcalá. Hospital U. Virgen de las Nieves. Granada. España

Christian Flotho. Hematología y Oncología Pediátrica. H.U. de Friburgo. Alemania

Cristina Verónica Navarrete Godoy. National Health Service NHS. Leeds. Reino Unido

Manuel Casal Román. Profesor Emérito. Universidad de Córdoba. España

Luis Rodríguez Padial. Jefe de Servicio de Cardiología del Complejo Hospitalario Virgen de la Salud. Toledo.

España

José Miguel Montero García. MSc NSCI University of Central Lancashire. Reino Unido José Antonio García Viudez. Medicina Interna y Reumatología. Almería. España

José Antonio Ortega Domínguez. Jefe del Servicio de Oncología. Clínica Quirón-Salud. Málaga España

Moisés Javier Mieles Cerchar. Urología Pediátrica. HMI Carlos Haya. Málaga. España

Carlos Ortiz Leyba. Medicina Interna. Hospital Quirónsalud Sagrado Corazón. Sevilla. España

Alfonso Rodríguez Herrera. Consultant Paediatrician. Assistant Clinical Professor. School of Medicina,

University College Dublin. St Luke’s General Hospital Irlanda. Dublín. Irlanda

\section{COMITÉ DE REDACCIÓN}

Luis Javier Aróstegui Plaza · M. Nieves Gallardo Collado · Montse López Ferres

\section{DISEÑO Y MAQUETACIÓN}


Presidente:

D. Martín López de la Torre Casares

Vicepresidente:

D. Alberto Moreno Carazo

\section{Secretario:}

D. Rafael Palomares Ortega

\section{Tesorero:}

D. Antonio Jesús Martínez Ortega

Vocales:

Almería: D. Francisco Javier Peñafiel Martínez Cádiz: $D^{a}$. Marta Iturregui Guevara

Córdoba: Da . María Rosa Alhambra Expósito

Granada: $D^{a}$. Carmen Tenorio Jiménez

Huelva: Da . María Lainez López

Jaén: $D^{a}$. Inmaculada Prior Sánchez

Málaga: D. José Carlos Fernández García

Sevilla: Da ${ }^{a}$ María del Castillo Tous Romero

Endocrinología Pediátrica, Málaga:

D. José Antonio López Medina

Investigación y Ciencias Básicas, Sevilla:

D. David Cano González

\section{CON LA COLABORACIÓN DE}

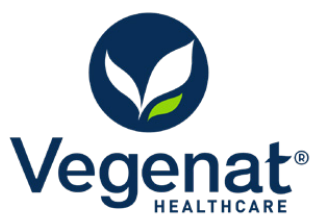

GRUPO NUTRISENS* 


\section{ÍNDICE}

COMUNICACIONES ORALES

RELACIÓN ENTRE LA COMPOSICIÓN CORPORAL Y LA ESTEATOSIS HEPÁTICA NO 11 ALCOHÓLICA

RELATIONSHIP BETWEEN BODY COMPOSITION AND NON-ALCOHOLIC LIVER STEATOSIS

ANÁLISIS COMPARATIVO DE DOS PROTOCOLOS DIAGNÓSTICOS DE DIABETES GESTACIONAL: SOBRECARGA ORAL DE GLUCOSA VS GLUCEMIA BASAL/ HEMOGLOBINA GLICOSILADA COMO ALTERNATIVA DURANTE LA PANDEMIA POR COVID-19

COMPARATIVE ANALYSIS OF TWO DIAGNOSTIC PROTOCOLS FOR GESTATIONAL DIABETES MELLITUS: ORAL GLUCOSE TOLERANCE TEST VS BASAL GLYCEMIA/ GLYCOSYLATED HEMOGLOBIN AS AN ALTERNATIVE IN THE COVID-19 PANDEMIC

VALORACIÓN DEL ESTADO NUTRICIONAL EN PACIENTES CON TUMORES DE CABEZA Y CUELLO

ASSESSMENT OF NUTRITIONAL STATUS IN PATIENTS WITH HEAD AND NECK TUMORS

EVALUACIÓN DE LA DETERMINACIÓN DE PTH EN EL LAVADO DE PAAF COMO PRUEBA DIAGNÓSTICA DEL ADENOMA DE PARATIROIDES

PARATHYROID HORMONE ASSESSMENT IN WASHING LIQUID AFTER FINE-NEEDLE ASPIRATION AS A DIAGNOSTIC TEST FOR PARATHYROID ADENOMA

MARCADORES MOLECULARES E INFLAMATORIOS EN LA VALORACIÓN NUTRICIONAL MORFOFUNCIONAL EN LA SARCOPENIA DE ORIGEN ONCOLÓGICO

MOLECULAR AND INFLAMMATION MARKERS IN THE MORPHOFUNCTIONAL NUTRITIONAL EVALUATION IN SARCOPENIA IN PATIENTS WITH CANCER

SEGUIMIENTO DE LA EDUCACIÓN TERAPÉUTICA(ET) EN PACIENTE DE DEBUT DE DIABETES EN UN HOSPITAL DE DÍA DE DIABETES(HDD)

FOLLOW-UP OF THERAPEUTIC EDUCATION (TE) IN PATIENTS WITH EARLY ONSET DIABETES IN A DIABETES DAY HOSPITAL (DDH)

IDENTIFICACIÓN DE VARIANTES PATOGÉNICAS ASOCIADAS A DIABETES MONOGÉNICA MEDIANTE UN PANEL DIRIGIDO CON TECNOLOGÍA NGS EN PACIENTES CON MODY $X$

IDENTIFICATION OF PATHOGENIC GENE VARIANTS OF MONOGENIC DIABETES USING TARGETED SEQUENCING BY NGS IN MODY X PATIENTS 
COMUNICACIONES TIPO PÓSTER

DESCRIPCIÓN DE PACIENTES CON PIE DIABÉTICO DE CAUSA NEUROPÁTICA Y VASCULAR ATENDIDOS EN UNA UNIDAD DE PIE DIABÉTICO MULTIDISCIPLINAR

DESCRIPTION OF PATIENTS WITH DIABETIC FOOT OF NEUROPATHIC AND VASCULAR CAUSE TREATED IN A MULTIDISCIPLINARY DIABETIC FOOT UNIT

RECLASIFICACIÓN METABÓLICA POSTPARTO EN MUJERES CON DIABETES MELLITUS GESTACIONAL

POSTPARTUM METABOLIC RECLASSIFICATION IN WOMEN WITH GESTATIONAL DIABETES MELLITUS

CARACTERIZACIÓN DE UNA COHORTE DE DIABETES LADA

CARACTERÍSTICAS CLÍNICAS E IMPACTO SOBRE EL CONTROL METABÓLICO TRAS 22 AÑOS DE SEGUIMIENTO EN UNA COHORTE DMI USUARIA DE ISCI

CLINICAL CHARACTERISTICS AND IMPACT ON METABOLIC CONTROL AFTER 22 YEARS OF FOLLOW-UP IN A DMT COHORT USING CSII

ADAPTACIÓN DE UN SENSOR NO INVASIVO DEL NIVEL DE GLUCOSA EN SANGRE PARA EVALUACIÓN EN UN ENTORNO CLÍNICO CONTROLADO

ADAPTATION OF A NON-INVASIVE BLOOD GLUCOSE LEVEL SENSOR FOR EVALUATION IN A CONTROLLED CLINICAL ENVIRONMENT

PATRONES DE MONITORIZACIÓN FLASH DE GLUCOSA EN VIDA REAL: ASOCIACIÓN ENTRE LA FRECUENCIA DE ESCANEO Y LA GLUCOMETRÍA.

REAL-LIFE FLASH GLUCOSE MONITORING PATTERNS: ASSOCIATION BETWEEN SELFMONITORING FREQUENCY AND GLYCAEMIC MEASURES

ANÁLISIS DE LA BASE DATOS DE LIBREVIEW EN LOS PACIENTES CON DIABETES MELLITUS TIPO 1. ¿HAY DIFERENCIA ENTRE LAS INSULINAS BASALES?

ANALYSIS OF THE LIBREVIEW DATABASE IN PATIENTS WITH TYPE 1 DIABETES MELLITUS. IS THERE A DIFFERENCE BETWEEN BASAL INSULINS?

EL CONFINAMIENTO DURANTE EL ESTADO DE ALARMA MEJORÓ EL CONTROL DE LOS DIABÉTICOS TIPO 1

CONFINEMENT DURING THE ALARM STATE IMPROVED THE CONTROL OF TYPE 1 DIABETES

EFECTO DE LA MONITORIZACIÓN FLASH DE GLUCOSA EN ADULTOS CON DIABETES 23 TIPO 1 TRATADOS CON BOMBA DE INSULINA

EFFECT OF FLASH GLUCOSE MONITORING IN ADULTS WITH TYPE 1 DIABETES MANAGED WITH INSULIN PUMP THERAPY 
IMPACTO DEL PASO DE TERAPIA CON SISTEMA HÍBRIDO EN PACIENTES DM1 CON TERAPIA INFUSIÓN CONTINUA DE INSULINA

IMPACT OF THE THERAPY WITH HYBRID CLOSED-LOOP SYSTEM IN DM1 PATIENTS WITH CONTINUOUS INSULIN INFUSION THERAPY

RESULTADOS EN VIDA REAL DE LA MONITORIZACIÓN CONTINUA DE GLUCOSA EN CONSULTA DE DIABETES MELLITUS TIPO 1

REAL-LIFE RESULTS OF CONTINUOUS GLUCOSE MONITORING IN TYPE 1 DIABETES MELLITUS OUTPATIENT REVIEW

PUESTA EN MARCHA DE UN NUEVO PROTOCOLO DE ATENCIÓN EN LA TRANSICIÓN A ADOLESCENTES CON DIABETES TIPO 1: RESULTADOS CLÍNICOS INICIALES TRAS SU IMPLANTACIÓN

IMPLEMENTATION OF A NEW DIABETES TRANSITION CARE PROGRAM IN ADOLESCENTS WITH TYPE 1 DIABETES: FIRST CLINICAL RESULTS AFTER ITS IMPLANTATION

MONITORIZACIÓN CONTINUA DE GLUCOSA FLASH: COMPARACIÓN DE PACIENTES CON DIABETES TIPO 1 EN TERAPIA CON INFUSIÓN SUBCUTÁNEA CONTINUA DE INSULINA, FRENTE AL TRATAMIENTO CON MÚLTIPLES DOSIS

CONTINUOUS FLASH GLUCOSE MONITORING: COMPARISON OF TYPE 1 DIABETES PATIENTS ON CONTINUOUS SUBCUTANEOUS INSULIN INFUSION THERAPY VS MULTIPLE DOSE TREATMENT.

TELECONSULTA EN TIEMPOS DE PANDEMIA

TELECONSULTATION IN TIME OF PANDEMIC

HIPOMAGNESEMIA Y PATOLOGÍAS DEL METABOLISMO MINERAL ÓSEO

HYPOMAGNESEMIA AND PATHOLOGIES OF BONE MINERAL METABOLISM

ANÁLISIS DE LAS INTERCONSULTAS HOSPITALARIAS, REALIZADAS AL SERVICIO DE ENDOCRINOLOGÍA DEL HOSPITAL JUAN RAMÓN JIMÉNEZ, EN EL PERIODO 2020

ANALYSIS OF HOSPITAL REFERRALS TO THE ENDOCRINOLOGY DEPARTMENT OF THE JUAN RAMÓN JIMÉNEZ HOSPITAL IN THE PERIOD 2020

CONSULTAS A ENDOCRINOLOGÍA POR TOXICIDAD INMUNOMEDIADA DURANTE EL TRATAMIENTO ONCOLÓGICO

ENDOCRINE CONSULTATIONS FOR IMMUNE-MEDIATED TOXICITY DURING ONCOLOGICAL TREATMENT

EL MONITORIZACIÓN FLASH DE GLUCOSA Y SUS BENEFICIOS POTENCIALES EN LOS PACIENTES CON DIABETES MELLITUS TIPO 1

FLASH GLUCOSE MONITORING AND ITS POTENTIAL BENEFITS IN PATIENTS WITH TYPE DIABETES MELLITUS 
PROGRAMA PILOTO DE IMPLANTACIÓN DE MÉTODO DE SCREENING DE DESNU-

TRICIÓN SNAQ

SNAQ MALNUTRITION SCREENING METHOD IMPLANTATION PILOT PROGRAM

SÍNDROME DE KALLMAN: ANÁLISIS DESCRIPTIVO DE UNA SERIE DE 16 PACIENTES

KALLMAN SYNDROME: A DESCRIPTIVE ANALYSIS OF A SERIES OF 16 PATIENTS

SELECCIÓN DE PACIENTES SUBSIDIARIOS DE TRATAMIENTO CORTICOIDEO EN CIRUGÍA

TRANSESFENOIDAL

SELECTION OF SUBSIDIARY PATIENTS FOR CORTICOID TREATMENT IN

TRANSSPHENOIDAL SURGERY

IMPACTO DE LA PANDEMIA COVID19 EN LOS INGRESOS HOSPITALARIOS EN LA UNIDAD DE ENDOCRINOLOGÍA Y NUTRICIÓN DEL HOSPITAL VIRGEN DEL ROCIO (HUVR)

IMPACT OFTHE COVID19 PANDEMIC ON HOSPITAL ADMISSIONS IN THEENDOCRINOLOGY

AND NUTRITION UNIT OF THE VIRGEN DEL ROCIO HOSPITAL (HUVR)

EVALUACIÓN DE LAS INTERCONSULTAS HOSPITALARIAS RECIBIDAS POR LA UNIDAD DE NUTRICIÓN EN EL HOSPITAL JUAN RAMÓN JIMÉNEZ EN EL ÚLTIMO AÑO EVALUATION OF INPATIENT NUTRITIONAL CONSULTATIONS RECEIVED AT JUAN RAMON JIMENEZ HOSPITAL LAST YEAR

VALORACIÓN NUTRICIONAL CON ENFOQUE MORFOFUNCIONAL EN PACIENTES CON CÁNCER DE CABEZA Y CUELLO, ESTUDIO DESCRIPTIVO DE UNA MUESTRA NUTRITIONAL ASSESSMENT WITH A MORPHOFUNCTIONAL APPROACH IN PATIENTS WITH HEAD AND NECK CANCER, A DESCRIPTIVE STUDY OF A SAMPLE

INCIDENTALOMA SUPRARRENAL. MÁS OSCURO DE LO ESPERADO

ADRENAL INCIDENTALOMA. DARKER THAN EXPECTED

ESTUDIO DESCRIPTIVO DE LA POBLACIÓN TRANSEXUAL ATENDIDA EN EL HOSPITAL PUERTA DEL MAR (2015-2019)

DESCRIPTIVE STUDY OF TRANSGENDER POPULATION ATTENDED AT PUERTA DEL MAB HOSPITAL (2015-2019)

DESCRIPCIÓN CLÍNICA Y ANALÍTICA DE NUESTRA COHORTE DE AFECTOS Y 35 PORTADORAS DE ADRENOLEUCODISTROFIA

CLINICAL AND ANALYTICAL DESCRIPTION OF OUR COHORT OF AFFECTS AND CARRIERS OF ADRENOLEUCODYSTROPHY

LESIONES QUÍSTICAS DE PARATIROIDES: A PROPÓSITO DE UNA ENTIDAD HETEROGÉNEA E INFRECUENTE. PRESENTACIÓN DE DOS CASOS CLÍNICOS

CYSTIC PARATHYROID LESIONS: ABOUT A RARE AND HETEROGENEOUS ENTITY. TWO CASES REPORT 
PAPEL PRONÓSTICO DE LOS INDICADORES METABÓLICOS DE INFLAMACIÓN EN EL

COVID-19

PROGNOSTIC VALUE OF METABOLIC AND INFLAMMATORY INIDCATORS IN

COVID-19

UTILIDAD DE LA CALCULADORA DE RIESGO DE MALIGNIDAD DEL NÓDULO TIROIDEO EN LA ESTRATIFICACIÓN DEL RIESGO EN NÓDULOS TIROIDEOS CON CITOLOGIA INDETERMINADA

THYROID NODULE RISK CALCULATOR USEFULNESS IN THE RISK STRATIFICATION OF INDETERMINATE THYROID NODULES

RESULTADOS DE CONSULTA DE ALTA RESOLUCIÓN DE PATOLOGÍA NODULAR TIROIDEA A TRAVÉS DE PAAF ECOGUIADA A CARGO DE ENDOCRINOLOGía EN EL ÁREA DE GESTIÓN SANITARIA SUR DE SEVILLA

RESULTS OF ULTRASOUND GUIDED FINE NEEDLE ASPIRATION FOR EVALUATION OF NODULAR THYROID DISEASE IN A HIGH RESOLUTION CONSULTATION OF ENDOCRINOLOGY IN SOUTHERN SEVILLE HEALTH AREA

DISFUNCIÓN TIROIDEA EN PACIENTES CON ESCLEROSIS MÚLTIPLE TRATADOS CON ALEMTUZUMAB

THYROID DYSFUNCTION IN PATIENTS WITH MULTIPLE SCLEROSIS TREATED WITH ALEMTUZUMAB

ANATOMÍA PATOLÓGICA DE TIROIDES EN PACIENTES CON ESCLEROSIS MÚLTIPLE TRATADOS CON ALEMTUZUMAB E INTERVENIDOS POR ALTERACIONES TIROIDEAS REFRACTARIAS

PATHOLOGICAL THYROID ANATOMY IN PATIENTS WITH MULTIPLE SCLEROSIS TREATED WITH ALEMTUZUMAB AND OPERATED ON FOR REFRACTORY THYROID DISORDERS

REESTADIFICACIÓN DEL CÁNCER DIFERENCIADO DE TIROIDES SEGÚN LA NUEVA EDICIÓN DE LA AJCC/TNM

RE-STAGING OF DIFFERENTIATED THYROID CANCER ACCORDING TO THE NEW EDITION OF THE AJCC / TNM

ANÁLISIS RETROSPECTIVO DEL CÁNCER DE TIROIDES EN EL ÁREA SANITARIA SUR DE SEVILLA DE 2012 A 2020

THYROID CANCER IN SOUTH SEVILLE HEALTH MANAGEMENT AREA: RETROSPECTIVE ANALYSIS OF THE PERIOD 2012 - 2020

PREVALENCIA DE CARCINOMAS DIFERENCIADOS DE TIROIDES (CDT) SOBRE NÓDULOS TIROIDEOS HIPERFUNCIONANTES O TÓXICOS

PREVALENCE OF DIFFERENTIATED THYROID CARCINOMAS (DTC) ON HYPERFUNCTIONING OR TOXIC THYROID NODULES 


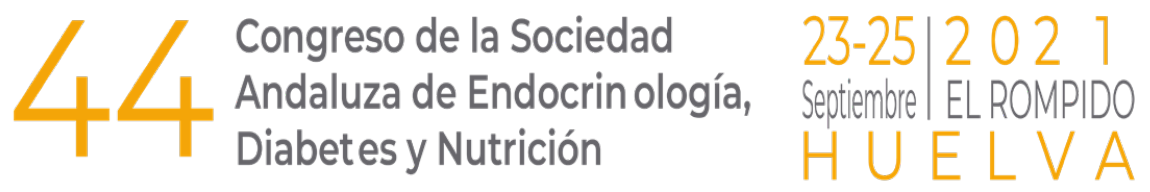

\section{O M U N I C A C IONES \\ DEL 44 CONGRESO DE LA SOCIEDAD ANDALUZA DE ENDOCRINOLOGÍA, DIABETES Y NUTRICIÓN}

(SAEDYN) 2021

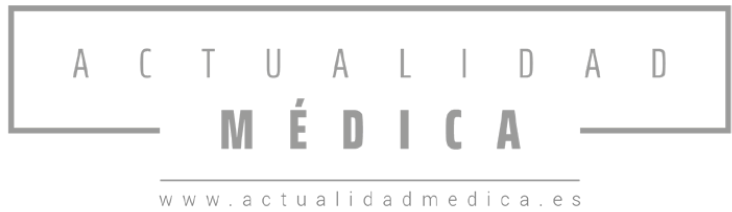




\section{RELACIÓN ENTRE LA COMPOSICIÓN COR- PORAL Y LA ESTEATOSIS HEPÁTICA NO ALCOHÓLICA}

\section{RELATIONSHIP BETWEEN BODY COMPOSI-} TION AND NON-ALCOHOLIC LIVER STEATOSIS

Ana Segarra Balao ${ }^{1 / 1}$; María De Damas Medina ${ }^{1 / 1}$; Roberto Carlos Romo Remigio ${ }^{1 / 1}$; Juan de Dios Barranco Ochoa ${ }^{1 / 1}$; María Sánchez-Prieto Castillo ${ }^{1 / 1}$; Carmen Gutiérrez Alcántara $^{1 / 1}$; Alberto Moreno Carazo ${ }^{1 / 1}$

(1) Complejo Hospitalario de Jaén

(1) Servicio de Endocrinología y Nutrición

NUTRICIÓN CLÍNICA

\section{INTRODUCCIÓN}

La obesidad y el síndrome metabólico son factores de riesgo conocidos para el desarrollo de esteatosis hepática no alcohólica (EHNA), que se caracteriza por el acúmulo de grasa en los hepatocitos en ausencia de otras etiologías de daño hepático.

\section{OBJETIVOS}

Comparar medidas de antropometría clásica (IMC, perímetro de cintura) ya validadas, con nuevas técnicas de composición corporal (bioimpedanciometría) y su relación con el grado de esteatosis y fibrosis hepática.

\section{MATERIAL Y MÉTODOS}

Estudio transversal descriptivo. Se recogen medidas antropométricas (índice de masa corporal, IMC, y perímetro de cintura, PC) y de composición corporal (Bioimpedanciometría Akern Bia $101^{\circledR}$ ) en pacientes con enzimas hepáticas alteradas, descartadas otras posibles causas de hepatitis. Se realiza ecografía hepática y Fibroscan ${ }^{\circledast}$ para diagnóstico de EHNA y fibrosis. Análisis estadístico con SPSS ${ }^{\circledast}$.

\section{RESULTADOS}

$\mathrm{N}=93$. Edad media $59.8 \pm 12.98$ años. $62.4 \%$ varones. IMC $30.05 \pm 5.96 \mathrm{Kg} / \mathrm{m} 2$. PC $101.98 \pm 14.46 \mathrm{~cm}$. Diabetes mellitus 24.7\%. HTA 51.6\%. Dislipemia 38.7\%. Se plantean regresiones logísticas individuales de variables analíticas, nutricionales y de características físicas de los pacientes, para comprobar qué variables son un factor de riesgo o protección a presentar un Grado de Esteatosis mayor de 2; y cuáles a presentar un Grado de Fibrosis mayor a 2. Posteriormente se plantea un modelo de regresiones logística multivariante hacia atrás tanto para el estudio del grado de esteatosis como el grado de fibrosis, con las variables que presentan efecto significativo en los modelos individuales. Para grado de Esteatosis: Se comprueba que las variables Leucocitos,
PC y FMe se manifiestan como factor de riesgo a presentar el evento; y la variable FM es un factor de protección al evento, siendo estas variables estadísticamente significativas. Para Grado Fibrosis: Se comprueba que las variables FM y GOT se manifiestan como factor de riesgo a presentar el evento y las variables Plaquetas y Colesterol LDL son factores de protección al evento, siendo estas variables estadísticamente significativas.

\section{CONCLUSIONES}

El PC y la FMe son factores de riesgo independientes para el desarrollo de EHNA. El PC tiene limitaciones para predecir el grado de fibrosis. En nuestro estudio, la FM sí es un predictor independiente para fibrosis.

ANÁLISIS COMPARATIVO DE DOS PRO-
TOCOLOS DIAGNÓSTICOS DE DIABETES
GESTACIONAL: SOBRECARGA ORAL DE
GLUCOSA VS GLUCEMIA BASAL/HE-
MOGLOBINA GLICOSILADA COMO AL-
TERNATIVA DURANTE LA PANDEMIA
POR COVID-19

COMPARATIVE ANALYSIS OF TWO DIAGNOSTIC PROTOCOLS FOR GESTATIONAL DIABETES MELLITUS: ORAL GLUCOSE TOLERANCE TEST VS BASAL GLYCEMIA/GLYCOSYLATED HEMOGLOBIN AS AN ALTERNATIVE IN THE COVID-19 PANDEMIC

José Ignacio Martínez Montoro ${ }^{1 / 1}$; Víctor José Simón Frapolli $^{1 / 1}$; María Molina Vega ${ }^{1 / 1}$; Sonsoles Morcillo Espina $^{1 / 1}$; María Suárez Arana ${ }^{2 / 2}$; Francisco J Tinahones $^{1 / 1}$; María José Picón César ${ }^{1 / 1}$

(1) Hospital Universitario Virgen de la Victoria/Instituto de Investigación Biomédica de Málaga-IBIMA, (2) Hospital Regional Universitario de Málaga

(1) Endocrinología y Nutrición, (2) Ginecología y Obstetricia

\section{DIABETES}

\section{INTRODUCCIÓN}

En mayo de 2020, durante la situación de pandemia por COVID-19, el Grupo Español de Diabetes y Embarazo publicó un documento de consenso en el que se establecían los criterios para el diagnóstico de diabetes gestacional (DG) en caso de no poder aplicar el protocolo habitual en dos fases por la situación de emergencia sanitaria.

\section{OBJETIVOS}

El objetivo del presente trabajo es realizar un análisis comparativo de las características de las mujeres con test de O'Sullivan positivo en el mismo trimestre de embarazo de 2019 y 2020 , en el que se aplicaron los criterios propuestos ante la imposibilidad de realizar la sobrecarga oral de glucosa (SOG) en nuestro centro. 


\section{MATERIAL Y MÉTODOS}

Estudio observacional retrospectivo en el que se comparan datos clínicos-analíticos de mujeres con test de O'Sullivan positivo en el trimestre de septiembre-octubre-noviembre de 2019 diagnóstico de DG mediante SOG-100 g y 2020 diagnóstico de DG mediante criterios de glucemia basal $\geq 100 \mathrm{mg} / \mathrm{dl}$ en primer trimestre; $\geq 95 \mathrm{mg} / \mathrm{dl}$ en segundo trimestre $/ \mathrm{HbA} 1 \mathrm{c} \geq 5.9 \%$ en primer trimestre; $\geq 5.7 \%$ en segundo trimestre.

\section{RESULTADOS}

Las principales características de ambos grupos se exponen en la tabla 1. Como resultados más relevantes: en el último trimestre de 2019 hubo 41 diagnósticos de DG (el 16\% de las pacientes con O'Sullivan positivo) por 37 en 2020 (13.8\%), p =0.489. 10 de los diagnósticos de 2019 se realizaron antes de la 24 semana de gestación por 17 en 2020 (15.4\% vs $17.7 \%$ p $=0.699) ; 31$ de los diagnósticos de 2019 se realizaron tras la 24 semana de gestación por 19 en $2020(16.1 \%$ vs $11.1 \% \mathrm{p}=0.699)$. No hubo diferencias significativas en cuanto a la modalidad de tratamiento que recibieron las pacientes en los dos períodos en comparación (dieta/insulinoterapia/metformina) $(\mathrm{p}=0.454)$.

\section{CONCLUSIONES}

La tasa de diagnóstico de DG fue similar utilizando los criterios de SOG (2019) y los criterios de glucemia basal/HbA1c por la situación de pandemia por COVID-19 (2020). Asimismo, no hubo diferencias en cuanto al número de pacientes que requirieron tratamiento farmacológico.

\begin{tabular}{|c|c|c|c|}
\hline & Grupo $2019(n=257)$ & Grupo $2020(n=268)$ & $\mathrm{p}$ \\
\hline Edad (años) & $33,6 \pm 6,38$ & $33,93 \pm 5,01$ & 0,535 \\
\hline IMC previo $\left(\mathrm{kg} / \mathrm{m}^{2}\right)$ & $27,87 \pm 6,86 \quad(n=233)$ & $27,15 \pm 6,15(n=265)$ & 0,222 \\
\hline Primíparas & $106(n=219)$ & $111(n=137)$ & $<0,001$ \\
\hline Antecedentes familiares DG & $60(n=224)$ & $87(n=264)$ & 0,139 \\
\hline Antecedentes personales DG & $12(n=123)$ & $32(n=154)$ & 0,013 \\
\hline Antecedentes macrosomía & $5(n=117)$ & $26(n=155)$ & 0,001 \\
\hline O'Sullivan (mg/dL) & $160 \pm 16,7$ & $159,41 \pm 28,71$ & 0,577 \\
\hline Glucosa $0^{\prime}(\mathrm{mg} / \mathrm{dL})$ & $84,6 \pm 7,88$ & $83,69 \pm 11,63$ & 0,293 \\
\hline Glucosa $60^{\circ}(\mathrm{mg} / \mathrm{dL})$ & $160,35 \pm 29,81$ & & \\
\hline Glucosa $120^{\prime}(\mathrm{mg} / \mathrm{dL})$ & $138,8 \pm 29,31$ & & \\
\hline Glucosa $180^{\circ}(\mathrm{mg} / \mathrm{dL})$ & $109,60 \pm 31,80$ & & \\
\hline $\mathrm{HbA} 1 \mathrm{c}(\%)$ & & $5,23 \pm 0,38$ & \\
\hline EG SOG-100 g(semanas) & $25,41 \pm 6,27$ & $23,91 \pm 6,97$ & 0,010 \\
\hline$>24$ semanas & $192(74.7 \%)$ & $171(63.8 \%)$ & \multirow{2}{*}{0,008} \\
\hline$\leq 24$ semanas & $65(25.3 \%)$ & $96(35.8 \%)$ & \\
\hline Diagnóstico de DG & $41(16 \%)$ & $37(13.8 \%)$ & 0,489 \\
\hline Tratamiento & & & 0,454 \\
\hline Insulina & $11(26.8 \%)$ & $14(37.8 \%)$ & \\
\hline Dieta & $29(70.7 \%)$ & $21(56.8 \%)$ & \\
\hline Metformina & $1(2.4 \%)$ & $2(5.4 \%)$ & \\
\hline
\end{tabular}

Tabla 1. (ANÁLISIS COMPARATIVO DE DOS PROTOCOLOS DIAGNÓSTICOS DE DIABETES GESTACIONAL: SOBRECARGA ORAL DE GLUCOSA VS GLUCEMIA BASAL/HEMOGLOBINA GLICOSILADA COMO ALTERNATIVA DURANTE LA PANDEMIA POR COVID-19) 


\section{VALORACIÓN DEL ESTADO NUTRICIONAL EN PACIENTES CON TUMORES DE CABEZA Y CUELLO}

\section{ASSESSMENT OF NUTRITIONAL STATUS IN} PATIENTS WITH HEAD AND NECK TUMORS

Andrea Fernández Valero ${ }^{1 / 1}$; Isabel María Vegas Aguilar ${ }^{1 / 1}$; Jose Ignacio Martínez Montoro ${ }^{1 / 1}$; Jose Manuel García Almeida $^{1 / 1}$; Francisco José Tinahones Madueño ${ }^{1 / 1}$

(1) Hospital Universitario Virgen de la Victoria

(1) Endocrinología y Nutrición

NUTRICIÓN CLÍNICA

\section{INTRODUCCIÓN}

Los pacientes con tumores de cabeza y cuello son pacientes con un elevado riesgo de desnutrición, tanto por la propia localización de la enfermedad y su evolución, como por los tratamientos agresivos a los que deben ser sometidos, que dificultan o impiden una ingesta oral adecuada.

\section{OBJETIVOS}

El objetivo de este trabajo es describir su estado nutricional en la primera visita a la consulta de Nutrición.

\section{MATERIAL Y MÉTODOS}

Estudio observacional retrospectivo en el que se recogieron los datos de 40 pacientes con tumores de cabeza y cuello valorados por primera vez en la consulta de Nutrición. Se recogieron datos analíticos (linfocitos, colesterol, albúmina y prealbúmina), datos antropométricos (índice de masa corporal, porcentaje de pérdida de peso), dinamometría de mano (Jamar), bioimpedanciometría y ángulo de fase (AF). Además se valoró si tenían algún tipo de soporte nutricional previo.

\section{RESULTADOS}

Se presentan los datos de 40 pacientes (32 hombres y 8 mujeres) con una edad media de $61,85 \pm 10,43$ años. En cuanto al tipo de tumor, el $92.5 \%$ era de tipo epidermoide, siendo la mayor parte (57\%) de localización laríngea y el $54.8 \%$ estadio IV. El 75\% de los pacientes ya recibían suplementación o nutrición enteral completa vía oral (43,3\%), SNG (33.3\%) o gastrostomía (23,3\%). En cuanto a la valoración nutricional, los datos analíticos fueron: linfocitos $1522 \pm 1105 \times 109$, albúmina 3,31 $\pm 0.66 \mathrm{~g} / \mathrm{dl}$, prealbúmina $22,8 \pm 8,47 \mathrm{mg} / \mathrm{dl}$ y colesterol total $180,32 \pm 36,3 \mathrm{mg} / \mathrm{dl}$. El peso medio fue de $63,1 \pm$ $12,7 \mathrm{~kg}$ con un IMC de $23,1 \pm 5,96$ y un porcentaje de pérdida de peso medio de 9,5\%. La dinamometría fue de $25,41 \pm 7,21$. Por último, el análisis de composición corporal por bioimpedancia mostraba una hidratación del 75,12\% $\pm 3,42$, agua extracelular 52,4 $\pm 5,7 \%$, masa grasa $19,8 \pm 9,35 \%$, masa libre de grasa $80,2 \pm$ $9,35 \%$, masa muscular 40,99 $\pm 7,71 \%$, nutrición 711,98 $\pm 150,43$, ángulo de fase $4,9 \pm 1,02 \%$ y ángulo de fase estandarizado $-0.71 \pm 1.67 \%$.

\section{CONCLUSIONES}

Un elevado porcentaje de pacientes cumple criterios GLIM de desnutrición moderada, ya que cumplen el criterio etiológico (enfermedad aguda y reducción de la ingesta) y el criterio fenotípico (pérdida de peso medio $9.5 \%$ ). De forma concordante, la utilización de las nuevas medidas de composición corporal como la bioimpedanciometría a través del AF y el AF estandarizado nos permite objetivar desnutrición a nivel celular.

EVALUACIÓN DE LA DETERMINACIÓN DE PTH EN EL LAVADO DE PAAF COMO PRUEBA DIAGNÓSTICA DEL ADENOMA DE PARATIROIDES

PARATHYROID HORMONE ASSESSMENT IN WASHING LIQUID AFTER FINE-NEEDLE ASPIRATION AS A DIAGNOSTIC TEST FOR PARATHYROID ADENOMA

Celia Gallego Díaz ${ }^{1 / 1}$; Manuel J. Caballero Segura ${ }^{1 / 1}$; Virginia Hernando Jiménez ${ }^{1 / 1}$; Guillermo Martínez de Pinillos Gordillo ${ }^{1 / 1}$; Joaquín Bobillo Lobato ${ }^{1 / 2}$

(1) Hospital Virgen de Valme

(1) Endocrinología y Nutrición, (2) Bioquímica Clínica

\section{TIROIDES-PARATIROIDES (GENERAL)}

\section{INTRODUCCIÓN}

Actualmente existen varias pruebas diagnósticas para el estudio de los adenomas de paratiroides, sin embargo la localización de éstos en algunos casos supone un desafío. La implementación de nuevas pruebas diagnósticas puede facilitar el abordaje quirúrgico mínimamente invasivo.

\section{OBJETIVOS}

Evaluar la utilidad de la determinación analítica de PTH en el lavado de PAAF como prueba diagnóstica del adenoma de paratiroides en pacientes con hiperparatiroidismo primario.

\section{MATERIAL Y MÉTODOS}

Estudio observacional retrospectivo de 31 pacientes diagnosticados de hiperparatiroidismo primario en nuestro hospital a los que se realizó PAAF ecoguiada de lesiones compatibles con adenoma de paratiroides con determinación de PTH en el lavado de aguja (PTHL). Se ha considerado como positivo un punto de corte para PTHL de $100 \mathrm{pg} / \mathrm{mL}$.

\section{RESULTADOS}

El $74,2 \%$ de la muestra fueron mujeres con una edad media de $61.5 \pm 8,7$ años. Se punzaron 31 lesiones con un diámetro medio de 13,74 $\pm 12,6 \mathrm{~mm}$, sin registrarse ninguna complicación relacionada con el procedimiento. El 80,7\% de los casos no presentaba captación 
en la gammagrafía con Sestamibi-Tc99m, en el 12,9\% se sospechaba adenoma intratiroideo y en el 6,4\% había discordancia entre estudios de imagen (ecografía, gammagrafía, TAC 4D paratiroideo). El valor medio de PTHL fue $4626 \pm 10430 \mathrm{pg} / \mathrm{mL}$, considerándose positivos el $74,2 \%$ de los casos. Hasta la realización del análisis se han intervenido 23 pacientes y el resultado de la cirugía ha sido concordante con la lesión localizada mediante PTHL en un $86,9 \%$ de los casos. La determinación de PTHL ( $\geq 100 \mathrm{pg} / \mathrm{mL}$ ) en nuestra serie, presenta una sensibilidad del $90 \%$, un valor predictivo positivo del $100 \%$, especificidad del $100 \%$ y el valor predictivo negativo del $60 \%$.

Se observaron 2 casos falsos negativos con valores de PTHL 64 y $72 \mathrm{pg} / \mathrm{mL}$.

\section{CONCLUSIONES}

La medición de PTH en el lavado de PAAF es una prueba diagnóstica asequible y de gran utilidad para confirmar la localización del adenoma de paratiroides. Son necesarios más estudios para establecer un punto de corte estandarizado para PTHL. Esta técnica podría establecerse como una prueba segura, complementaria o alternativa, en casos de difícil localización o con pruebas de imagen discordantes.

\section{MARCADORES MOLECULARES E INFLA- MATORIOS EN LA VALORACIÓN NUTRI- CIONAL MORFOFUNCIONAL EN LA SAR- COPENIA DE ORIGEN ONCOLÓGICO}

\section{MOLECULAR AND INFLAMMATION MARKERS IN THE MORPHOFUNCTIONAL NUTRITIONAL EVALUATION IN SARCOPENIA IN PATIENTS WITH CANCER}

\section{Aura D. Herrera Martinez ${ }^{1 / 1}$; Soraya León Idougou- rram $^{1 / 1}$; Concepción Muñoz Jiménez ${ }^{1 / 1}$; Prudencio Sáez-Martínez ${ }^{1 / 1}$; Gregorio Manzano ${ }^{1 / 1}$; Fernando L-López $^{1 / 1}$; María José Molina Puerta ${ }^{1 / 1}$; María Ánge- les Gálvez Moreno ${ }^{1 / 1}$; Manuel D. Gahete ${ }^{1 / 1}$; Raúl M. Lu- que $^{1 / 1}$}

(1) Hospital Universitario Reina Sofia. Instituto Maimónides de Investigación Biomédica de Córdoba (IMIBIC)

(1) Endocrinologia y Nutrición

ENDOCRINOLOGÍA BÁSICA

\section{INTRODUCCIÓN}

La carga inflamatoria es un criterio etiológico en el diagnostico de la malnutrición; algunas citoquinas pueden estimular el catabolismo proteico e inhibir la síntesis de proteínas; adicionalmente, algún componente del inflamasoma se ha relacionado con pérdida de masa muscular en la vejez, sin embargo, se desconoce su rol en la sarcopenia tumoral.

\section{OBJETIVOS}

Determinar la expresión molecular de componentes del inflamasoma (receptores NOD-like,citoquinas/ componentes de apoptosis, reguladores de activación, daño celular/ADN) en pacientes oncológicos $(n=45)$, y su relación con el estado nutricional.

\section{MATERIAL Y MÉTODOS}

La valoración morfofuncional incluyó: antropometría, bioimpedanciometria, ecografia muscular y de tejido adiposo, así como estudio bioquímico y biopsia liquida en los 45 pacientes evaluados.

\section{RESULTADOS}

Parámetros ecográficos de tejido adiposo y muscular se correlacionaron con niveles de PCR, IL6 y expresión molecular de componentes del inflamasoma $(\mathrm{p}<0.05)$. Éstos últimos se correlacionaron con parámetros antropométricos/bioquímicos, impedanciometria, ángulo de fase (AF), y se asoció con la presencia de síntomas gastrointestinales y nivel de dependencia $(\mathrm{p}<0.05)$.

Un AF estandarizado (AFS) $<-1.65$ (asociado con mayor mortalidad en oncología) se asoció con menor tejido adiposo en muslo y mayores niveles de IL6 $(\mathrm{p}<0.05)$. Pacientes con pérdida de peso reciente mostraron cambios en la expresión molecular de IL18, IL1RA, TLR4, IL6R y P19; mientras que la pérdida de peso más prolongada mostró además alteración en niveles de TGFB y CXCL8 $(\mathrm{p}<0.05)$. La IL6 sérica se asoció con el AF, niveles de tejido adiposo y la expresión molecular de IFI16, IL1RA y SIRT1 $(\mathrm{p}<0.05)$. La combinación de la determinación de niveles séricos de PCR, IL6 y algunos componentes moleculares (p27,ASC,CCL2, NLRP12,IL1R,CXCL3,IL1RA) permitieron discriminar adecuadamente los pacientes con malnutrición (VIP scores 1.4-2.3).

\section{CONCLUSIONES}

Componentes del inflamasoma se relacionan con parámetros nutricionales clínicos, antropométricos, ecográficos y bioquímicos. Su estudio podría ofrecer información precoz para predecir la evolución de la sarcopenia y mejorar el abordaje nutricional en pacientes oncológicos.

\section{SEGUIMIENTO DE LA EDUCACIÓN TERA- PÉUTICA(ET) EN PACIENTE DE DEBUT DE DIABETES EN UN HOSPITAL DE DÍA DE DIABETES(HDD)}

FOLLOW-UP OF THERAPEUTIC EDUCATION (TE) IN PATIENTS WITH EARLY ONSET DIABETES IN A DIABETES DAY HOSPITAL (DDH)

Pilar SantaCruz Álvarez ${ }^{1 / 1}$; Fátima Farfán Díaz ${ }^{1 / 1} ;$ Carmen Amelia Ruiz Trillo ${ }^{1 / 1}$; Ana Pérez Morales; ${ }^{1 / 1}$; Mónica Enríquez Macías ${ }^{1 / 1}$ 
(1) H.U.Virgen del Rocio

(1) Endocrinologia y Nutricion

ENFERMERÍA Y EDUCACIÓN TERAPÉUTICA

\section{INTRODUCCIÓN}

El PAI DM indica que a todas las personas con DMT1 y sus cuidadores se les ofertará, al debut de la enfermedad, un programa de ET de supervivencia, adaptado a sus capacidades. El programa de supervivencia se completará, en un plazo máximo de 3 meses, con un programa avanzado.

\section{OBJETIVOS}

Evaluar seguimiento y resultados del programa de Educación Terapéutica (ET) de supervivencia y avanzada en diabetes de novo durante 2020 .

\section{MATERIAL Y MÉTODOS}

Estudio descriptivo observacional del seguimiento de personas con diabetes de novo, en el HDD durante 2020. Derivados desde AP o Urgencias de hospitalización de nuestra área hospitalaria, con clínica cardinal y sin filiar tipo de diabetes y que precisan insulinizacion. La enfermera realiza ET estructurada:Educación de Supervivencia (ES) de 4 días y refuerzos según necesidades, en HDD. A continuación, Educación Grupal Avanzada ( EGA) entre 1-3 meses después de la ES.

\section{RESULTADOS}

El total de pacientes ha sido 68 , edad media de 31,3 años. Precisaron, inicialmente, tratamiento con insulina. El 50\% se filio con DM tipo1, el 41,2\% DM tipo2 y un $0,08 \%$ otros tipo de diabetes. El $28 \%$ mujeres: con DMtipol el 47,3\%, con DMtipo 2 el $47,3 \%$ y otro tipo de diabetes el 5,4\%. El 72\% hombres: con DMtipol el $51 \%$, con DMtipo2 el 38,7\% y otro tipo de diabetes el $10 \%$ Se realiza Educación de Supervivencia en el 100\% y EGA en el 70\% de DM tipo1 y en DMtipo2 en el 7,1\%. La HbA1C de inicio es de 12,1 de media en el total de pacientes. Los que realizan EGA,previo al curso tienen una HbA1C de 8,6 de media(1 a 3 meses del inicio). Tras el curso de EGA , HbA1C es 6,46 de media $(6 \pm 2$ meses del inicio).

\section{CONCLUSIONES}

La ES en el debut se realiza en todos los pacientes, se deja constancia en la HC del paciente. La EGA se realiza en tipo 1 y tipo 2 con múltiples dosis de insulina. En tipo2, una vez control metabólico estable y con insulina basal y/o ADOS, continúan seguimiento y ET en AP El 30\% de DMtipo1 que no acuden a cita de EGA, se les asigna nueva cita. El control metabólico y glucemia mejora, significativamente, tras el inicio de tto y educación terapéutica estructurada. Fundamental que el profesional realice seguimiento de todo el proceso de ET de las personas con diabetes, para segurar la implicación, los conocimientos y habilidades en el manejo de su enfermedad.
IDENTIFICACIÓN DE VARIANTES PATOGÉNICAS ASOCIADAS A DIABETES MONOGÉNICA MEDIANTE UN PANEL DIRIGIDO CON TECNOLOGÍA NGS EN PACIENTES CON MODY $X$

IDENTIFICATION OF PATHOGENIC GENE VARIANTS OF MONOGENIC DIABETES USING TARGETED SEQUENCING BY NGS IN MODY $X$ PATIENTS

Ana Maria Lago-Sampedro ${ }^{1 / 1}$; Juan Miguel Gómez-Zumaquero ${ }^{2 / 2}$; María Jesús Pinto-Medel ${ }^{2 / 2}$; Ignacio Ruiz $^{1 / 1}$; María del Carmen Benito-López ${ }^{1 / 4}$; Natalia Colomo-Rodríguez ${ }^{1 / 1}$; Marta Domínguez ${ }^{1 / 1}$; Rosario Vallejo-Mora ${ }^{1 / 1}$; Diego Lozano-Peral ${ }^{3 / 4}$; María Soledad Ruíz de Adana ${ }^{1 / 1}$

(1) Hospital Regional Universitario de Málaga, (2) IBIMA,

(3) Universidad de Málaga

(1) UGC Endocrinología y Nutrición, (2) ECAI de Genómica, (3) UGC de Genética, (4) Centro de supercomputación y Bioinnovación - Unidad de Genómica

\section{DIABETES}

\section{INTRODUCCIÓN}

La diabetes monogénica representa aproximadamente el 1-3\% de todos los casos de diabetes. Su diagnóstico genético es importante pues supone cambios terapéuticos, pronósticos significativos e implicaciones para los miembros de la familia. Unos 14 genes descritos en la literatura científica están estrechamente relacionados con la aparición del fenotipo MODY, aunque aún existe una alta prevalencia de casos sin diagnóstico genético denominados MODY-X.

\section{OBJETIVOS}

Identificar variantes patogénicas mediante tecnología de secuenciación masiva (NGS), empleando un panel de 32 genes en pacientes con sospecha clínica de diabetes monogénica y con estudio previo Sanger negativo para los genes frecuentemente implicados en este tipo de diabetes (HNF1A, GCK, HNF1B, HNF4A e INSR).

\section{MATERIAL Y MÉTODOS}

Se seleccionaron 106 pacientes con fenotipo característico de diabetes monogénicas, de los cuales 41 presentaron resultados negativos mediante Sanger para variantes en los genes HNF1A, GCK, HNF1B, HNF4A, INSR y diabetes mitocondrial.

Mediante un panel dirigido de secuenciación masiva de 32 genes relacionados con diabetes monogénicas, se evaluó la patogenicidad de las variantes identificadas de acuerdo con las directrices de "ACMG-AMP".

Las mutaciones encontradas se confirmaron mediante secuenciación Sanger. 


\section{RESULTADOS}

De los 106 sujetos estudiados mediante Sanger, en 65 sujetos $(61 \%)$ se encontraron variantes patogénicas en algunos de los genes más frecuentemente implicados (HNF1A, GCK, HNF1B, HNF4A e INSR), quedando 41 casos $(39 \%)$ sin diagnosticar a los que denominamos MODY X. Del total de casos MODY X, se logran diagnosticar a 15 pacientes más mediante el panel dirigido con tecnología NGS, identificando variantes patogénicas en un 37\% de estos MODY X; encontrándose un $5 \%$ de estas variantes en el gen HNF4A, un $12 \%$ en HNF1A (de estos un paciente presentó también variante para HNF1B, siendo bigénico), un 2,5\% en PDX 1 , un $2,5 \%$ en CEL, un $5 \%$ en INS, un $2,5 \%$ en ABCC 8 , un $2,5 \%$ en PTF1A y un $5 \%$ en SLC2A2.

\begin{tabular}{|c|c|}
\hline $\begin{array}{l}\text { Variante patogénica } \\
\text { en el gen; }\end{array}$ & $\begin{array}{l}\text { Porcentaje } \\
\text { de diagnóstico } \\
(\%)\end{array}$ \\
\hline HNF4A & 5 \\
\hline HNF1A* & 12 \\
\hline PDX1 & 2.5 \\
\hline CEL & 2.5 \\
\hline INS & 5 \\
\hline ABCC8 & 2.5 \\
\hline PTF1A & 2.5 \\
\hline SLC2A2 & 5 \\
\hline $\begin{array}{l}\text { Total de pacientes } \\
\text { con variantes patogénicas } \\
\text { diagnosticadas (15) }\end{array}$ & $37 \%$ \\
\hline $\begin{array}{l}\text { Pacientes sin diagnostico } \\
\text { tras NGS (26) }\end{array}$ & $63 \%$ \\
\hline
\end{tabular}

Tabla 1.*Uno de ellos con variante también para HNF1B, por tanto el paciente es bigénico. (IDENTIFICACIÓN DE VARIANTES PATOGÉNICAS ASOCIADAS A DIABETES MONOGÉNICA MEDIANTE UN PANEL DIRIGIDO CON TECNOLOGÍA NGS EN PACIENTES CON MODY $X$ )

\section{CONCLUSIONES}

Utilizando NGS mediante un panel de 32 genes específico de diabetes monogénica dirigido a pacientes fenotipados en consulta de Diabetes y Genética, se puede conseguir un incremento de un $14 \%$ en el rendimiento de diagnóstico genético respecto a la tecnología Sanger, con menores costes, en un escenario de medicina personalizada de precisión aplicada a la diabetes. 


\section{DESCRIPCIÓN DE PACIENTES CON PIE DIABÉTICO DE CAUSA NEUROPÁTICA Y VASCULAR ATENDIDOS EN UNA UNI- DAD DE PIE DIABÉTICO MULTIDISCI- PLINAR}

DESCRIPTION OF PATIENTS WITH DIABETIC FOOT OF NEUROPATHIC AND VASCULAR CAUSE TREATED IN A MULTIDISCIPLINARY DIABETIC FOOT UNIT

Ana Piñar Gutiérrez ${ }^{1 / 1}$; Noelia Gros Herguido ${ }^{1 / 1}$; Fernando Losada Viñau ${ }^{1 / 1}$; Fátima Farfán Díaz ${ }^{1 / 1}$; Mónica Enríquez Pérez ${ }^{1 / 1}$; Ana Pérez Ruiz ${ }^{1 / 1}$; Carmen Ruiz Trillo $^{1 / 1}$; Luis Tallón Aguilar ${ }^{1 / 2}$; Enriqueta Bataller Dejuán ${ }^{1 / 3}$; Alfonso Soto Moreno ${ }^{1 / 1}$

(1) Hospital Universitario Virgen del Rocío

(1) UGC Endocrinología y Nutrición, (2) Servicio Cirugía

General, (3) Servicio Cirugía Vascular

\section{DIABETES}

\section{INTRODUCCIÓN}

El $6 \%$ de diabéticos presentan pie diabético como complicación, lo cual supone una mayor morbimortalidad respecto a quienes no la presentan. El diagnóstico del mismo y su manejo mediante equipos multidisciplinares que incluya a cirujanos puede mejorar la atención a estos pacientes.

\section{OBJETIVOS}

1) Análisis descriptivo de las características y resultados en salud de una cohorte de pacientes atendidos en una unidad multidisciplinar de pie diabético.

2) Evaluación de las diferencias de la afectación neuropática vs vascular.

\section{MATERIAL Y MÉTODOS}

Estudio descriptivo retrospectivo. Analizamos 2 poblaciones atendidas durante 14 meses en una Unidad multidisciplinar de Pie Diabético del Hospital Virgen del Rocío.

- Población1. Pacientes con pulso periférico (Cía General-Endocrino).

-Población2. Pacientes sin pulso (Cía Vascular-Endocrino) Exclusión: no diabéticos, úlceras no localizadas en pie, pie de riesgo sin úlcera.

Variables cuantitativas: P50(P25-P75); cualitativas: $\mathrm{n}(\%)$. Para la comparación de proporciones se utilizó X2, para medianas la prueba no paramétrica para muestras independientes.

\begin{tabular}{|c|c|c|}
\hline$*$ Diferencias $(p<0.05)$ & & \\
\hline & Con pulso & Sin pulso \\
\hline $\mathrm{N}$ & 135 & 138 \\
\hline Varón & $108(80 \%)$ & $95(69 \%)$ \\
\hline Edad* & $60(54-67)$ & $64(75-81)$ \\
\hline $\mathrm{HbA} 1 \mathrm{c}(\%)$ & $7,6(6,7-9,5)$ & $\begin{array}{c}6.9(5,6- \\
8,05)\end{array}$ \\
\hline Diabetes T2 & $118(87 \%)$ & $128(93 \%)$ \\
\hline Úlceras previas* & $71(52 \%)$ & $37(27 \%)$ \\
\hline HTA* & $88(65 \%)$ & $114(82 \%)$ \\
\hline Dislipemia* & $78(60 \%)$ & $107(77 \%)$ \\
\hline Tabaquismo & $83(61 \%)$ & $63(46 \%)$ \\
\hline Nefropatía & $47(35 \%)$ & $48(35 \%)$ \\
\hline Retinopatía* & $45(50 \%)$ & $28(32 \%)$ \\
\hline Enf coronaria* & $11(8 \%)$ & $40(29 \%)$ \\
\hline Enf cerebrovascular* & $9(7 \%)$ & $25(18 \%)$ \\
\hline $\mathrm{N}^{\circ}$ consultas* & $3(1-6)$ & $1(1-2)$ \\
\hline Ingreso & $38(28 \%)$ & $49(35,5 \%)$ \\
\hline Amputación & $31(23 \%)$ & $43(31 \%)$ \\
\hline Amputación mayor* & $2(1,4 \%)$ & $17(12,3 \%)$ \\
\hline Antibioterapia* & $87(64,4 \%)$ & $71(51,4 \%)$ \\
\hline Antibioterapia iv & $38(28 \%)$ & $44(32 \%)$ \\
\hline Revascularización & & $28(20 \%)$ \\
\hline
\end{tabular}

Tabla 1.Escala de Texas (grupo mayoritario)*:

- Población1: 1a=46(34\%).

- Población2: 1c=23(16.7\%)

(DESCRIPCIÓN DE PACIENTES CON PIE DIABÉTICO DE CAUSA NEUROPÁTICA Y VASCULAR ATENDIDOS EN UNA UNIDAD DE PIE DIABÉTICO MULTIDISCIPLINAR) 


\section{RESULTADOS}

${ }^{*}$ Diferencias $(\mathrm{p}<0.05)$. Con pulso Sin pulso N 135 138 Varón 108(80\%) 95(69\%) Edad* 60(54-67) 64(7581) HbA1c(\%) 7,6(6,7-9,5) 6.9(5,6-8,05) Diabetes T2 118(87\%) 128(93\%) Úlceras previas* 71(52\%) 37(27\%) HTA $^{*}$ 88(65\%) 114(82\%) Dislipemia* 78(60\%) 107(77\%) Tabaquismo 83(61\%) 63(46\%) Nefropatía $47(35 \%) 48(35 \%)$ Retinopatía* 45(50\%) 28(32\%) Enf coronaria* 11(8\%) 40(29\%) Enf cerebrovascular* 9(7\%) 25(18\%) $\mathrm{N}^{\circ}$ consultas* Ingreso 3(1-6) 38(28\%) 1(1-2) 49(35,5\%) Amputación Amputación mayor* $31(23 \%) \quad 2(1,4 \%) \quad 43(31 \%) \quad 17(12,3 \%) \quad$ Antibioterapia* Antibioterapia iv 87(64,4\%) 38(28\%) 71(51,4\%) $44(32 \%)$ Revascularización $28(20 \%)$ Escala de Texas (grupo mayoritario)*: Población 1 : $1 \mathrm{a}=46(34 \%)$. Población2: $1 \mathrm{c}=23(16.7 \%)$.

\section{CONCLUSIONES}

Los pacientes con afectación vascular son mayores, y presentan mayor carga macrovascular. Tienen más antecedentes de úlceras previas y en ellos se realizan más amputaciones mayores.

Sin embargo, los pacientes con pie neuropático tienen más complicaciones microvasculares entre sus antecedentes siendo en ambos grupos el control metabólico similar.

\section{RECLASIFICACIÓN METABÓLICA POS- TPARTO EN MUJERES CON DIABETES ME- LLITUS GESTACIONAL}

\section{POSTPARTUM METABOLIC RECLASSIFICA- TION IN WOMEN WITH GESTATIONAL DIA- BETES MELLITUS}

Almudena Lara Barea ${ }^{1 / 1}$; Juan José Raposo López ${ }^{2 / 2}$; Álvaro Vidal Suárez ${ }^{1 / 1}$; Antonio Campos Caro ${ }^{1 / 3}$; Manuel Aguilar Diosdado ${ }^{1 / 1}$; Cristina López Tinoco ${ }^{1 / 1}$

(1) Hospital Universitario Puerta del Mar, (2) Universidad de Cádiz

(1) Endocrinología y Nutrición, (2) UCA, (3) Inmunología,

\section{DIABETES}

\section{INTRODUCCIÓN}

Las mujeres con antecedentes de Diabetes Mellitus Gestacional (DMG) tienen mayor riesgo de desarrollar Diabetes Mellitus Tipo 2 (DM2), Síndrome metabólico (SM) y Enfermedad Cardiovascular (ECV) en el futuro. Un estado proinflamatorio común podría incrementar la resistencia a la insulina y el riesgo de ECV.

\section{OBJETIVOS}

Evaluar la prevalencia de DM2 y SM en mujeres que presentaron DMG y analizar la presencia e influencia de factores de riesgo clásicos y no clásicos de ECV.

\section{MATERIAL Y MÉTODOS}

Reevaluación retrospectiva de casos (mujeres con antecedentes de DMG) y controles (sin antecedentes de DMG) en 234 mujeres atendidas en la Consulta de Alto Riesgo de Endocrinología y Embarazo del Hospital Puerta del Mar de Cádiz, al menos un año después del parto. Se analizaron datos demográficos, clínicos y analíticos, citocinas pro y antiinflamatorias. Para el diagnóstico de las alteraciones del metabolismo de los hidratos de carbono y SM se utilizaron los criterios de la OMS.

\section{RESULTADOS}

Encontramos diferencias estadísticamente significativas controles vs casos en: índice de masa corporal (IMC) pregestacional $25.1 \pm 4.3$ vs $27.3 \pm 5.1 \mathrm{~kg} / \mathrm{m} 2$ $(p=0.001)$, ganancia ponderal en el embarazo $10.7 \pm 4.5$ vs $8.2 \pm 4.7 \mathrm{~kg}(\mathrm{p}<0.001)$, glucemia basal $83 \pm 5$ vs $90 \pm 1$ $\mathrm{mg} / \mathrm{dL} \quad(\mathrm{p}=0.005)$, resistina $8.38 \pm 3.25$ vs $7.29 \pm 3.1$ $(\mathrm{p}=0.002)$, IMC posparto $25.6 \pm 5.1 \mathrm{vs} 27.7 \pm 5.5 \mathrm{~kg} / \mathrm{m} 2$ $(\mathrm{p}=0.008)$ y glucemia basal posparto $86 \pm 9$ vs $93 \pm 23$ $\mathrm{mg} / \mathrm{dl}(\mathrm{p}=0.009)$. En las mujeres con antecedente de DMG, el análisis multivariante mostró que el IMC se comportaba como factor de riesgo para SM con una OR de 1.363 (IC 95\% 1.152 - 1.613, p<0.001), y la obesidad y la HbAlc se comportaban como factor de riesgo para la reclasificación del metabolismo de los hidratos de carbono anómala con una OR de 5.919 (IC $95 \% 1.473-23.787, p=0.012$ ) y 9.697 (IC $95 \%$ $1.523-61.721, \mathrm{p}=0.016)$, respectivamente.

\section{CONCLUSIONES}

Las mujeres con antecedentes de DMG tienen mayor prevalencia de SM y reclasificación del metabolismo de los hidratos de carbono anómala en el posparto y, en consecuencia, mayor riesgo de ECV. El principal factor de riesgo independiente para ambos procesos es la obesidad pregestacional.

Son necesarios más estudios para identificar precozmente el papel de los marcadores no clásicos de ECV en estas mujeres, poniendo a su alcance intervenciones higiénico-dietéticas y/o farmacológicas que eviten o retrasen la aparición de enfermedad metabólica y ECV.

\section{CARACTERIZACIÓN DE UNA COHORTE DE DIABETES LADA}

\section{LADA CHARACTERIZATION COHORT}

Juan Manuel Canelo Moreno ${ }^{1 / 1}$; Bothayna Oulad Ahmed $^{1 / 1}$; Noelia Gros Herguido ${ }^{1 / 1}$; Sandra Amuedo Domínguez ${ }^{1 / 1}$; Alfonso Pumar López ${ }^{1 / 1}$; Domingo Acosta Delgado ${ }^{1 / 1}$; Miguel Ángel Mangas Cruz ${ }^{1 / 1}$; Virginia Bellido Castañeda ${ }^{1 / 1}$; Fernando Losada Viñau ${ }^{1 / 1}$; Gema Lopez Gallardo ${ }^{1 / 1}$; Alfonso Soto Moreno ${ }^{1 / 1}$ (1) Hospital Universitario Virgen Del Rocio (1) Endocrinología Y Nutrición 
DIABETES

\section{INTRODUCCIÓN}

LADA subtipo de DM1, con debut en la adultez, anticuerpos positivos y retraso en la insulinización.

\section{OBJETIVOS}

Caracterizar desde el punto de vista clínico a los pacientes LADA de nuestra cohorte. Comparar el grupo LADA con una muestra de pacientes con diabetes mellitus tipo 1 de la misma cohorte.

\section{MATERIAL Y MÉTODOS}

Estudio descriptivo transversal retrospectivo de la cohorte de pacientes LADA del Hospital Universitario Virgen del Rocío $(\mathrm{N}=155)$. Se comparó con una muestra aleatoria simple de pacientes con DM1 clásica a razón 1:1. Las variables de estudio fueron edad, edad debut, tiempo de evolución, control glucémico por $\mathrm{HbA1c}$, complicaciones microvasculares, complicaciones macrovasculares, HTA, dislipemia y antecedentes familiares de DM, además en pacientes LADA se determinó valores de péptido $\mathrm{C}$ al debut y el actual, el tratamiento actual y la positividad para el ac-GADA.

\section{RESULTADOS}

De la muestra de 155 pacientes con LADA el 54,8\% fueron mujeres. Tenían una edad media de $56 \pm 12,3$ años, con una mediana de tiempo de evolución de diabetes de 11 años y 43 años fue la mediana de debut. Mientras que los pacientes con DM1 tenían una edad de $42,47 \pm 15,73$ años $(p<0,001)$, una edad de debut de 18 años $(\mathrm{p}<0,001)$ y un tiempo de evolución de 21 años $(\mathrm{p}<0,001)$. Los pacientes LADA tenían una media de HbA1c del 7,58\% frente a 7,91\% de los pacientes con DM1 $(\mathrm{p}=0,014)$. Una prevalencia de HTA del $34,2 \%$ vs $22,6 \%(p=0,023)$ y de dislipemia del $52,3 \%$ vs $32,3 \%(\mathrm{p}<0,001)$ para los pacientes LADA y DM1 respectivamente. Por otra parte, la prevalencia de retinopatía fue del $12,9 \%$ vs $36,6 \%$ $(\mathrm{p}<0,001)$ y de neuropatía $1,9 \%$ vs $7,1 \%(\mathrm{p}=0,029)$. No existían diferencias en cuanto a nefropatía o la afectación macrovascular. El 56,3\% de los pacientes LADA presentaban antecedentes familiares de DM, mientras que la prevalencia en DM1 fue del 43,5\% $(p=0,026)$. De los pacientes LADA el $88,4 \%$ estaba en tratamiento con terapia bolo/basal ya sea junto a antidiabéticos orales o no. La media de péptido C inicial fue $1,21 \pm 0,84 \mathrm{ng} / \mathrm{ml}$, mientras que la del péptido $C$ actual $0,74 \pm 0,68 \mathrm{ng} / \mathrm{ml}$. El 96,1\% presentó ac-GADA positivo.

\section{CONCLUSIONES}

La edad de debut, el péptido $C$ inicial y la presencia de GADA se correlaciona con lo recogido en la literatura. Los pacientes LADA tenían un mejor control glucémico, menor tiempo de evolución de DM, más factores de riesgo vascular y menor prevalencia de retinopatía y neuropatía.

\section{CARACTERÍSTICAS CLÍNICAS E IMPACTO SOBRE EL CONTROL METABÓLICO TRAS 22 AÑOS DE SEGUIMIENTO EN UNA CO- HORTE DM1 USUARIA DE ISCI}

CLINICAL CHARACTERISTICS AND IMPACT ON METABOLIC CONTROL AFTER 22 YEARS OF FOLLOW-UP IN A DM1 COHORT USING CSII

Bothayna Oulad Ahmed ${ }^{1 / 1}$, Noelia Gros Herguido ${ }^{1 / 1}$, Lucia Gónzalez Gracia ${ }^{1 / 1}$, Virginia Bellido Castañeda $^{1 / 1}$, Gema López García ${ }^{1 / 1}$, Fernando Losada Viñau ${ }^{1 / 1}$, Domingo Acosta Delgado ${ }^{1 / 1}$, Miguel Angel Mangas $\mathrm{Cruz}^{1 / 1}$, Ana Pérez Morales ${ }^{1 / 1}$, Mónica Enríquez Macias $^{1 / 1}$, Alfonso Soto Moreno ${ }^{1 / 1}$

(1) Hospital Virgen del Rocío

(1) Endocrinología y Nutrición

\section{DIABETES}

\section{INTRODUCCIÓN}

La terapia con infusión subcutánea continua de insulina (ISCI) es una opción de tratamiento aceptada para la Diabetes Mellitus tipo 1 (DM1). Sin embargo, los resultados en mejora del control metabólico y reducción de hipoglucemias son controvertidos.

\section{OBJETIVOS}

Analizar las características clínicas de una cohorte con DM1 usuaria de ISCI, así como evaluar la eficacia y control metabólico desde la implantación de la terapia.

\section{MATERIAL Y MÉTODOS}

Estudio observacional retrospectivo que incluye pacientes con DM1 que iniciaron terapia ISCI entre los años 1998 y 2020 del Hospital Universitario Virgen del Rocío (Sevilla). Se han analizado las características basales, el motivo de implantación, así como la presencia de complicaciones.

Se ha evaluado el control metabólico atendiendo a la HbAlc en el momento de la implantación, al año, 3 y 5 años y en el momento actual.

\section{RESULTADOS}

Se han implantado un total de 350 ISCI, de las cuales 292 ISCI siguen activas y 58 se han retirado. El $28,6 \%$ son sistemas integrados y el $48,8 \%$ son portadores de sistema de monitorización Flash. El 64,8\% (189) fueron mujeres, con una edad media de 43,62 +/- 12,79 años y un tiempo de evolución de 26,33 +/11,74 años siendo el tiempo medio hasta la implantación de ISCI de 19,20 +/- 11,07 años. Las dos indicaciones principales para el inicio de ISCI fueron: Variabilidad glucémica 58\% e hipoglucemia $28 \%$. En cuanto a las complicaciones microvasculares, el $31,6 \%$ presentaba retinopatía y el $2,73 \%$ nefropatía en el 2,73\%. El 5,74\% de los pacientes ha presentado complicaciones macrovasculares. 
Las HbA1c a la implantación, al año, a los 3 años, a los 5 años y la actual fueron de 7,65 \% $\pm 0,98 \%, 7,18 \% \pm$ $0,89 \%, 7,41 \%, 7,52 \%$ y $7,463 \% \pm 0,92(p=0,00)$, respectivamente. El $54,30 \%$ de los pacientes alcanzaron al año el objetivo de $\mathrm{HbA} 1 \mathrm{c}<7 \%$ y actualmente un $31,5 \%$ presenta $\mathrm{HbA} 1 \mathrm{c}<7 \%(\mathrm{p}=0,00)$.

\section{CONCLUSIONES}

El porcentaje mayoritario en terapia con ISCI eran mujeres, siendo la complicación más frecuente la retinopatía. La indicación fundamental de implantación fue la variabilidad glucémica y las hipoglucemias. El control metabólico mejoró signicativamente el primer año coincidiendo con lo descrito en la literatura, aunque posteriormente hubo un discreto empeoramiento.

\section{ADAPTACIÓN DE UN SENSOR NO INVASI- VO DEL NIVEL DE GLUCOSA EN SANGRE PARA EVALUACIÓN EN UN ENTORNO CLÍ- NICO CONTROLADO}

\section{ADAPTATION OF A NON-INVASIVE BLOOD GLUCOSE LEVEL SENSOR FOR EVALUA- TION IN A CONTROLLED CLINICAL ENVI- RONMENT}

\section{Mariola Méndez Muros ${ }^{1 / 1}$; David Naranjo Hernández ${ }^{2 / 2}$; Javier Reina Tosina ${ }^{2 / 2}$; Laura María Roa Romero ${ }^{2 / 2}$; Ge- rardo Barbarov Rostán ${ }^{2 / 2}$; María Asunción Martínez Brocca $^{1 / 1}$}

(1) Hospital Universitario Virgen Macarena, (2) Universidad de Sevilla

(1) Servicio de Endocrinología y Nutrición, (2) Grupo de Ingeniería Biomédica, Departamento de Teoría de la Señal y Comunicaciones

\section{DIABETES}

\section{INTRODUCCIÓN}

El Grupo de Ingeniería Biomédica de la Universidad de Sevilla está investigando y desarrollando un novedoso dispositivo para la medida no invasiva del nivel de glucosa en sangre, en colaboración con la Unidad de Endocrinología y Nutrición del Hospital Universitario Virgen Macarena de Sevilla (UEN-HUVM) y la empresa Igluco Tech.

\section{OBJETIVOS}

El objetivo de esta comunicación es describir las adaptaciones realizadas a un prototipo preliminar para su evaluación en un entorno clínico controlado.

\section{MATERIAL Y MÉTODOS}

El dispositivo propuesto pretende ser evaluado en un estudio en pacientes con diabetes atendidos en consultas de la UEN-HUVM, tomando como referencia muestras capilares. En el prototipo preliminar las medidas no podían realizarse sin conexión por cable a un ordenador portátil y la presencia de personal técnico, por lo que no era adecuado para su uso en las condiciones de seguridad propias del estado de alarma y las consecuencias de la pandemia COVID-19.

Ha sido necesaria una adaptación del dispositivo y los protocolos clínicos de medida para que el estudio de evaluación pueda ser realizado de forma autónoma por el equipo clínico.

\section{RESULTADOS}

El dispositivo ha sido integrado en una carcasa compacta $(9 \mathrm{~cm} \times 7 \mathrm{~cm} \times 3 \mathrm{~cm})$, con una interfaz sencilla para facilitar su uso por el personal clínico: tres botones pulsadores asociados a funciones y menús, y pantalla LCD color de 3 pulgadas que guía el proceso de realización de medidas con mensajes informativos y con arreglo a la siguiente secuencia: a) activar el dispositivo, b) comprobar su correcto funcionamiento, c) iniciar una medida, d) registrar el nivel de glucosa de referencia.

Para facilitar el registro y el trasvase de la información, las medidas son almacenadas en una tarjeta de memoria SD.

Se ha iniciado el estudio de evaluación con dos unidades del prototipo adaptado, habiéndose realizado hasta la fecha más de 240 determinaciones, sin que en ninguna de ellas se haya necesitado intervención del equipo técnico más allá de la transferencia de los datos de la tarjeta de memoria SD para su análisis.

\section{CONCLUSIONES}

Se ha realizado la adaptación de un prototipo de un sensor no invasivo del nivel de glucosa en sangre para su evaluación en un entorno clínico controlado, superando las limitaciones que ha planteado la COVID-19. Desde que se inició la validación clínica no se han producido incidencias técnicas.

\section{PATRONES DE MONITORIZACIÓN FLASH DE GLUCOSA EN VIDA REAL: ASOCIACIÓN ENTRE LA FRECUENCIA DE ESCANEO Y LA GLUCOMETRÍA}

REAL-LIFE FLASH GLUCOSE MONITORING PATTERNS: ASSOCIATION BETWEEN SELFMONITORING FREQUENCY AND GLYCAEMIC MEASURES

Lucía González Gracia ${ }^{1 / 1}$; Bothayna Oulad Ahmed ${ }^{1 / 1}$; Sandra Amuedo Domínguez ${ }^{1 / 1}$; Noelia Gros Herguido $^{1 / 1}$; Gema López Gallardo ${ }^{1 / 1}$; Alfonso Soto Moreno ${ }^{1 / 1}$; Virginia Bellido Castañeda ${ }^{1 / 1}$

(1) Hospital Universitario Virgen del Rocío

(1) Endocrinología y Nutrición

DIABETES 


\section{INTRODUCCIÓN}

Un mayor número de controles de glucemia se ha asociado con un mejor control glucémico.

\section{OBJETIVOS}

El objetivo de este estudio es analizar la relación de la frecuencia de escaneos con los datos de glucometría en usuarios de monitorización flash de glucosa de nuestro centro.

\section{MATERIAL Y MÉTODOS}

Estudio observacional descriptivo. Realizamos un corte transversal en Junio de 2021 analizando los datos de glucometría obtenidos de la plataforma Libreview ${ }^{\oplus}$ de aquellos pacientes con datos descargados en los últimos 3 meses. Se seleccionaron aquellos pacientes con $>$ $70 \%$ de datos captados.

\section{RESULTADOS}

Se analizaron datos de 1792 pacientes. La glucosa promedio fue $159,32 \pm 31,34 \mathrm{mg} / \mathrm{dl}$ y el indicador de gestión de glucosa (GMI) 7,17 $\pm 0,73 \%$. El tiempo medio en rango [TIR (70-180 $\mathrm{mg} / \mathrm{dl})]$ fue $60,89 \pm 16,31 \%$, el tiempo por encima de rango [TAR $(>180 \mathrm{mg} / \mathrm{dl})]$ $33,29 \pm 17,89 \%$ y el tiempo por debajo de rango [TBR $(<70 \mathrm{mg} / \mathrm{dl})] 5,82 \pm 6,03 \%$. El coeficiente de variación (CV) medio fue 36,71 $\pm 6,78 \%$ y la desviación estándar (DE) media 58,02 $\pm 15,2$.

El uso promedio del sensor fue $88,29 \pm 14,09 \%$. Se dividieron los pacientes en 4 grupos en función del número de escaneos. Los pacientes con menor número de escaneos (<5/día) presentaron un TIR de 52,65 \pm $17,04 \%$, tiempo en hiperglucemia de 40,47 $\pm 19,33 \%$, tiempo en hipoglucemia de 6,88 $\pm 6,94 \%$ y CV de 42,39 $\pm 7,96 \%$. Los pacientes con mayor número de escaneos (>13/día) presentaron TIR de 67,92 $\pm 15,57 \%$, tiempo en hiperglucemia de $27,36 \pm 17,24 \%$, tiempo en hipoglucemia de $4,71 \pm 4,95 \%$ y CV de $32,82 \pm 6,08 \%$.

\section{CONCLUSIONES}

Los datos en vida real confirman que una mayor frecuencia de escaneos con el sistema de monitorización flash de glucosa se asocia con mayor tiempo en rango, menor tiempo en hiperglucemia e hipoglucemia y menor variabilidad glucémica.

\begin{tabular}{|l|c|c|c|c|c|}
\hline & Grupo 1 & Grupo 2 & Grupo 3 & Grupo 4 & p \\
\hline N & 363 & 548 & 404 & 477 & - \\
\hline Escaneos/día & $<5$ & $5-9$ & $9-13$ & $>13$ & - \\
\hline $\begin{array}{l}\text { Glucosa } \\
\text { promedio (mg/dl) }\end{array}$ & $171,93 \pm$ & $160,26 \pm$ & $157,35 \pm$ & $150,33 \pm$ & $<0,001$ \\
\hline GMI (\%) & 38,04 & 29,11 & 27,98 & 27,45 & 0,003 \\
\hline TIR (70-180) (\%) & $52,65 \pm 17,04$ & $59,15 \pm 14,40$ & $62,36 \pm 15,07$ & $67,92 \pm 15,57$ & $<0,001$ \\
\hline TAR (>180) (\%) & $40,47 \pm 19,33$ & $34,50 \pm 16,51$ & $32,20 \pm 16,60$ & $27,36 \pm 17,89$ & $<0,001$ \\
\hline TAR (>250) (\%) & $16,30 \pm 14,39$ & $10,49 \pm 10,32$ & $9,05 \pm 9,38$ & $6,40 \pm 8,51$ & $<0,001$ \\
\hline TBR (<70) (\%) & $6,88 \pm 6,94$ & $6,34 \pm 6,55$ & $5,44 \pm 5,32$ & $4,71 \pm 4,95$ & $<0,001$ \\
\hline CV (\%) & $39,06 \pm 7,02$ & $37,28 \pm 6,67$ & $36,28 \pm 6,26$ & $33,79 \pm 5,87$ & $<0,001$ \\
\hline DE (mg/dl) & $65,03 \pm 16,31$ & $58,41 \pm 13,45$ & $57,31 \pm 13,82$ & $50,21 \pm 12,45$ & $<0,001$ \\
\hline Rango IQ & $99,87 \pm 34,23$ & $87,08 \pm 23,18$ & $81,78 \pm 22,23$ & $71,74 \pm 19,80$ & $<0,001$ \\
\hline
\end{tabular}

Tabla 1. (PATRONES DE MONITORIZACIÓN FLASH DE GLUCOSA EN VIDA REAL: ASOCIACIÓN ENTRE LA FRECUENCIA DE ESCANEO Y LA GLUCOMETRÍA) 
ANÁLISIS DE LA BASE DATOS DE LIBREVIEW EN LOS PACIENTES CON DIABETES MELLITUS TIPO 1. ¿HAY DIFERENCIA ENTRE LAS INSULINAS BASALES?

\section{ANALYSIS OF THE LIBREVIEW DATABASE IN PATIENTS WITH TYPE 1 DIABETES MELLI- TUS. IS THERE A DIFFERENCE BETWEEN BA- SAL INSULINS?}

Rossana Sofia Manzanares Córdova ${ }^{1 / 1}$; Diego Jesus Del Can Sánchez ${ }^{1 / 1}$; María Laínez López ${ }^{1 / 1}$; Luna Ojeda Florencio ${ }^{1 / 1}$; María Isabel Rebollo Perez ${ }^{1 / 1}$ (1) Hospital Juan Ramón Jiménez de Huelva (1) Endocrinología y Nutrición

\section{DIABETES}

\section{INTRODUCCIÓN}

Existen estudios comparativos entre los análogos basales de nueva generación con resultados dispares en pacientes DM tipo 1 y 2 en cuanto a glucometría. Nos planteamos el análisis en un subgrupo de pacientes DM tipo 1 para ver si existen diferencias.

\section{OBJETIVOS}

Analizar el efecto de las principales insulinas basales en el control metabólico de los pacientes con Diabetes Mellitus tipo 1 (DM1) del área de Huelva que utilizan el sensor FreeStyle.

\section{MATERIAL Y MÉTODOS}

Se realizó un análisis retrospectivo de los pacientes con DM1 incluidos en la base de datos online "LibreView" del Hospital Juan Ramón Jiménez (Huelva) hasta Julio de 2021. Se evaluaron los distintos parámetros obtenidos de las descargas de datos que realizaron los pacientes desde sus sensores FreeStyle hasta la plataforma online. Se estratificó la muestra en dos grupos según el tipo de insulina lenta utilizada (Grupo A: Glargina U300 vs Grupo B: Degludec). A continuación, se compararon los parámetros referidos entre los dos grupos con la prueba $t$ de student mediante el programa estadístico SPSS v26.

\section{RESULTADOS}

Se analizaron en total 250 pacientes con DM1. 103(50 mujeres) en el Grupo de U300 y con una mediana de edad de 42[32-50] años vs 147(75 mujeres) en el Grupo de Degludec y con una mediana de edad de 40 [30-50] años. El tiempo medio activo del sensor en los dos grupos de estudio fue superior al 90\%: 93 [8597]\% en el grupo A y de 94[93-97]\% en el grupo B. Al comparar los 2 grupos analizados (Glargina U300 vs Degludec), se encontraron parámetros con valores similares entre los dos tipos de insulinas. Se observó: un Tiempo en hipoglucemia de $4[2-7] \%$ vs $4[1-8] \%$, $\mathrm{p}=0.31$; un coeficiente de varabilidad (CV) de 37[33$41] \%$ vs $37[32-43] \%, p=0.82$; un indicador de gestión de glucosa (GMI) de 7,2[6,7-7,5]\% vs 7,0 [6,7-7,7]\%, $\mathrm{p}=0.53 ; \mathrm{y}$ un Tiempo en rango de 61[53-74]\% vs 60 $[45-72] \%, \mathrm{p}=0.30$; respectivamente.

\section{CONCLUSIONES}

En nuestra muestra, las diferencias entre las dos insulinas estudiadas (Glargina U300 vs Degludec) son casi inexistentes. Por tanto, no se encuentra asociación significativa entre el tipo de insulina utilizada y ninguna de las variables analizadas.

\section{EL CONFINAMIENTO DURANTE EL ESTA- DO DE ALARMA MEJORÓ EL CONTROL DE LOS DIABÉTICOS TIPO 1}

CONFINEMENT DURING THE ALARM STATE IMPROVED THE CONTROL OF TYPE 1 DIABETES

Roberto Carlos Romo Remigio ${ }^{1 / 1}$; Jesús Manuel López Vasco $^{2 / 1}$; Juan de Dios Barranco Ochoaz ${ }^{1 / 1}$; Ana Segarra Balao ${ }^{1 / 1}$; Carmen Gutiérrez Alcantara ${ }^{1 / 1}$

(1) Hospital Universitario de Jaén, (2) Universidad de Granada

(1) Endocrinología y Nutrición

\section{DIABETES}

\section{INTRODUCCIÓN}

Diversos estudios en diferentes países muestran mejoras en el control metabólico de los pacientes con DM tras un periodo de confinamiento domiciliario.

\section{OBJETIVOS}

Estudiar el efecto que tuvo confinamiento domiciliario decretado en la primavera de 2020 en España en el control metabólico de los pacientes Diabetes Mellitus tipo 1 (DM1) que atendemos en nuestra Unidad con monitorización continua de glucosa flash (MCG) en ese momento.

\section{MATERIAL Y MÉTODOS}

Estudio longitudinal retrospectivo. Se obtuvieron datos de Monitorización Continua de Glucosa (MCG) a través de la plataforma LibreView de todos los pacientes con DM1 de nuestra consulta, conectados entre el 1 de Marzo y el 8 de Junio de 2020. Se comparan los datos de glucometría [Hba1c estimada \%, glucosa promedio $\mathrm{mg} / \mathrm{dl}$, variabilidad expresada como coeficiente de variación (CV) \%, Tiempo en rango (TIR), tiempo en hipoglucemia (TBR) y tiempo por encima de rango (TAR); registrados en 3 etapas: A) 2 semanas antes de la declaración del estado de alarma, B) 2 primeras semanas del mismo y C) últimos 14 días. Análisis estadístico con paquete SPSS ${ }^{\circledast}$ para Windows.

\section{RESULTADOS}

$\mathrm{n}=$ 92; Edad media $36,92 \pm 11,13$ años; $54,3 \%$ mujeres. El uso del sensor fue similar en los periodos compa- 
rados, no encontrando diferencias ni en promedio de lecturas al día $(93,64 \pm 9,81$ vs. $92,4 \pm 7,48 \mathrm{p}=0,335) \mathrm{ni}$ en $\%$ captación de datos $(12,41 \pm 6,62$ vs. $11,76 \pm 7,04$ $\mathrm{p}=0.272)$. Encontramos mejoría significativa del promedio de glucosa, HbA1c y aumento del TIR a expensas de una reducción del TAR, que son precoces ya en el periodo B y se mantienen en el C. Se describe una diferencia en el CV sólo en el periodo C. Se resumen cambios en tabla 1. No detectamos diferencias significativas por edad o sexo en cuanto a la mejoría observada. A B p C p Glu Prom 154,89 $\pm 30,50$ 150,89 \pm $27,140,009147,26 \pm 25,580,01 \mathrm{CV} \mathrm{36,99 \pm 6,5636,44}$ $\pm 6,500,06936,03 \pm 6,080,028 \mathrm{HbA} 1 \mathrm{c}(\%) 7,01 \pm 0,72$ $6,91 \pm 0,640,0116,75 \pm 0,860,003$ TIR (\%) 62,75 \pm $16,3566,42 \pm 14,320,00067,61 \pm 14,160,001 \mathrm{TBR}$ (\%) $6,22 \pm 5,966,08 \pm 5,220,9096,48 \pm 6,820,722$ TAR $(\%) 31,07 \pm 18,0727,67 \pm 15,920,00125,89 \pm$ $15,420,002$.

\section{CONCLUSIONES}

El confinamiento se relacionó en nuestros pacientes con cambios glucométricos que expresan mejoría del control metabólico, independientes de edad o sexo.

\section{EFECTO DE LA MONITORIZACIÓN FLASH DE GLUCOSA EN ADULTOS CON DIABE- TES TIPO 1 TRATADOS CON BOMBA DE INSULINA}

\section{EFFECT OF FLASH GLUCOSE MONITORING IN ADULTS WITH TYPE 1 DIABETES MANA- GED WITH INSULIN PUMP THERAPY}

Sandra Amuedo Domínguez ${ }^{1 / 1}$; Noelia Gros Herguido ${ }^{1 / 1}$; Virginia Bellido Castañeda ${ }^{1 / 1}$; Gema López GaIlardo ${ }^{1 / 1}$; Fátima Farfán Díaz ${ }^{1 / 1}$; Pilar SantaCruz Álvarez $^{1 / 1}$; Alfonso Soto Moreno ${ }^{1 / 1}$

(1) Hospital Universitario Virgen del Rocío

(1) Unidad de Gestión Clínica de Endocrinología y Nutrición

\section{DIABETES}

\section{INTRODUCCIÓN}

Ensayos clínicos aleatorizados han demostrado que el uso de la monitorización flash de glucosa intersticial (MFG) produce mejoras significativas en el control glucémico y la hipoglucemia, además de proporcionar una mayor calidad de vida en adultos con diabetes tipo 1 (DT1) en comparación con la autorrealización de glucemia capilar tradicional.

\section{OBJETIVOS}

1) Evaluar el impacto de la MFG en términos de control glucémico a los 3 y 6 meses tras la implantación en comparación con los resultados glucémicos preimplantación en adultos con DT1 en terapia con bomba de insulina (ISCI). 2) Evaluar el grado de uso de la MFG tras 6 meses de utilización.

\section{MATERIAL Y MÉTODOS}

Estudio cuasiexperimental pre-post intervención. Se compararon las variables de estudio de la descarga de la ISCI (Minimed 640G) preimplantación a la MFG con FreeStyle Libre respecto a las descargas de la MFG realizadas a los 3 y 6 meses posimplantación. Criterios de inclusión: DM1 adultos > 18 años usuarios de ISCI.

\section{RESULTADOS}

78 adultos DT1 (60,8\% mujeres, edad media 43,3 \pm 13,3 años). Se objetivó un descenso significativo del tiempo en hipoglucemia $<70 \mathrm{mg} / \mathrm{dl}(8,8 \pm 8,1$ preimplantación vs $7,3 \% \pm 13,1 \% 3$ meses vs $5,7 \% \pm 5,5 \% 6$ meses; $\mathrm{p}=0.000)$ y $<54 \mathrm{mg} / \mathrm{dl}(1,1 \pm 2,3$ vs $0,8 \pm 1,2$; $\mathrm{p}=0.001)$ y de la variabilidad glucémica medida por el coeficiente de variación $(43,7 \pm 8,7$ vs $37,3 \pm 7$ vs $36,3 \pm$ $4,5 ; \mathrm{p}=0.000)$. Se produjeron mejoras en el tiempo en hiperglucemia $>180 \mathrm{mg} / \mathrm{dL}(34,2 \pm 14$ vs $23,8 \pm 11,4$ vs $23,8 \pm 11,3 ; \mathrm{p}=0.000)$ y en el tiempo en rango $(56,1 \pm$ $12,4$ vs $61,1 \pm 13,8$ vs $61,5 \pm 14,5$; $\mathrm{p}=0.000)$. No encontramos diferencias en la HbAlc preimplantación respecto a los 6 meses $(7,4 \pm 0,9$ vs 7,3 $\pm 0,8)$. En relación con el uso de la MFG, hubo diferencias en el número de escaneos diarios $(12,4 \pm 7,6$ vs $9,8 \pm 6$ vs $9,6 \pm 5,7$; $\mathrm{p}=0.000)$ y en el $\%$ de datos captados (92 $\pm 13,4$ vs $84,2 \pm 19,8$ vs $90,5 \pm 14 ; \mathrm{p}=0.000)$ en las descargas realizadas a los 14 días, 3 y 6 meses posimplantación.

\section{CONCLUSIONES}

1) La MFG mejora el control glucémico en términos de descenso del tiempo en hipoglucemia, incremento del tiempo en rango, reducción del tiempo en hiperglucemia y de la variabilidad glucémica, resultados que se mantienen tras 6 meses de uso continuado.

2) El grado de uso del dispositivo es óptimo y, tanto el número de escaneos diarios como el \% de datos captados, permanece estable a los 6 meses de la implantación.

\section{IMPACTO DEL PASO DE TERAPIA CON SISTEMA HÍBRIDO EN PACIENTES DM 1 CON TERAPIA INFUSIÓN CONTINUA DE INSULINA}

IMPACT OF THE THERAPY WITH HYBRID CLOSED-LOOP SYSTEM IN DMI PATIENTS WITH CONTINUOUS INSULIN INFUSION THERAPY

Reyes Ravé García ${ }^{1 / 1}$; Carmen Polvillo Verdugo ${ }^{1 / 1}$; Carmen Mateo Rodríguez ${ }^{1 / 1}$; Isabel Serrano OImedo ${ }^{1 / 1}$; Cristóbal Morales Portillo ${ }^{1 / 1}$; María Asunción Martínez Brocca ${ }^{1 / 1}$

(1) Hospital Universitario Virgen Macarena, Sevilla

(1) UGC Endocrinología y Nutrición

\section{DIABETES}




\section{INTRODUCCIÓN}

Tras la evaluación de una cohorte de pacientes diabéticos tipo 1 (DM1), se objetivó que el paso de infusión subcutánea continua de insulina (ISCI) a un sistema híbrido de infusión subcutánea de insulina de asa cerrada (SIH) con Medtronic 670G, conseguía una reducción del tiempo en hipoglucemia, variabilidad glucémica y una mejora del tiempo en rango, sin que la sobrecarga tecnológica provocara un deterioro en la calidad de vida.

\section{OBJETIVOS}

Evaluar el impacto de la implantación de un SIH en el control glucémico y calidad de vida de pacientes con DM1 en tratamiento con ISCI previa.

\section{MATERIAL Y MÉTODOS}

Se evaluó de forma prospectiva la transición a un SIH Medtronic $780 \mathrm{~g}$ en adultos con DM1 tratados previamente con ISCI. Evaluación basal y a los 3 meses del paso a automático de: control glucémico, calidad de vida y percepción de hipoglucemias test de Clarke, Miedo a hipoglucemias FH15, ES DQoL, DTSQ satisfacción con el tratamiento, Diabetes Distress scale DDS17S y test de calidad de sueño Pittsburg.

\section{RESULTADOS}

9 pacientes DM1 (66\% mujeres; $44 \pm 8,8$ años; 26 $\pm 9,5$ años de evolución, IMC $27,8 \pm 3,9 \mathrm{Kg} / \mathrm{m} 2$ y 9 $\pm 4,7$ años con ISCI). $33 \%$ presentaban complicaciones microvasculares y 1 paciente macrovasculares. Indicación SIH: hipoglucemias inadvertidas y graves, $66 \%$, necesidad de intensificación 34\%. 2 de los pacientes habían tenido un control inadecuado con SIH $670 \mathrm{G}$ por hiperglucemia y paso continuo a modo automático, por los que se indicó el cambio a $780 \mathrm{G}$. A los 3 meses el uso del sensor fue de $96,13 \%$ y tiempo en automático de $98,5 \%$. Los resultados del con- trol glucémico fueron: - A1C \%: basal: 7,26 $\pm 0,9.3$ Meses 6,5 $\pm 0,52(p=0,035)$ - Glucemia media $\mathrm{mg} / \mathrm{dl}$ : basal:160,7 $\pm 20,1.3$ meses:140,6 $\pm 7,4$. $(p=0,017)$ CV \%: basal: $34,3 \pm 6,5.3$ meses: $30 \pm 3,3$. $(p=0,67)-$ Tiempo en rango (TER\%): Basal: $62,25 \pm 14,13.3$ meses: $82,2 \pm 3,3$. $(\mathrm{p}=0,018)$ - Tiempo muy alto $(>250) \%$ : Basal 4,5[2;18,7]. 3 meses 1,5 [0;2]. $(p=0,058)$ - Tiempo alto (181-250)\%: Basal $25 \pm 4,5$. 3 meses $15,5 \pm$ 4,2. $(\mathrm{p}=0,018)$ - Tiempo hipoglucemia total \%: Basal $2[0,2 ; 6,7] .3$ meses $1[0 ; 2](p=0,1)$.

\section{CONCLUSIONES}

En pacientes adultos con DM1 de larga evolución el paso de ISCI a SIH con 780 G consigue una mejora del control glucémico, variabilidad glucémica, mejora del tiempo en rango y una reducción del tiempo en hipoglucemia. La utilización de cuestionarios validados tiene valor en el seguimiento de estos pacientes.

\section{RESULTADOS EN VIDA REAL DE LA MONI- TORIZACIÓN CONTINUA DE GLUCOSA EN CONSULTA DE DIABETES MELLITUS TIPO 1}

\section{REAL-LIFE RESULTS OF CONTINUOUS GLU- COSE MONITORING IN TYPE 1 DIABETES MELLITUS OUTPATIENT REVIEW}

Irene Zayas Aguilar ${ }^{1 / 1}$; Fernando Piñero Martínez ${ }^{2 / 2}$; Esteban Sánchez Toscano ${ }^{1 / 1}$; Jesús Manuel Cornejo Dominguez ${ }^{1 / 1}$; Almudena Lara Barea ${ }^{1 / 1}$; José Ortego Rojo ${ }^{3 / 3}$; María del Mar Roca-Rodríguez ${ }^{1 / 1}$; Manuel Aguilar-Diosdado ${ }^{1 / 1}$

(1) Hospital Puerta del Mar, (2) Facultad de Medicina

(1) Endocrinología y Nutrición, (2) Universidad de Cádiz,

\section{DIABETES}

\begin{tabular}{|c|c|c|c|}
\hline & Basal & 3 Meses & Significación \\
\hline A1C \% & $7,26 \pm 0,9$ & $6,5 \pm 0,52$ & 0,035 \\
\hline Glucemia mg/dl & $160,7 \pm 20,1$ & $140,6 \pm 7,4$ & 0,017 \\
\hline CV \% & $34,3 \pm 6,5$ & $30 \pm 3,3$ & 0,67 \\
\hline TER\% & $62,25 \pm 14,13$ & $82,2 \pm 3,3$ & 0,018 \\
\hline Tiempo muy alto $(>250) \%$ & $4,5[2 ; 18,7]$ & $1,5[0 ; 2]$ & 0,058 \\
\hline Tiempo alto $(181-250) \%$ & $25 \pm 4,5$ & $15,5 \pm 4,2$ & 0,018 \\
\hline Tiempo hipoglucemia total \% & $2[0,2 ; 6,7]$ & $1[0 ; 2]$ & 0,1 \\
\hline
\end{tabular}

Tabla 1. Datos expresados: media $\pm D E ;$ mediana [p25;p75]

(IMPACTO DEL PASO DE TERAPIA CON SISTEMA HÍBRIDO EN PACIENTES DM1 CON TERAPIA INFUSIÓN CONTINUA DE INSULINA) 


\section{INTRODUCCIÓN}

Los sistemas de monitorización continua de glucosa flash (i-MCG) permiten un control más exhaustivo de los perfiles de glucemia.

\section{OBJETIVOS}

Evaluar el impacto de la i-MCG sobre el control metabólico y las hipoglucemias en pacientes con DM1.

\section{MATERIAL Y MÉTODOS}

Es un estudio epidemiológico observacional de tipo retrospectivo con medidas de cambio intrasujeto antes y después de i-MCG en sujetos con DM1 atendidos en las consultas externas del servicio de Endocrinología y Nutrición del Hospital Puerta del Mar de Cádiz.

\section{RESULTADOS}

Evaluamos 95 pacientes (55,8\% varones) con DM1 , edad media 44,43 $\pm 12,54$ años y duración media de diabetes $23,56 \pm 14,27$ años. El $100 \%$ de pacientes estaban con terapia bolo-basal y un $11,6 \%$, además antidiabético. Se evaluó la visita previa al sensor y tras $5,44 \pm 2,36$ y $3,88 \pm 1,94$ meses de su instauración. La HbA1c presentó una disminución progresiva $(p=0,03)$, así como la variable sin hipoglucemias mejoría significativa en ambas visitas con sensor $(\mathrm{p}<0,01)$; las variables glucemia basal e hipoglucemias graves mejoraron en la tercera visita sin alcanzar significación estadística, y LDL y TG se mantuvieron sin cambios. El análisis de regresión lineal con $\mathrm{HbA1c}$ de la tercera visita como variable dependiente mostró relación significativa con glucemia promedio $(p=0,03)$, rango muy alto $(p=0,02)$, alto $(p=0,03)$ y coeficiente de variación $(\mathrm{p}=0,04)$. El análisis de regresión logística con hipoglucemias en tercera visita como variable dependiente mostró asociación significativa $(\mathrm{p}=0,01)$ con tipo de insulina rápida, y explicaría a modo de hipótesis entre el 0,18 y 0,30 de la variable dependiente.

\section{CONCLUSIONES}

los resultados preliminares de la i-MCG en nuestra práctica clínica muestran un control glucémico aceptable, aunque subóptimo en tiempos muy alto, en objetivo y bajo, y que el uso de esta herramienta mejora el número hipoglucemias de forma significativa, así como las hipoglucemias graves. Además, la HbAlc se asocia de forma significativa a los nuevos parámetros de control glucémico.

\section{PUESTA EN MARCHA DE UN NUEVO PRO- TOCOLO DE ATENCIÓN EN LA TRANSI- CIÓN A ADOLESCENTES CON DIABETES TIPO 1: RESULTADOS CLÍNICOS INICIA- LES TRAS SU IMPLANTACIÓN}



IMPLEMENTATION OF A NEW DIABETES TRANSITION CARE PROGRAM IN ADOLESCENTS WITH TYPE 1 DIABETES: FIRST CLINICAL RESULTS AFTER ITS IMPLANTATION

Raquel Guerrero-Vázquez ${ }^{1 / 1}$; María del Mar Romero Pérez $^{1 / 2}$; Eduardo Torrecillas ${ }^{1 / 1}$; Isabel Serrano Olmedo $^{1 / 1}$; Carmen Polvillo ${ }^{1 / 1}$; María Asunción Martínez Brocca $^{1 / 1}$

(1) Hospital Universitario Virgen Macarena

(1) Endocrinología y Nutrición, (2) Pediatría

\section{DIABETES}

\section{INTRODUCCIÓN}

\section{OBJETIVOS}

1) Presentar el protocolo de transición (PT) de la edad pediátrica a la edad adulta en personas con diabetes mellitus (DM) puesto en marcha entre las Unidades de Endocrinología pediátrica y Endocrinología de adultos del Hospital Universitario Virgen Macarena. 2) Analizar las características clínicas, metabólicas, tasa de complicaciones agudas, pérdidas de seguimiento e inasistencia a consultas durante el primer año de atención en la Unidad de adultos.

\section{MATERIAL Y MÉTODOS}

Estudio observacional descriptivo prospectivo, iniciado en marzo 2018. Criterios de inclusión: todas las personas con DM mayores de 18 años considerados aptos para el proceso de transición. Se analizaron variables de control glucémico, \% de pérdidas en el seguimiento, $\mathrm{n}^{\circ}$ de inasistencias a consulta y tasa de complicaciones agudas en el primer año tras la transferencia.

\section{RESULTADOS}

En este PT se organiza todo el periodo de la transición, que se inicia un año antes de la transferencia, con reuniones conjuntas de un equipo multidisciplinar y una consulta de atención compartida y conjunta entre el Pediatra y el Endocrinólogo de referencia, antes de la transferencia. 42 adolescentes DM tipo 1 (64,3\% mujeres); edad 19,01 (SD 0,60) y tiempo de evolución de $9,1(4,17)$ años. $34(81 \%)$ en régimen bolo basal y 8 con sistemas de infusión continua de insulina o híbrido. El $69 \%$ era portador de MFG en la visita conjunta. $27(64,3 \%)$ llevan más de un año de seguimiento en adultos. Las variables de control glucémico en la consulta conjunta y al año de seguimiento fueron: HbAlc $8,14(1,45)$ vs $8,01(0,88) \%$; glucemia promedio $184,08(41,53)$ vs $177,53(18,41)$ $\mathrm{mg} / \mathrm{dL}$; CV 45,67 $(7,35)$ vs $43,74(5,46) \%$; \% TIR 48,73 $(12,66)$ vs $50,32(19,00)$; \% TAR $40,69(18,76)$ vs 39,25 $(13,99)$ y \% TBR $7,2(4,65)$ vs $5,42(3,59)$; respectivamente ( $\mathrm{p}$ ns para todos los pares de muestras). La tasa de complicaciones agudas en el año de preparación fue 3.73 eventos CAD/100 persona/año y 11.1 hipoglucemias severas/100 persona/año. En el año de seguimiento en adultos: $3.73 \mathrm{CAD} / 100$ persona/año y 3.73 hipoglucemias severas/100 persona/año. Se registraron 12 inasistencias a la consulta ( 8 faltaron a una y 2 a dos) y un total de $4(14,81 \%)$ pérdidas completas de seguimiento. 


\section{CONCLUSIONES}

1) El desarrollo y ejecución de un PT conjunto entre las Unidades pediátricas y de adultos, permite organizar este proceso de manera eficiente y coordinada. 2) El control glucémico se mantiene estable durante el primer año, sin incremento de la tasa de complicaciones agudas. La inasistencia a consultas durante el primer año y las pérdidas en el seguimiento continúan siendo áreas de mejora que precisan procedimientos de recaptación efectivos.

\section{MONITORIZACIÓN CONTINUA DE GLUCO- SA FLASH: COMPARACIÓN DE PACIEN- TES CON DIABETES TIPO 1 EN TERAPIA CON INFUSIÓN SUBCUTÁNEA CONTINUA DE INSULINA, FRENTE AL TRATAMIENTO CON MÚLTIPLES DOSIS}

\section{CONTINUOUS FLASH GLUCOSE MONITO- RING: COMPARISON OF TYPE 1 DIABETES PATIENTS ON CONTINUOUS SUBCUTANEOUS INSULIN INFUSION THERAPY VS. MULTIPLE DOSE TREATMENT.}

\section{Rocío Domínguez Rabadan ${ }^{1 / 1}$; María Laínez López ${ }^{1 / 1}$; Luna Florencio Ojeda ${ }^{1 / 1}$; Rossana Manzanares Córdo-} va $^{1 / 1}$; María Isabel Rebollo Pérez ${ }^{1 / 1}$

(1) Hospital Juan Ramón Jiménez

(1) Endocrinología y Nutrición

\section{DIABETES}

\section{INTRODUCCIÓN}

El sistema de monitorización continua de glucosa intersticial flash, es una herramienta de trabajo indispensable en la actualidad, al permitirnos obtener un control glucémico más estrecho de nuestros pacientes.

\section{OBJETIVOS}

Comparar el control glucémico, mediante el sistema de monitorización flash de glucosa intersticial, en el grupo de infusión subcutánea continua de insulina (ISCI) frente a la terapia con múltiples dosis de insulina (MDI).

\section{MATERIAL Y MÉTODOS}

Estudio observacional retrospectivo de una cohorte de pacientes con Diabetes Mellitus tipo 1, en seguimiento en nuestras consultas, los cuales llevan implantados el sistema de monitorización flash de glucosa. Atendiendo a la terapéutica empleada, es decir, infusión subcutánea continua de insulina (ISCI) frente a múltiples dosis (MDI), se comparan las siguientes variables de monitorización: glucemia media, tiempo en rango, tiempo en hiperglucemia, tiempo en hipoglucemia, variabilidad, e indicador de gestión de glucosa (GMI).

\section{RESULTADOS}

Se incluyen 754 pacientes (N:699 MDI; y N:56 ISCI), con una edad promedio entre 40 y 50 años, de los cuales $51,3 \%$ son varones, y $48,8 \%$ mujeres. Atendiendo a los datos de monitorización ambulatoria flash, vemos que el grupo ISCI presenta un mejor control glucémico con una glucemia media $151 \mathrm{mg} / \mathrm{dl}$ versus 167,3 $\mathrm{mg} / \mathrm{dl}$ en grupo MDI; así como GMI 6,9\% en ISCI VS $7,2 \%$ MDI. El tiempo en rango de objetivo también es superior en pacientes con ISCI: $64,4 \%$ frente al $58 \%$ del grupo con MDI. Respecto a las hipoglucemias, el tiempo de monitorización es menor para los MDI, con lo cual, los pacientes con ISCI suelen tener más eventos de glucemia baja $(6,4 \%$ vs $5,1 \%)$. Por el contrario, el tiempo en hiperglucemia es mayor en grupo MDI que en grupo ISCI (36,7\% VS 29\%).

\section{CONCLUSIONES}

Atendiendo a los distintos parámetros, observamos en nuestro estudio, que el grupo de pacientes con Diabetes tipo 1 en terapia con ISCI, presentan un mejor control glucémico,en comparación con aquellos que emplean sistema de múltiples dosis de insulina.Por otra parte, en este último grupo de pacientes, se ha visto un mejor control del tiempo en hipoglucemia, respecto al primero.

\section{TELECONSULTA EN TIEMPOS DE PANDEMIA}

\section{TELECONSULTATION IN TIME OF PANDEMIC}

\section{Sara León Utrero ${ }^{1}$; Elena López-Mezquita Torres ${ }^{1}$; Pa- blo López Ibarra ${ }^{1}$}

(1) Servicio Endocrinología y Nutrición Hospital Universitario San Cecilio

\section{ENDOCRINOLOGÍA BÁSICA}

\section{INTRODUCCIÓN}

En junio 2020 comienza a realizarse teleconsulta con médicos de atención primaria de nuestra área. Inicio con 5 procesos diagnósticos que se han ampliado a lo largo del año hasta un total de 10.

\section{OBJETIVOS}

Se analizan los datos de la actividad Teleconsulta en el Hospital Universitario San Cecilio de junio 2020 a junio 2021.

\section{MATERIAL Y MÉTODOS}

Los datos se han extraído de Diraya, plataforma por la que se contesta la teleconsulta, se han analizado retrospectivamente mediante Excel.

\section{RESULTADOS}

Se han atendido un total de 1441 teleconsultas, de las cuales 61 no se han considerado tributarias y 287 no se han clasificado con diagnóstico. Un total de 1154 han sido clasificadas según diagnóstico y resolución. 


\begin{tabular}{|l|l|l|}
\hline JUICIO CLINICO & N ${ }^{\circ}$ PACIENTES & $\%$ PACIENTES \\
\hline Disfunción Tiroidea & 409 & $35,4 \%$ \\
\hline Nódulo Tiroideo & 231 & $20 \%$ \\
\hline Diabetes Mellitus & 193 & $16,7 \%$ \\
\hline Hiperprolactinemia & 128 & $11 \%$ \\
\hline Disfunción Tiroidea Gestacional & 76 & $6,6 \%$ \\
\hline Diabetes Mellitus Gestacional & 42 & $3,6 \%$ \\
\hline Hipercalcemia & 33 & $1,7 \%$ \\
\hline Osteoporosis & 20 & $1,2 \%$ \\
\hline Renovación Visado & 14 & $0,6 \%$ \\
\hline Nutrición Enteral Domiciliaria & 8 & 1154 \\
\hline TOTAL & & \\
\hline
\end{tabular}

Tabla 1. (TELECONSULTA EN TIEMPOS DE PANDEMIA)

\begin{tabular}{|c|c|c|c|}
\hline JUICIO CLINICO & $\%$ ALTA & $\%$ SEGUIMIENTO & $\%$ CONSULTA \\
\hline Disfunción Tiroidea & $33,7 \%$ & $55,5 \%$ & $10,7 \%$ \\
\hline Nódulo Tiroideo & $39,8 \%$ & $16,8 \%$ & $43,2 \%$ \\
\hline Diabetes Mellitus & $29,5 \%$ & $33,1 \%$ & $37,3 \%$ \\
\hline Hiperprolactinemia & $48,4 \%$ & $33,6 \%$ & $18 \%$ \\
\hline Disfunción Tiroidea Gestacional & $22,3 \%$ & $64,5 \%$ & $13,1 \%$ \\
\hline Diabetes Mellitus Gestacional & $11,9 \%$ & $7,1 \%$ & $80,9 \%$ \\
\hline Hipercalcemia & $21,2 \%$ & $18,2 \%$ & $60,6 \%$ \\
\hline Osteoporosis & $25 \%$ & $30 \%$ & $45 \%$ \\
\hline Renovación Visado & $85,7 \%$ & $7,1 \%$ & $7,1 \%$ \\
\hline Nutrición Enteral Domiciliaria & $100 \%$ & $0 \%$ & $27,1 \%$ \\
\hline TOTAL & $34,9 \%$ & $37,9 \%$ & 0 \\
\hline
\end{tabular}

Tabla 2. (TELECONSULTA EN TIEMPOS DE PANDEMIA) 
Entre los motivos más frecuentes se encuentra la Disfunción tiroidea $(35,4 \%)$, Nódulo tiroideo $(20 \%)$, Diabetes (16,7\%) e Hiperprolactinemia (11 \%). El $34,9 \%$ han sido dadas de alta, un $37,9 \%$ han tenido seguimiento telemático y un $27,1 \%$ han necesitado valoración presencial. JUICIO CLINICO $\mathrm{N}^{\circ}$ PACIENTES \% PACIENTES Disfunción Tiroidea 409 35,4 \% Nódulo Tiroideo 23120 \% Diabetes Mellitus 193 16,7 \% Hiperprolactinemia 12811 \% Disfunción Tiroidea Gestacional 76 6,6 \% Diabetes Mellitus Gestacional 42 3,6 \% Hipercalcemia 33 2,8\% Osteoporosis 20 1,7 \% Renovación Visado 14 1,2 \% Nutrición Enteral Domiciliaria 8 0,6 \% TOTAL 1154 JUICIO CLINICO \% ALTA \% SEGUIMIENTO \% CONSULTA Disfunción Tiroidea 33,7 \% 55,5 \% 10,7 \% Nódulo Tiroideo 39,8 \% 16,8 \% 43,2 \% Diabetes Mellitus 29,5 $\% 33,1 \% 37,3$ \% Hiperprolactinemia 48,4 \% 33,6 \% $18 \%$ Disfunción Tiroidea Gestacional 22,3 \% 64,5 \% 13,1 \% Diabetes Mellitus Gestacional 11,9 \% 7,1 \% $80,9 \%$ Hipercalcemia 21,2 \% 18,2 \% 60,6 \% Osteoporosis $25 \% 30 \% 45 \%$ Renovación Visado 85,7 \% 7,1\% $7,1 \%$ Nutrición Enteral Domiciliaria $100 \% 0 \% 0 \%$ TOTAL 34,9 \% 37,9\% 27,1\%.

\section{CONCLUSIONES}

La teleconsulta en nuestro centro ha demostrado ser una herramienta adecuada de comunicación con los médicos de atención primaria, es eficiente y resolutiva, disminuyendo de forma significativa el número de consultas presenciales.

Es necesario un feed back con atención primaria para definir de manera adecuada los objetivos que permitan la mejora continua de este sistema.

\section{HIPOMAGNESEMIA Y PATOLOGÍAS DEL METABOLISMO MINERAL ÓSEO}

HYPOMAGNESEMIA AND PATHOLOGIES OF BONE MINERAL METABOLISM

María del Carmen Andreo López ${ }^{1 / 1}$; Verónica Ávila Rubio $^{1 / 1}$; Pablo J López-Ibarra Lozano ${ }^{1 / 1}$; Manuel Muñoz Torres ${ }^{1 / 1}$

(1) Hospital Universitario San Cecilio

(1) UCG Endocrinología y Nutrición

ENDOCRINOLOGÍA BÁSICA

\section{INTRODUCCIÓN}

La hipomagnesemia (hipoMg) tiene alta incidencia en hospitalizados, especialmente en UCI (11-60\% respectivamente).

Sin embargo, su diagnóstico en pacientes ambulatorios es difícil de establecer debido a su clínica inespecífica y a que no es un parámetro analítico de rutina.

\section{OBJETIVOS}

Estimar la prevalencia de hipoMg en pacientes ambulatorios evaluados en consulta de Metabolismo Mineral del H.U. San Cecilio de Granada.

\section{MATERIAL Y MÉTODOS}

Estudio transversal descriptivo de una cohorte de 100 pacientes valorados en Mayo-Julio 2021 por patologías metabólicas óseas diferentes a hipoMg. Variables de estudio: concentraciones plasmáticas de $\mathrm{Mg}$ (parámetro de rutina en esta consulta), variables clínicas (diagnósticos específicos, patologías concomitantes, fármacos, hábitos tóxicos) y demográficas (edad, sexo).

Se establecen 3 categorías de hipoMg: <1.9 mg/dl (según valor de referencia de nuestro laboratorio), <1.8 $\mathrm{mg} / \mathrm{dl}$ (por definición según la mayoría de los consensos); $<1.4 \mathrm{mg} / \mathrm{dl}$ (hipoMg grave).

\section{RESULTADOS}

Prevalencia de HipoMg < 1.9 mg/dl: $31 \%$; $<1.8 \mathrm{mg} / \mathrm{dl}$ : $17 \%$; <1.4 mg/dl: 2\%. Rango de edad 39-85 años; $80 \%$ mujeres. Patología metabólica ósea: $45 \%$ osteoporosis, $16 \%$ HPTP, $25 \%$ ambas y resto miscelánea. En el grupo de hipoMg $<1.8 \mathrm{mg} / \mathrm{dl}$, el 76\% tomaba diuréticos y/o IBPs ( $41 \%$ ambos fármacos y $35 \%$ alguno de ellos) y el $88 \%$ presentaba patologías relacionadas con hipoMg: 64\% DM2, 30\% HPTP, 30\% DM2+HPTP, 11\% ERC, 8\% déficit $25 \mathrm{OHD}$, casos aislados de diarrea crónica no filiada, osteomalacia, hepatopatía crónica con malnutrición asociada y alcoholismo moderado.

\section{CONCLUSIONES}

En nuestro medio, la prevalencia de hipoMg en pacientes ambulatorios es elevada, entre ellos, existe un alto porcentaje que toman diuréticos e IBPs.

Es necesario investigar la presencia de sintomatología, establecer un adecuado diagnóstico etiológico, eliminar o corregir potenciales factores causales e instaurar suplementación en los casos que lo requieran.

\section{ANÁLISIS DE LAS INTERCONSULTAS HOSPITALARIAS, REALIZADAS AL SERVI- CIO DE ENDOCRINOLOGÍA DEL HOSPITAL JUAN RAMÓN JIMÉNEZ, EN EL PERIODO 2020}

ANALYSIS OF HOSPITAL REFERRALS TO THE ENDOCRINOLOGY DEPARTMENT OF THE JUAN RAMÓN JIMÉNEZ HOSPITAL IN THE PERIOD 2020

Miriam Cózar Dueñas ${ }^{1 / 1}$; Rocío Domínguez Rabadán ${ }^{1 / 1}$; Carmen Carretero Marín ${ }^{1 / 1}$; Luna Florencio Ojeda ${ }^{1 / 1}$; María Laínez López ${ }^{1 / 1}$; María Isabel Rebollo Pérez ${ }^{1 / 1}$

(1) Hospital Juan Ramón Jiménez

(1) Endocrinología y Nutrición 
ENDOCRINOLOGÍA BÁSICA

\section{INTRODUCCIÓN}

El manejo de las descompensaciones diabéticas,de pacientes hospitalizados, es primordial para evitar complicaciones y mayor estancia hospitalaria.

\section{OBJETIVOS}

Valoración del motivo y frecuencia de las interconsultas de pacientes hospitalizados al servicio de Endocrinología, en el último año. Atendiendo a las interconsultas por patología diabética, análisis del control metabólico en el momento de la hospitalización; así como evolución de la enfermedad, presencia de complicaciones vasculares; y necesidad de posterior seguimiento al alta en consultas de Hospital de Día de Diabetes.

\section{MATERIAL Y MÉTODOS}

Estudio descriptivo, retrospectivo de interconsultas de hospitalización realizadas al servicio de Endocrinología, en el año 2020. Se recogen las siguientes variables: edad del paciente, sexo, servicio médico solicitante, tipo de patología endocrina, tiempo de seguimiento durante la hospitalización, presencia de patología Covid. Respecto a la patología diabética, se recoge: control metabólico, evolución, presencia de complicaciones vasculares, tratamiento inicial, así como necesidad de seguimiento posterior en Hospital de Día de Diabetes.

\section{RESULTADOS}

Se incluyen 253 pacientes, con una edad promedio de 59 años, de los cuales $52,6 \%$ son varones, y $47,4 \% \mathrm{mu}-$ jeres. Los servicios solicitantes con mayor realización de interconsultas fueron Medicina Interna (27,7\%), Angiología (15,4\%), Salud Mental (9,1\%), y Cardiología $(7,5 \%)$. La patología consultada más frecuente fue Diabetes Mellitus tipo 2 (43,9\%), seguida de tipo $1(11,1 \%)$. El tiempo medio de seguimiento fueron 14,9 días. Por otra parte, el 6,3\% de las interconsultas fueron referidas a pacientes diagnosticados de Covid. Respecto al subgrupo de pacientes diabéticos (N: 139), el promedio de Hbalc al ingreso fue 9,8\%, y la evolución de la enfermedad 14 años. Se objetivó retinopatía diabética en un $23,7 \%$; nefropatía $18 \%$; pie diabético $33,18 \%$; ICTUS $7,9 \%$; y cardiopatía $17,3 \%$. La mayoría de los pacientes $(27 \%)$ sólo tomaban antidiabéticos orales previo al ingreso. La media de seguimiento durante la hospitalización fue 17 días. Al alta, 61,3\% se derivó a Hospital de Día de Diabetes.

\section{CONCLUSIONES}

El manejo de la Diabetes Mellitus tipo 2 es el principal motivo de las interconsultas realizadas, seguido del tipo 1 .

Se deben realizar más estudios, ya que existen escasas referencias bibliográficas que analicen este tipo de asistencia.

\section{CONSULTAS A ENDOCRINOLOGÍA POR TOXICIDAD INMUNOMEDIADA DURANTE EL TRATAMIENTO ONCOLÓGICO}

\section{ENDOCRINE CONSULTATIONS FOR IMMU- NE-MEDIATED TOXICITY DURING ONCOLO- GICAL TREATMENT}

\author{
María Sanchez-Prieto Castillo ${ }^{1 / 1}$; Roberto Carlos \\ Romo Remigio ${ }^{1 / 1}$; Juan Francisco Marin Pozo ${ }^{1 / 2}$; Ana \\ Segarra Balao ${ }^{1 / 1}$; Carmen Gutiérrez Alcántara ${ }^{1 / 1}$ \\ (1) Hospital Universitario de Jaén \\ (1) Endocrinología y Nutricion, (2) UCG Farmacia
}

ENDOCRINOLOGÍA BÁSICA

\section{INTRODUCCIÓN}

La inmunoterapia es una nueva línea de tratamiento oncológico con aumento de su uso de forma explosiva en últimos años. Si bien ha demostrado eficacia antitumoral se relaciona con efectos adversos inmunomediados, entre ellos endocrinológicos.

\section{OBJETIVOS}

Describir la frecuencia de consultas a Endocrinología por sospecha de efectos adversos derivados de la inmunoterapia.

\section{MATERIAL Y MÉTODOS}

Estudio descriptivo retrospectivo Se analizaron las historias clínicas de todos los pacientes tratados con algún tratamiento inmunoterápico del 1 de Julio de 2020 al 1 de Julio de 2021 en el HU de Jaén. Se registró cuál de ellos había sido evaluado por la UCG de Endocrinología de dicho hospital debido a sospecha de efectos adversos endocrinológicos (bien en consultas externas, hospital de día o interconsulta durante ingresos). Se uso el SPSS 25( para el análisis estadístico con porcentajes para cualitativas y descriptivos para cuantitativas.

\section{RESULTADOS}

211 pacientes se habían tratado con algún inmunoterápico en dicho periodo: $169(80,1 \%)$ hombres, de edad 66,5 $\pm 9,4 ; 108$ casos con Pembrolizumab, (51,2\%), 55 Nivolumab, 32 con Atezulizumab, 10 estuvieron con 2 fármacos distintos, 6 con otros fármacos. Los tumores más frecuentes fueron pulmón $(\mathrm{N}=111)$, Melanoma $(\mathrm{N}=27)$ y Cabeza y cuello $(\mathrm{n}=27)$.

En 30 casos nos consultaron a Endocrino (14,7\%) durante ese periodo, en 16 de los casos por alteraciones tiroideas, 12 por sospecha de alteración hipofisaria (en 8 casos por hipocortisolismo secundario), 1 por hipoadrenalismo primario y 1 diabetes autoinmune.

La consulta con Endocrinología no se relacionó con el sexo, ni con la edad ni el tipo concreto de inmunoterápico o de patología tumoral. 


\section{CONCLUSIONES}

Casi el 15\% de los pacientes oncológicos tratados con inmunoterapia precisan evaluación por Endocrinología por posibles efectos adversos Dado el auge de estas terapias sería importante crear protocolos de manejo multidisciplinar de esta toxicidad, junto con Oncología.

\section{EL MONITORIZACIÓN FLASH DE GLUCO- SA Y SUS BENEFICIOS POTENCIALES EN LOS PACIENTES CON DIABETES MELLI- TUS TIPO 1}

\section{FLASH GLUCOSE MONITORING AND ITS PO- TENTIAL BENEFITS IN PATIENTS WITH TYPE 1 DIABETES MELLITUS}

Silvia Ponce Delgado ${ }^{1 / 1}$; Ana Domínguez Navarro ${ }^{1 / 1}$; Dolores Cepero Ramírez ${ }^{1 / 1}$; Concepción Cruzado Bégines ${ }^{1 / 1}$

(1) Hospital Universitario Jerez de la Frontera

(1) UGC Endocrino y Nutrición

ENFERMERÍA Y EDUCACIÓN TERAPÉUTICA

\section{INTRODUCCIÓN}

El sistema de Monitorización Flash de Glucosa (MFG) es un sensor que lee la glucosa en el líquido intersticial, ofreciendo un valor numérico de glucosa y una flecha de tendencia. Este sistema se compone de un sensor desechable con un filamento flexible insertado bajo la piel con un aplicador también desechable, con una vida media de 14 días y un lector que dispone de un glucómetro clásico de glucemia capilar que envía la señal a un monitor (pudiendo ser un monitor externo, el teléfono móvil...) para informar sobre el nivel de glucosa en el líquido intersticial. Está demostrado que tiene buenos resultados de exactitud en comparación con la glucemia capilar. Asimismo, el uso de MFG permite una reducción importante en el número de glucemias capilares y buenos resultados en términos de control metabólico y seguridad, mejorando la calidad de vida de los pacientes.

\section{OBJETIVOS}

Comprender el potencial que tiene el sistema de monitorización flash para el control metabólico del paciente con diabetes mellitus portador de este monitor.

\section{MATERIAL Y MÉTODOS}

Se ha llevado a cabo una revisión bibliográfica en profundidad, donde se han revisado las principales bases de datos de Ciencias de la Salud.

\section{RESULTADOS}

La MFG permite la detección temprana y el tratamiento de las desviaciones de la glucemia dentro del rango objetivo. Además, es una innovación tecnológica clave para una toma de decisiones más informadas tanto por parte de los pacientes como por los profesionales. Detecta y ayuda a reducir significativamente las hipoglucemias y la variabilidad glucémica de los pacientes. Permite la toma de consciencia del paciente de la necesidad de cambio de conducta.

\section{CONCLUSIONES}

La MFG puede favorecer el buen control metabólico al proporcionar una gran información sobre el paciente con la monitorización. No obstante, el MFG por sí mismo, no mejora el control metabólico. Para aprovechar al máximo el sistema, es imprescindible completarlo con el esfuerzo educativo y con las herramientas necesarias para lograr cambios de conductas del paciente y empoderarlo en el autocuidado de su diabetes. El uso de la MFG supone una importante inversión en tiempo, recursos asistenciales y formación para el paciente y los profesionales. En este contexto, la motivación del paciente y su formación en programas estructurados por equipos de educación diabetológica con experiencia es de crucial importancia.

\section{PROGRAMA PILOTO DE IMPLANTACIÓN DE MÉTODO DE SCREENING DE DESNU- TRICIÓN SNAQ}

\section{SNAQ MALNUTRITION SCREENING METHOD IMPLANTATION PILOT PROGRAM}

Matilde Évora Díaz ${ }^{1 / 1}$; María Lainez López ${ }^{1 / 1} ;$ Gabriel Pereda Sánchez ${ }^{1 / 1}$; Rocío Guisado Morán ${ }^{1 / 1}$; $M^{a}$ Isabel Rebollo Pérez ${ }^{1 / 1}$

(1) Hospital Juan Ramón Jiménez Huelva

(1) UNCYD de la UCG de Endocrinología y Nutrición

ENFERMERÍA Y EDUCACIÓN TERAPÉUTICA

\section{INTRODUCCIÓN}

\section{OBJETIVOS}

Validar el proceso de implantación en un subgrupo de pacientes hospitalizados del método de screening de desnutrición SNAQ con objeto de determinar la prevalencia de desnutrición y/o riesgo de desnutrición y la necesidad de prever recursos para su implantación general.

\section{MATERIAL Y MÉTODOS}

Durante noviembre de 2020 un técnico de la UNCYD durante las primeras $48 \mathrm{~h}$ de ingreso realizó el SNAQ en los pacientes de las plantas de M Interna ( 1.2 ) y Digestivo ( 3.4 ). Según la puntuación se procedía: revisión semanal de ingesta ( 1 punto); enriquecer dieta ( lácteos o fruta ) + un recuento de ingesta de 5 días ( 2 puntos o más ); instando a enfermería y/o médico responsable a suplementar con SNO y/o avisar a la UNCYD ( 3 puntos o más ) 


\section{RESULTADOS}

Se visitaros a 152 pacientes y se estudiaron a 131 ( 65 en M Interna ; 66 en Digestivo )., El $79 \%$ no presentan riesgo de desnutrición o desnutrición y el $21 \%$ presentan desnutrición o en riesgo de padecerla. A todos los pacientes con de 2 o más puntos se realizó enriquecimiento de la dieta y recuento de ingesta.

Todos los pacientes con 3 ptos o más se valoraron por UNCYD y se instauró SNO 3 puntos (o más) :28 pacientes 2 puntos : 14 pacientes 1 punto: 25 pacientes 0 puntos: 64 pacientes Pacientes ausentes, ocupados-enfermería,etc : 21 pacientes.

\section{CONCLUSIONES}

El SNAQ es un cuestionario rápido y fácil que al ingreso hospitalario del paciente se puede implementar de forma inmediata. La prevalencia de desnutrición es similar a lo recogido en la literatura. El protocolo es útil para educar a los pacientes sobre su situación nutricional y el motivo por el cual han llegado a un estado de desnutrición, así como darles unas nociones básicas de alimentación, recibidas con interés y agradecimiento por parte de los pacientes. Se avisó a todos los pacientes con diagnóstico de desnutrición a la UNCYD. Se identifica la necesidad de formación a médicos y enfermería de planta de hospitalización en el inicio de enriquecimiento de la dieta e inicio de SNO.

\section{SÍNDROME DE KALLMAN: ANÁLISIS DESCRIPTIVO DE UNA SERIE DE 16 PA- CIENTES}

\section{KALLMAN SYNDROME: A DESCRIPTIVE ANALYSIS OF A SERIES OF 16 PATIENTS}

Eva Venegas Moreno ${ }^{1 / 1}$; Xavier Pérez Candel ${ }^{1 / 1}$; Elena Dios Fuentes $^{1 / 1}$; Ana Piñar Gutiérrez ${ }^{1 / 1}$; Irene de Lara Rodríguez $^{1 / 1}$; Juan Manuel Canelo Moreno ${ }^{1 / 1}$; Pablo J. Remón Ruiz ${ }^{1 / 1}$; Alfonso Soto Moreno ${ }^{1 / 1}$

(1) Hospital Universitario Virgen del Rocío

(1) Servicio de Endocrinología y Nutrición

\section{HIPÓFISIS Y TUMORES NEUROENDOCRINOS}

\section{INTRODUCCIÓN}

La deficiencia aislada de hormona liberadora de gonadotropinas con anosmia/hiposmia denominada Síndrome de Kallman (SK) es una entidad rara con gran heterogeneidad clínica, se relacionada a alteraciones renales, neurológicas, audiométricas con frecuencia variable, sin menospreciar sus complicaciones por el déficit hormonal gonadal.

\section{OBJETIVOS}

Analizamos una serie de pacientes con diagnóstico de SK en seguimiento en las consultas de endocrinología y Nutrición del Hospital Virgen del Rocío.

\section{MATERIAL Y MÉTODOS}

Estudio retrospectivo, análisis descriptivo. Programa estadístico SPSS25. Se determino mediana y rango intercuartílico.

\section{RESULTADOS}

$\mathrm{N}=16$, Hombres $\mathrm{n}=11(68.75 \%)$. Edad $1^{\circ}$ consulta: Hombres: 26,5[17,75-31,75] años, Mujeres: 18[1630,5] años. Motivo de consulta: Hombres: síntomas de hipogonadismo 3 (27,3\%), Retraso puberal 2 (18,2\%), Mujeres: Amenorrea 4 (80\%), retraso puberal 1 (20\%). Desarrollo puberal incompleto: $6(37,5 \%)$. Estimulo fertilidad: 3 (18,75\%), éxito: 1 (33,3\%). Factores de riesgo cardiovascular (FRCV): IMC >25: $5(31,3 \%)]$, fumador: $4(25 \%)$, dislipidemia: $4(25 \%)$, hipertensión: 4 (25\%), diabetes/pre-DM: 3 (18,75\%). Enfermedad metabólica ósea (Osteopenia/Osteoporosis): $10(62,5 \%), 7$ varones $(63,7 \%), 3$ mujeres $(60 \%)$. Otras anomalías: Riñón en herradura: $2(12,5 \%)$, micropene: $2(18,2 \%)$, testes atróficos $5(36,4 \%)$, disfunción vesicoureteral y criptorquidia: $1(9,1 \%)$; Paladar hendido: $1(6,25 \%)$. Pruebas de imagen (RMN): Ninguna alteración morfológica hipotálamo-hipofisaria (no descritas anomalías en surcos ni bulbos olfatorios) Estudio genético: realizado en 7 pacientes $(43,7 \%), 3$ positivos $(42,85 \%)$. Todos heterocigotos. Mutaciones: 1 gen FGFR1 (14,28\%), 2 gen ProkR2 (28,57\%).

\section{CONCLUSIONES}

En esta serie de pacientes observamos que la enfermedad metabólica ósea es prevalente. Más de la mitad de casos presentó al menos 1 FRCV, destacando el consumo de tabaco, dado el riesgo de enfermedad tromboembólica al que predispone. No se pudo inducir pubertad a tiempo en más de $1 / 3$ de los pacientes, posiblemente en algunos casos relacionado a una derivación tardía. El estudio genético fue positivo en el $42 \%$ de los casos solicitados. Sin embargo, la mutación KAL-1 no fue detectada. Dado el patrón de herencia variable de esta patología, es adecuado el consejo genético.

\section{SELECCIÓN DE PACIENTES SUBSIDIA- RIOS DE TRATAMIENTO CORTICOIDEO EN CIRUGÍA TRANSESFENOIDAL}

SELECTION OF SUBSIDIARY PATIENTS FOR CORTICOID TREATMENT IN TRANSSPHENOIDAL SURGERY

Jesús Manuel Cornejo Domínguez ${ }^{1 / 1}$; Marta Martínez Ruiz ${ }^{2 / 2}$; Esteban Sanchez Toscano ${ }^{1 / 1}$; Irene Zayas Aguilar $^{1 / 1}$; Irene Iglesias Lozano ${ }^{1 / 3}$; Pedro Muriel Cueto ${ }^{1 / 4}$; Inmaculada Gavilán Villarejo ${ }^{1 / 1}$; Maria del Mar Roca-Rodríguez ${ }^{1 / 1}$; Manuel Aguilar-Diosdado ${ }^{1 / 1}$

(1) Hospital universitario Puerta del Mar, Cádiz, (2) Univesidad de Cádiz

(1) Endocrinología y nutrición, (2) Facultad de medicina,

(3) Neurocirugía, (4) Anatomia patológica 


\section{HIPÓFISIS Y TUMORES NEUROENDOCRINOS}

\section{INTRODUCCIÓN}

La mayoría de los pacientes que se intervienen de cirugía transesfenoidal (CTE) hipofisaria reciben dosis suprafisiológicas de hidrocortisona perioperatoria independientemente de la alteración o normalidad de la función del eje hipotálamo-hipofisario-adrenal. Estudios recientes ponen en duda la necesidad de dicho tratamiento en todos los pacientes.

\section{OBJETIVOS}

Evaluar la necesidad de tratamiento corticoideo perioperatorio en pacientes con normalidad de la función eje hipotálamo-hipofisario-adrenal previa a la CTE por adenoma hipofisario.

\section{MATERIAL Y MÉTODOS}

Estudio retrospectivo con medidas de cambio intrasujeto antes-después con análisis de variables clínicas, analíticas y radiológicas en pacientes sometidos a CTE por adenomas hipofisarios entre 2012-2020

\section{RESULTADOS}

Estudiamos a $21(57,1 \%$ varones $)$ pacientes con una edad media de 50,43 $\pm 10,76$ años. El tamaño medio del adenoma fue $23,31 \pm 10,18 \mathrm{~mm}(85,3 \%$ macroadenomas y $14,3 \%$ microadenomas). Antes de la CTE, el $23,8 \%$ tenían hipotiroidismo y un $28,6 \%$ hipogonadismo, sin existir hipocortisolismo, déficit somatotropo ni diabetes insípida y un $38,1 \%$ presentaban afectación campimétrica. Tras CTE: La campimetría mejoró en $42,9 \%$ ( $19,1 \%$ resolución completa y $23,8 \%$ parcial). Se normalizó un 56\% la acromegalia y 50\% la hiperprolactinemia, se hallaron déficits hipofisarios no registrados previamente: $47,6 \%$ hipotiroidismo, $38,1 \%$ hipogonadismo, $28,6 \%$ déficit somatotropo y un $23,8 \%$ desarrolló diabetes insípida. En cuanto al cortisol basal, la media postoperatoria fue $13,31 \pm 7,24 \mathrm{mcg} / \mathrm{dl}$. La reevaluación de cortisol postoperatorio fue necesaria en el $33,3 \%$ de los pacientes $(57,1 \%$ test de ACTH $1 \mathrm{mg}$ y $42,9 \%$ prueba de hipoglucemia insulínica). La dosis de hidroaltesona al inicio fue $26,90 \pm 7,82 \mathrm{mg} /$ día, siendo al año 10,24 $\pm 14,96 \mathrm{mg} /$ día. Al año un $44,7 \%$ precisó tratamiento corticoideo sustitutivo.

\section{CONCLUSIONES}

Existe un aumento de déficits hormonales tras la CTE, mejorando la afectación campimétrica. Tras la reevaluación de cortisol basal postoperatorio, $66,7 \%$ no precisaban tratamiento sustitutivo, destacando la necesidad de seleccionar qué pacientes precisan o no terapia corticoidea perioperatoria.

\section{IMPACTO DE LA PANDEMIA COVID19 EN LOS INGRESOS HOSPITALARIOS EN LA UNIDAD DE ENDOCRINOLOGÍA Y NUTRI- CIÓN DEL HOSPITAL VIRGEN DEL ROCIO (HUVR)}

IMPACT OF THE COVID19 PANDEMIC ON HOSPITAL ADMISSIONS IN THE ENDOCRINOLOGY AND NUTRITION UNIT OF THE VIRGEN DEL ROCIO HOSPITAL (HUVR)

\section{Elena Dios ${ }^{1 / 1}$; Irene De Lara $^{1 / 1}$; Sandra Amuedo ${ }^{1 / 1}$; Gema López ${ }^{1 / 1}$; Eva Venegas ${ }^{1 / 1}$; Domingo Acosta ${ }^{1 / 1}$; Pablo Remón ${ }^{1 / 1}$; Alfonso Soto ${ }^{1 / 1}$}

(1) Hospital Virgen del Rocio

(1) Endocrinología y Nutrición

NUTRICIÓN CLÍNICA

\section{INTRODUCCIÓN}

La pandemia COVID-19 obligó a decretar el estado de alarma el 14 de marzo de 2020 y llevó al confinamiento de la población. En los hospitales se suspendieron cirugías no urgentes, ingresos programados y se reconvirtieron las plantas para atención de pacientes COVID19. La pandemia ha dificultado la asistencia sanitaria de pacientes con enfermedades crónicas "no COVID19" y se ha reducido de forma significativa las urgencias y los ingresos hospitalarios. Entre las causas descritas está el miedo al contagio y la reducción de la actividad no urgente. Por otro lado, el confinamiento ha provocado un mayor abandono del autocuidado en pacientes crónicos y se ha observado un mayor número de problemas de Salud Mental, sobre todo en niños y adolescentes, como un aumento en el número de casos de Trastornos de la conducta alimentaria (TCA) y su gravedad.

\section{OBJETIVOS}

Analizar el impacto del confinamiento y la pandemia en las hospitalizaciones a cargo de Endocrinología y Nutrición durante el año 2020, a partir del estado de alarma.

\section{MATERIAL Y MÉTODOS}

Estudio descriptivo retrospectivo. Se analizan los ingresos hospitalarios urgentes y programados desde el $14 / 3$ hasta $31 / 12 / 2020$. Los resultados se expresan en números totales y medias.

\section{RESULTADOS}

Ingresos en 2020: $n=34$ Ingresos en 2019: $n=61$. Descenso de ingresos/año $44.3 \%$ Periodo analizado 14/3 al $31 / 12 / 20$ - Ingresos $n=23$ - Diagnósticos al alta: 8 TCA (34\%), 6 Cetoacidosis diabética CAD (26\%), 3 gastrostomías radioscópicas (13\%), 2 pie diabético no quirúrgico $(8.7 \%), 1$ hiponatremia grave (craneofaringioma), 1 descompensación en acidemia metilmalónica, 2 intestino corto ( 1 exitus), 1 tormenta tiroidea. • TCA: $5<18$ años (62.5\%), IMC medio al ingreso: $13.9 \mathrm{~kg} / \mathrm{m} 2$ (10.4-15.2). Estancia media 16.5 días (1 caso 58 días) - CAD: 1 Debut DM tipo 1. Estancia media 3.8 días.

\section{CONCLUSIONES}

Existe un descenso brusco del número de ingresos hospitalarios en la Unidad durante este periodo, si- 
milar a lo publicado a nivel nacional. La suspensión de ingresos programados para pruebas funcionales y las cirugías electivas puede estar relacionado, así como el mantenimiento de consultas externas y la incorporación de la telemedicina, que puede haber favorecido la asistencia de forma ambulatoria. El mayor peso de los ingresos durante la pandemia ha sido de pacientes con diagnóstico de TCA, en la mayoría de los casos eran menores ( $<18$ años) y con desnutrición grave (IMC <15), posiblemente como consecuencia del impacto negativo del confinamiento en pacientes adolescentes vulnerables.

\section{EVALUACIÓN DE LAS INTERCONSULTAS HOSPITALARIAS RECIBIDAS POR LA UNI- DAD DE NUTRICIÓN EN EL HOSPITAL JUAN RAMÓN JIMÉNEZ EN EL ÚLTIMO AÑO}

\section{EVALUATION OF INPATIENT NUTRITIONAL CONSULTATIONS RECEIVED AT JUAN RA- MON JIMENEZ HOSPITAL LAST YEAR}

Carmen Carretero Marín ${ }^{1 / 1}$; Luna Florencio Ojeda ${ }^{1 / 1}$; Rocío Domínguez Rabadán ${ }^{1 / 1}$; Miriam Cózar Dueñas ${ }^{1 / 1}$; María Laínez López ${ }^{1 / 1}$; María Isabel Rebollo Pérez ${ }^{1 / 1}$

(1) Hospital Juan Ramón Jiménez

(1) UGC Endocrinología y Nutrición

NUTRICIÓN CLÍNICA

\section{INTRODUCCIÓN}

Identificar y tratar la desnutrición hospitalaria es fundamental para mejorar la evolución del paciente, reducir complicaciones y acortar la estancia hospitalaria.

\section{OBJETIVOS}

Evaluamos la actividad desarrollada por la Unidad de Nutrición Clínica y Dietética (UNCYD) en interconsultas hospitalarias para valorar qué tipo de paciente se atiende y qué intervención nutricional se realiza.

\section{MATERIAL Y MÉTODOS}

Estudio descriptivo retrospectivo de las interconsultas realizadas a la UNCYD del hospital Juan Ramón Jiménez en el año 2020. Se analiza la unidad solicitante, edad y sexo del paciente, datos antropométricos, tipo de patología, días de ingreso hospitalario hasta que se realiza la interconsulta y tiempo de seguimiento durante la hospitalización, intervención nutricional realizada y planteamiento al alta.

\section{RESULTADOS}

Recibimos 495 interconsultas. Las especialidades más solicitantes fueron Medicina Interna (30,5\%), Cirugía General (10,7\%), Digestivo (9,9\%) y Oncología $(9,3 \%)$. La edad media de los pacientes fue de $66,3 \pm$ 15,3 años, varones un 56,2\%. IMC medio fue de 23,04 $\pm 5,95 \mathrm{~kg} / \mathrm{m} 2$, con un $11,9 \%$ en rango de bajo peso (IMC $<18,5)$. Según criterios GLIM se clasifican un $30,3 \%$ como desnutrición moderada y un $37,2 \%$ como severa. Las patologías más consultadas fueron enfermedad oncológica $(34,4 \%)$, patología neurológica $(19,1 \%)$ y procesos quirúrgicos $(12 \%)$. La neoplasia digestiva fue la patología oncológica que más motivó la interconsulta (19,8\%). El principal motivo de consulta fue la valoración nutricional del paciente $(47,9 \%)$.

Con respecto a la intervención nutricional realizada, el $38 \%$ precisó SNO, el $35,4 \%$ NE por sonda y el $19 \%$ NPT. La mediana de tiempo de hospitalización hasta que se realiza la interconsulta fue de 6 días. La mediana de seguimiento durante la hospitalización fue de 10 días. Al alta se prescribió SNO en un 47,9\% y NE por sonda en un $11,5 \%$. Un $27,3 \%$ de los pacientes falleció durante el ingreso.

\section{CONCLUSIONES}

La patología oncológica es aquella que con más frecuencia requiere la actuación por parte de la UNCYD en el ámbito hospitalario. Se atienden una gran cantidad de interconsultas hospitalarias, desde la UNCYD debemos impulsar a realizar una valoración nutricional precoz al resto de especialidades con el objetivo de mejorar la evolución clínica del paciente, ya que identificar y tratar la desnutrición hospitalaria es una estrategia coste-eficaz.

\section{VALORACIÓN NUTRICIONAL CON ENFO- QUE MORFOFUNCIONAL EN PACIENTES CON CÁNCER DE CABEZA Y CUELLO, ES- TUDIO DESCRIPTIVO DE UNA MUESTRA}

NUTRITIONAL ASSESSMENT WITH A MORPHOFUNCTIONAL APPROACH IN PATIENTS WITH HEAD AND NECK CANCER, A DESCRIPTIVE STUDY OF A SAMPLE

Juan Manuel Guardia Baena ${ }^{1 / 1}$; María Novo Rodríguez $^{1 / 1}$; Jorge Monroy Sánchez ${ }^{1 / 1}$; Cristina Novo Rodríguez $^{1 / 1}$; Araceli Muñoz Garach ${ }^{1 / 1}$; Isabel Herrera Montes ${ }^{1 / 1}$; Carmen Tenorio Jiménez ${ }^{1 / 1}$; Victoria Luna López $^{1 / 1}$; Gonzalo Piédrola Maroto ${ }^{1 / 1}$; Martín López de la Torre Casares ${ }^{1 / 1}$

(1) Hospital Universitario Virgen de las Nieves

(1) Servicio de Endocrinología y Nutrición

\section{NUTRICIÓN CLÍNICA}

\section{INTRODUCCIÓN}

Las neoplasias de cabeza y cuello (CyC) van asociadas en la mayoría de los casos a un elevado riesgo nutricional por el compromiso al que se ve expuesto la vía digestiva superior por el propio tumor y/o por los tratamientos subsidiarios de ser llevados a cabo. 


\section{OBJETIVOS}

Se analizan los datos obtenidos de la valoración de la muestra.

\section{MATERIAL Y MÉTODOS}

Estudio descriptivo en el que se valoran los principales resultados obtenidos incluyendo los parámetros nutricionales clásicos y avanzados con análisis de bioimpedanciometría vectorial (BIVA) y dinamometría de una muestra de 72 pacientes recogida entre diciembre 2020-julio 2021.

\section{RESULTADOS}

Edad media $63.6 \pm 10.7$ años. $73.6 \%$ varones $/ 26.4 \%$ mujeres. Los tumores más frecuentes fueron los localizados en orofaringe/cavidad oral el 56\% seguido de la hipofaringe/laringe $30.5 \%$ con claro predominio en el sexo masculino. El $65.3 \%$ de los pacientes recibió cirugía, $52.8 \%$ radioterapia y el $29.2 \%$ quimioterapia, en muchos casos los tratamientos fueron combinados. El $88.9 \%$ de los pacientes precisó soporte nutricional: 59.4\% SON /39\% NE/1.6\% NP. BIVA general: Ángulo de Fase $4.93 \pm 1.06^{\circ}$ (varones $5.09 \pm 1.01^{\circ}$ y mujeres $4.46 \pm 1.08^{\circ}$ ). Masa celular corporal $23.3 \pm 7.29 \mathrm{~kg}$ (varones $25.12 \pm 6.88 \mathrm{~kg}$ y mujeres $18.29 \pm 6.09 \mathrm{~kg}$ ). Masa libre de grasa $48.8 \pm 10.4 \mathrm{~kg}$. Masa grasa $18.7 \pm 10.3$ $\mathrm{kg}$. Dinamometría general: $28.1 \pm 13.8 \mathrm{~kg}$ (varones $31.46 \pm 13.91 \mathrm{~kg}$ y mujeres $18.93 \pm 8.53 \mathrm{~kg}$ ). Comparando las dos localizaciones de CyC más prevalentes, se observaron peores datos nutricionales en el grupo de hipofaringe/laringe tanto analíticos como de BIVA y dinamometría. Frente al $15.2 \%$ de diabéticos de la muestra, la media general de A1c era $6.39 \pm 1.44 \%$ y de glucemia basal $104 \pm 51.3 \mathrm{mg} / \mathrm{dL}$ siendo rangos de prediabetes/glucemia basal alterada.

\section{CONCLUSIONES}

Los tumores de CyC presentan un marcado predominio en varones y su localización principal fueron los de orofaringe y cavidad oral aunque el grupo de hipofaringe/laringeson los que presentaron peores datos nutricionales. 9 de cada 10 pacientes requieren abordaje nutricional siendo el $40 \%$ por vía enteral. Incluir BIVA y dinamometría ayuda a profundizar en la valoración nutricional hacia una visión morfofuncional. En nuestra muestra hay una posible alteración del metabolismo hidrocarbonado sin diagnosticar. Será clave comparar la evolución de la muestra en su seguimiento para valorar la respuesta al abordaje nutricional implementado.

\section{INCIDENTALOMA SUPRARRENAL. MÁS OSCURO DE LO ESPERADO}

\author{
ADRENAL INCIDENTALOMA. DARKER THAN \\ EXPECTED.
}

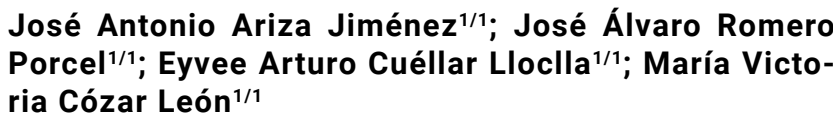

José Antonio Ariza Jiménez ${ }^{1 / 1}$; José Álvaro Romero Porcel $^{1 / 1}$; Eyvee Arturo Cuéllar Lloclla ${ }^{1 / 1}$; María Victoria Cózar León ${ }^{1 / 1}$

(1) Hospital Universitario Virgen de Valme

(1) Endocrinología y Nutrición

\section{SUPRARRENALES Y GÓNADAS (GENERAL)}

\section{INTRODUCCIÓN}

El Black-Adenoma es un tumor suprarrenal poco frecuente, benigno y no funcionante. Aún así hay descritos casos asociados a síndrome de Cushing o síndrome de Conn. Las técnicas de imagen actuales (FDG-Dopa, TAC, RMN) no nos permiten hacer un diagnóstico diferencial con otros incidentalomas suprarrenales, por lo que su diagnóstico es histológico.

\section{OBJETIVOS}

Ampliar conocimientos sobre el manejo diagnóstico y terapéutico del Black-Adenoma.

\section{MATERIAL Y MÉTODOS}

Analizamos el caso de un varón con un incidentaloma suprarrenal relacionado con un adenoma poco conocido.

\section{RESULTADOS}

Varón de 66 años, hipertenso, fumador y en tratamiento con Enalapril $20 \mathrm{mg} / 24 \mathrm{~h}$, en el que en estudio de cirugía biliar por colelitiasis sintomática se detecta en TC una tumoración de la glándula suprarrenal izquierda $(39,2 \times 36,1 \times 41,1 \mathrm{~mm})$. Se amplía estudio con RM que no descarta posible feocromocitoma frente a metaplasia lipoidea. Se realiza estudio PET donde se describe lesión hipermetabólica sugestiva de malignidad. Es derivado a nuestras consultas para filiar etiología del incidentaloma, donde descartamos funcionalidad del mismo con test de Nugent (cortisol $1.5 \mu \mathrm{g} /$ dl), cortisol libre urinario $(121.44 \mu \mathrm{g} / 24 \mathrm{~h})$, cociente aldosterona/ARP (Ald/ARP 4.05) y catecolaminas en orina (Metanefrinas $0.9 \mathrm{nmol} / \mathrm{mgCr}$, Normetanefrinas $1.5 \mathrm{nmol} / \mathrm{mgCr}$ ), todos normales. Dados los hallazgos de sospecha del PET se decide cirugía laparoscópica para suprarrenalectomía izquierda y colecistectomía. El análisis histológico del tumor describe un adenoma cortical con predominio de células claras con áreas oncocíticas pigmentadas "Black adenoma" y transformación mielolipomatosa focal. Dichas áreas estaban teñidas por el pigmento granular de lipofuscina, lo que permitió hacer el diagnóstico diferencial con el melanoma adrenal y la hemorragia suprarrenal. Actualmente, tras 3 años desde la intervención, el paciente se encuentra asintomático, presentando una excelente evolución clínica y analítica.

\section{CONCLUSIONES}

- El Black adenoma es un adenoma benigno que se diagnostica en raras ocasiones. - A pesar de que es poco frecuente debe considerarse en el diagnóstico diferencial del síndrome de Cushing y síndrome de Conn. - Las técnicas de imagen actuales (TC, RM y PET-FDOPA) no son suficientes para el diagnóstico del Black adenoma. Sólo es posible su diagnóstico a partir del estudio anatomopatológico de la pieza. 


\section{ESTUDIO DESCRIPTIVO DE LA POBLACIÓN TRANSEXUAL ATENDIDA EN EL HOSPITAL PUERTA DEL MAR (2015-2019)}

\section{DESCRIPTIVE STUDY OF TRANSGENDER PO- PULATION ATTENDED AT PUERTA DEL MAR HOSPITAL (2015-2019)}

\section{Esteban Sánchez Toscano ${ }^{1 / 1}$; Isabel Mateo Gavira ${ }^{1 / 1}$; Laura Larrán Escandón ${ }^{1 / 1}$; Irene Zayas Aguilar ${ }^{1 / 1}$; Cris- tina López Tinoco ${ }^{1 / 1}$; Manuel Aguilar Diosdado ${ }^{1 / 1}$ \\ (1) Hospital Universitario Puerta del Mar \\ (1) Endocrinología y Nutrición \\ SUPRARRENALES Y GÓNADAS (GENERAL)}

\section{INTRODUCCIÓN}

Se entiende por personas transexuales aquéllas que viven o quieren vivir con una expresión y/o identidad de género distinta a la asignada al nacer lo requiere, en la mayoría de los casos, una serie de adaptaciones hormonales, anatómicas, legales y psicosociales. En Andalucía, tras la implantación del nuevo marco legislativo, se han instaurado cambios en el modelo asistencial de atención a personas transexuales, descentralizándose la atención de la UTIG de Málaga y creándose UAPT provinciales. Desde entonces, la demanda de asistencia a personas transexuales ha aumentado notablemente, lo que podría deberse, en parte, a una disminución de la discriminación por identidad de género y a su despatologización en el marco legal, asistencial y social.

\section{OBJETIVOS}

Evaluar las diferentes variables epidemiológicas y el tipo de demanda asistencial de las personas transexuales atendidas en la UAPT del Hospital Puerta del Mar, así como analizar la evolución de dicha demanda a lo largo del tiempo.

\section{MATERIAL Y MÉTODOS}

Se diseña un estudio observacional, descriptivo, longitudinal y retrospectivo de serie de casos con objeto de evaluar la evolución de la demanda en la atención a personas transexuales en la UAPT del Hospital Puerta del Mar de Cádiz desde abril de 2015 a diciembre de 2019.

\section{RESULTADOS}

De las 340 personas transexuales analizadas, el 55.30\% $(\mathrm{n}=188)$ corresponden a hombres transexuales y el $44.70 \%(\mathrm{n}=152)$ a mujeres transexuales. Las derivaciones analizadas según su procedencia por Área Sanitaria muestran una distribución homogénea de las cuatro áreas de referencia para la UAPT de Cádiz. La edad media derivación al inicio de la actividad asistencial de la UAPT fue de $24.55 \pm 8.66$ años frente a $20.98 \pm 8.22$ años en el último período, $\mathrm{p}=0.014$. El 3.11\% $(n=11)$ iniciaron supresión de la pubertad con análogos de GnRH con edad inferior a 14 años y el $78.1 \%(n=264)$ de las personas atendidas iniciaron tratamiento hormonal cruzado. El $18.5 \%$ precisó ayu- da psicológica y el $17.64 \%(n=60)$ ya se han realizado la gonadectomía.

\section{CONCLUSIONES}

La demanda asistencial de atención a personas transexuales ha aumentado considerablemente en los últimos años, especialmente a expensas de población adolescente. En nuestro medio, se ha invertido la ratio entre mujer y hombre transexual y no se ha detectado tasa de arrepentimiento una vez iniciada la terapia hormonal cruzada.

\section{DESCRIPCIÓN CLÍNICA Y ANALÍTICA DE NUESTRA COHORTE DE AFECTOS Y POR- TADORAS DE ADRENOLEUCODISTROFIA}

\section{CLINICAL AND ANALYTICAL DESCRIPTION OF OUR COHORT OF AFFECTS AND CA- RRIERS OF ADRENOLEUCODYSTROPHY.}

\begin{abstract}
Irene De Lara Rodríguez ${ }^{1 / 1}$; Elena Dios Fuentes ${ }^{1 / 1}$; María del Amor Bueno Delgado ${ }^{1 / 2}$; Ana Piñar Guitiérrez ${ }^{1 / 1}$; Sandra Amuedo Rodríguez ${ }^{1 / 1}$; Juan Manuel Canelo Moreno $^{1 / 1}$; Alfonso Soto Moreno ${ }^{1 / 1}$; Eva Venegas Moreno ${ }^{1 / 1}$

(1) Hospital Universitario Virgen del Rocío

(1) Endocrinología y Nutrición, (2) Pediatría
\end{abstract}

\section{SUPRARRENALES Y GÓNADAS (GENERAL)}

\section{INTRODUCCIÓN}

La adrenoleucodistrofia (ALD) está causada por la mutación del gen ABCD1 (Xq28) con trasmisión recesiva ligada al X. Conlleva la acumulación en la corteza suprarrenal, testículos y sistema nervioso de ácidos grasos de cadena muy larga (VLCFA). Se presenta en varones e implica insuficiencia suprarrenal primaria, hipogonadismo y mieloneuropatía.

\section{OBJETIVOS}

Describir las características clínicas y bioquímicas de los pacientes con ALD del Hospital Universitario Virgen del Rocío. Analizar las diferencias entre pacientes portadores de la mutación en homocigosis o heterocigosis.

\section{MATERIAL Y MÉTODOS}

Estudio descriptivo retrospectivo de los pacientes con mutaciones del gen ABCD1. Se recogieron variables clínicas (sexo, edad, presencia de clínica), analíticas (VLCFA, cortisol) y estudios genéticos. Las variables cuantitativas se expresan como mediana[p25-p75] y las cualitativas como $\mathrm{n}(\%)$. Dado que no presentaban distribución normal se usó la prueba U de Mann-Whitney.

\section{RESULTADOS}

N: 16: Enfermos 8(50\%) Portadores 8(50\%) p Los valores de C24/C22 (p0,005*) y C26/C22 (p0,042*) fueron mayores en los pacientes afectos que en los portadores a pesar de tratamiento Están en tratamiento con "aceite de Lorenzo" (aceite de triacilgliceroles de ácido oleico 
y erúcico) 4 de los 8 pacientes. Se realizó terapia génica en un paciente y trasplante de médula ósea en otro. Dos pacientes están sin tratamiento por ser asintomáticos. Solo uno de los 8 pacientes ha fallecido. La mutación más frecuente en nuestra cohorte fue c.971G>A (p.Arg324His) identificada en 5 portadores y los 2 afectos asintomáticos. Con respecto al análisis de las portadoras, una presenta hipocortisolismo basal sin otros datos de insuficiencia suprarrenal, otra ataxia de extremidades por desmielinización axonal y otra, fallo ovárico precoz. Todas realizan seguimiento en consultas.

\section{CONCLUSIONES}

La ALD es una enfermedad grave que precisa un diagnóstico precoz. Aunque el inicio es temprano, describimos casos asintomáticos de ALD en pacientes adultos varones. Por otro lado, las mujeres portadoras pueden desarrollarla en menor grado y mayor edad por lo que es fundamental el seguimiento.
LESIONES QUÍSTICAS DE PARATIROIDES: A PROPÓSITO DE UNA ENTIDAD HETEROGÉNEA E INFRECUENTE. PRESENTACIÓN DE DOS CASOS CLÍNICOS

\section{CYSTIC PARATHYROID LESIONS: ABOUT A RARE AND HETEROGENEOUS ENTITY. TWO CASES REPORT}

Pablo Rodríguez de Vera Gómez ${ }^{1}$; Jesús Machuca Aguado $^{2}$; Ignacio Jiménez Varo'; Miguel Ángel Idoate Gastearena ${ }^{2}$; María Asunción Martínez-Brocca ${ }^{1}$; Tomás Martín Hernández ${ }^{1}$

(1) Servicio de Endocrinología y Nutrición Hospital Universitario Virgen Macarena Sevilla, (2) Servicio de Anatomía Patológica, Hospital Universitario Virgen Macarena Sevilla

\section{TIROIDES-PARATIROIDES (GENERAL)}

Figura 1. a-e: caso 1. f-i: caso 2

a) Ecografía tiroidea, se observa lesión quística pura en polo inferior de lóbulo tiroideo izquierdo, de $16,8 \times 17,9 \times 36,7 \mathrm{~mm}$, con una cápsula gruesa y refuerzo acústico posterior

b) Imagen histológica con tinción hematoxilina-eosina, se observa la luz quística con tejido paratiroideo circundante $(P)$, con tejido tiroideo normal en su periferia $(T)$. c) Epitelio de revestimiento de la luz quística, mononucleado, simple y cúbico. Externo a él se encuentra tejido conectivo en primer lugar y células de origen paratiroideo posteriormente.

d) Tinción inmunohistoquímica con TTF-1 correspondiente a la imagen similar a la anterior (c), que resulta negativa, descartando origen tiroideo celular tanto en el epitelio de revestimiento como en el entramado celular circundante.

e) Tinción inmunohistoquímica con PTH correspondiente a imagen similar a c), que capta de forma llamativa en células paratiroideas marginales, siendo negativa en el epitelio de revestimiento.

f) Ecografía tiroidea, lesión quística con polo sólido situada en el tercio inferior del lóbulo tiroideo derecho de $15.3 \times 19.8 \times 24.6 \mathrm{~mm}$. Destacan refuerzo acústico posterior y contornos lobulados de la lesión.

g) Ecografía doopler color de la misma lesión de la imagen anterior (f) que muestra intensa vascularización del polo sólido de la lesión quística, que nace en arteria nutricia sobre el polo superior del quiste.

h) Imagen histológica con tinción mediante hematoxilina eosina. En el margen izquierdo se observa la luz quística, con tejido fibroso como revestimiento sin epitelio, probablemente originado por efecto compresivo del líquido quístico sobre las paredes de la lesión. i) Imagen histológica a mayor aumento. Se muestran células paratiroideas maduras de morfología normal, junto con tejido adiposo circundante. (LESIONES QUÍSTICAS DE PARATIROIDES: A PROPÓSITO DE UNA ENTIDAD HETEROGÉNEA E INFRECUENTE. PRESENTACIÓN DE DOS CASOS CLÍNICOS)
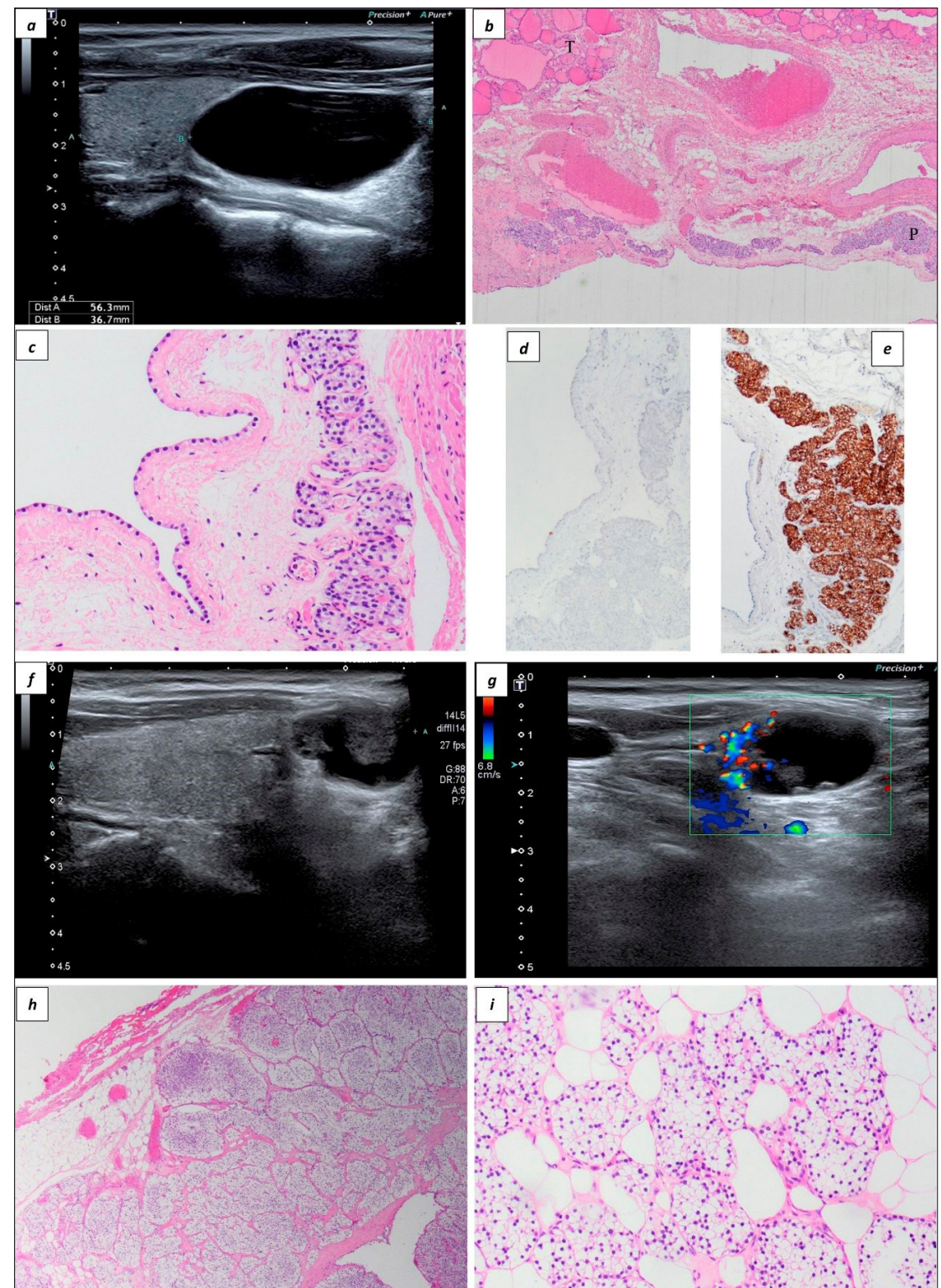


\section{INTRODUCCIÓN}

El término quistes paratiroideos designa lesiones nodulares quísticas que implican a las glándulas paratiroides en su formación. Se distingue entre quistes funcionantes y no funcionantes. Sin embargo, no existen criterios diagnósticos histológicos para esta entidad.

\section{OBJETIVOS}

Reportar dos casos clínicos Proponer criterios definitorios anatomopatológicos

\section{MATERIAL Y MÉTODOS}

Reportar dos casos clínicos

\section{RESULTADOS}

Caso 1. Mujer de 47 años que consulta por masa cervical. Ecografía: nódulo quístico de $36,7 \mathrm{~mm}$ (eje mayor) en tercio inferior del lóbulo tiroideo izquierdo. Mediante PAAF se extraen $6 \mathrm{ml}$ de líquido quístico claro. PTH en lavado de aguja $18,7 \mathrm{pg} / \mathrm{ml}$. Se decide hemitiroidectomía izquierda por persistencia de alteraciones estéticas a pesar de evacuaciones sucesivas. Análisis histológico: formación quística con una luz tapizada por epitelio cuboidal simple (similar al presente en quistes de origen branquial) rodeado de tejido paratiroideo maduro. Las tinciones para PTH y TTF-1 fueron negativas en dicho epitelio, reforzando la teoría de un origen ectópico. Juicio clínico: quiste intratiroideo de probable origen branquial con tejido paratiroideo maduro circundante, sin alteraciones funcionales asociadas. No recidivas durante el seguimiento. Caso 2. Varón de 49 años atendido por crisis paratiroidea (PTH $1560 \mathrm{pg} / \mathrm{ml}$, Ca corregido 17,5 mg/ dl). Presentaba fracaso renal agudo y calcificación de partes blandas (tendinopatía aquílea bilateral). Ecografía cervical: nódulo predominantemente quístico de $24,6 \mathrm{~mm}$ (eje mayor) en polo inferior del lóbulo tiroideo derecho. Se extrajeron $3 \mathrm{ml}$ de líquido claro mediante PAAF, con una concentración de PTH de $6,6 \times 10^{\wedge} 6 \mathrm{pg} / \mathrm{mL}$. Se programó hemitiroidectomía en bloque. El análisis histológico de la pieza fue compatible con adenoma pseudo-quístico de paratiroides, con una cavidad tapizada por una banda de tejido fibroso sin revestimiento epitelial. La evolución clínica postquirúrgica fue lenta pero favorable, con normalización de los niveles de calcio y PTH a 4 meses de seguimiento y una recuperación parcial de la función renal.

\section{CONCLUSIONES}

Proponemos el término "pseudoquiste paratiroideo" en lesiones sin epitelio de revestimiento en la luz quística, y "quiste cervical de origen indeterminado con tejido paratiroideo asociado" en lesiones con revestimiento epitelial de origen no paratiroideo.

\section{PAPEL PRONÓSTICO DE LOS INDICADO- RES METABÓLICOS DE INFLAMACIÓN EN EL COVID19}

PROGNOSTIC VALUE OF METABOLIC AND INFLAMMATORY INIDCATORS IN COVID19

Juan de Dios Barranco Ochoa ${ }^{1 / 1}$; María de Damas Medina ${ }^{1 / 1}$; Inmaculada Prior Sánchez ${ }^{1 / 1}$

(1) Hospital Universitario de Jaén

(1) Endocrinología y Nutrición

\section{TIROIDES-PARATIROIDES (GENERAL)}

\section{INTRODUCCIÓN}

La gravedad del COVID19 viene dada por un estado de hiperinflamación pulmonar bajo una tormenta de citokinas que puede condicionar la muerte.

\section{OBJETIVOS}

Analizar el papel pronóstico de marcadores metabólicos que actúan como indicadores indirectos de inflamación: Índice Pronóstico Nutricional (IPN) e hiperglucemia en la mortalidad por COVID-19.

\section{MATERIAL Y MÉTODOS}

Estudio retrospectivo longitudinal. Se incluyeron a todos los pacientes con COVID19 durante el mes de Noviembre de 2020 en el Hospital de Jaén. Se analizaron variables demográficas, clínicas y analíticas al ingreso: linfocitos $/ \mathrm{mm} 3$, albúmina $(\mathrm{g} / \mathrm{dl})$, Proteína $\mathrm{C}$ Reactiva [PCR $(\mathrm{mg} / \mathrm{L})]$, Ferritina $(\mathrm{ng} / \mathrm{mL})$, Interleucina-6 [IL-6 (pg/mL)], Vitamina D 25-OH (ng/mL), glucemia (mg/dl); y determinaciones de glucemia capilar durante toda la estancia hospitalaria. Análisis estadístico mediante SPSS $^{\circledR}$ El IPN se calculó al ingreso: 10 $\mathrm{x}$ albúmina $(\mathrm{g} / \mathrm{dl})+0,005 \mathrm{x}$ linfocitos totales $(/ \mathrm{mm} 3)$.

Se recogieron datos de: estancia hospitalaria, distrés respiratorio, ingreso en UCI, necesidad de ventilación mecánica y exitus.

\section{RESULTADOS}

$\mathrm{n}=288$, edad media $68.11 \pm 16.6$ años, $55.2 \%$ varones, $27.4 \%$ con antecedente de Diabetes Mellitus(DM). Exitus $19,8 \%$ Se plantean regresiones logísticas individuales de variables analíticas, edad y glucemia máxima, para comprobar qué variables son un factor de riesgo o protección a presentar exitus. Posteriormente se plantea un modelo de regresiones logística multivariante hacia atrás, con las variables que presentan efecto significativo en los modelos individuales. En el modelo multivariante se comprueba que las variables Il-6, PCR, edad, IPN y glucemia se manifiestan como factor de riesgo a presentar el evento y la siendo estas variables estadísticamente significativas. En el Anexo 1 se recogen los resultados de la regresión logística múltiple. A través de este modelo se calcula un Score del riesgo de exitus -Score $<3$ puntos son clasificados como pacientes que no van a fallecer -Score $>3$ puntos son clasificados como pacientes que van a fallecer AUC 83\%, IC95\%(78-88,1); Sensibilidad 96.3\%, IC95\%(90,3-100) y Especificidad 69,78\%, IC95\% $(63,56-76)$. 


\begin{tabular}{|c|c|c|c|c|c|c|}
\hline \multirow[b]{2}{*}{ Variable } & \multirow[b]{2}{*}{$\begin{array}{l}\text { Categoría de } \\
\text { referencia } \\
\text { (riesgo) }\end{array}$} & \multirow[b]{2}{*}{ p_valor } & \multirow[b]{2}{*}{$\begin{array}{l}\text { OR } \\
\text { ajustada }\end{array}$} & \multicolumn{2}{|c|}{ I.C. $95 \%$ para OR } & \multirow[b]{2}{*}{$\begin{array}{l}\text { Puntos } \\
\text { score }\end{array}$} \\
\hline & & & & Inferior & Superior & \\
\hline IL6 & $>25$ & 012 & 3,280 & 1,299 & 8,277 & 1 \\
\hline IPN & $<=40,2$ & ,002 & 3,499 & 1,557 & 7,867 & 1 \\
\hline GLUCEMIA_MAXIMA & $>145$ & ,020 & 2,695 & 1,167 & 6,225 & 1 \\
\hline Edad & $>77$ &, 000 & 9,767 & 4,146 & 23,006 & 2 \\
\hline PCR & $>=94$ & ,003 & 3,638 & 1,561 & 8,477 & 1 \\
\hline
\end{tabular}

Tabla 1. Este modelo presenta una buena capacidad pronóstica del evento. La curva ROC presenta un AUC del 90.6\%, IC 95\% (86,8-94.4); p <0,001(PAPEL PRONÓSTICO DE LOS INDICADORES METABÓLICOS DE INFLAMACIÓN EN EL COVID19)

\section{CONCLUSIONES}

El IPN y la glucemia tienen un alto valor pronóstico y junto con otros parámetros conocidos como la IL6, la edad y la PCR se puede calcular un Score de riesgo con una alta sensibilidad para predecir mortalidad en los pacientes con COVID19.

\section{UTILIDAD DE LA CALCULADORA DE RIES- GO DE MALIGNIDAD DEL NÓDULO TIROI- DEO EN LA ESTRATIFICACIÓN DEL RIESGO EN NÓDULOS TIROIDEOS CON CITOLOGIA INDETERMINADA}

THYROID NODULE RISK CALCULATOR USEFULNESS IN THE RISK STRATIFICATION OF INDETERMINATE THYROID NODULES

Florentino Carral San Laureano ${ }^{1 / 1}$; Juan Jesús Fernández Alba ${ }^{1 / 2}$; Ángela Hens Perez ${ }^{1 / 3}$; Mariana Tomé Fernández-Ladreda ${ }^{1 / 1}$; Ana Isabel Jiménez Millán ${ }^{1 / 1}$; Concepción García Calzado ${ }^{1 / 1}$; Maria Del Carmen Ayala Ortega $a^{1 / 1}$

(1) Hospital Universitario Puerto Real

(1) Endocrinología y Nutrición, (2) Obstetricia y Ginecología, (3) Anatomía Patológica

\section{TIROIDES-PARATIROIDES (GENERAL)}

\section{INTRODUCCIÓN}

La calculadora de riesgo de malignidad del nódulo tiroideo (CRMNT) disponible en la página web de la SAEDYN permite estimar el riesgo de malignidad (RM) individualizado. Los nódulos tiroideos con citología indeterminada (NTCI) constituyen un reto en la práctica clínica, al no disponerse de pruebas diagnósticas que orienten sobre el riesgo de malignidad en estos casos.

\section{OBJETIVOS}

Evaluar si la CRMNT podría ser utilizada para estratificar el riesgo de malignidad de los nódulos tiroideos con citología indeterminada (NTCI).

\section{MATERIAL Y MÉTODOS}

Estudio observacional retrospectivo unicéntrico en el que se evalúan los resultados de 2018 pacientes atendidos en consultas de eco-paaf de tiroides entre 2013 y 2021, identificándose los casos con citología indeterminada (Bethesda III o IV). Se realiza un análisis de la curva ROC para validar el RM estimado por la calculadora como prueba diagnóstica.

\section{RESULTADOS}

El 11,9\% $(n=241)$ de los nódulos tiroideos evaluados entre 2013 y 2021 fueron clasificados como indeterminados (72 Bethesda III y 169 Bethesda IV). El RM fue superior en los NTCI que en los nódulos Bethesda II pero inferior a los nódulos Bethesda V/VI (8,9 \pm $15,8 \%$ vs $20,9 \pm 23,9 \%$ vs $67,5 \pm 28,9 \%$; p $<0,001)$. El $22,5 \%$ de los nódulos intervenidos fueron malignos (46/204), siendo el RM superior al de los nódulos benignos $(42,0 \pm 31,4 \%$ vs $16,3 \pm 19,1 \%$; $<<0.001)$. El área bajo la curva ROC del RM para el diagnóstico de cáncer de tiroides fue de 0,763 (IC 95\%: 0,684-0,842), siendo similar para nódulos Bethesda III (0,734; IC 95\% 0,536-0,932) que para nódulos Bethesda IV (0,777; IC 95\% 0,692-0,862). Los nódulos tiroideos con un $\mathrm{RM} \leq 4 \%$ (48 pacientes; $23,5 \%$ del total) fueron mayoritariamente benignos (46 pacientes; $96 \%$ sensibilidad) sugiriendo una actitud conservadora en estos casos, mientras que los nódulos con $\mathrm{RM} \geq 25 \%$ (61 pacientes; $20 \%$ del total) fueron frecuentemente malignos ( 28 casos; $46 \%$ de todos los nódulos con RM $\geq 25 \%$ y $60 \%$ de todos los cánceres) por lo que la cirugía debería ser indicada. En los nódulos con RM entre 4,1 y $24,9 \%$ (94 pacientes; $46,5 \%$ de los casos) la actitud clínica debería individualizarse. 


\section{CONCLUSIONES}

La calculadora de riesgo de malignidad del nódulo tiroideo (CRMNT), disponible en la página web de la SAEDYN, podría ayudar en la toma de decisiones en pacientes con nódulos tiroideos con citología indeterminada, sugiriéndose una actitud conservadora en los casos con riesgo de malignidad estimado $\leq 4 \%$ y la indicación quirúrgica si el riesgo de malignidad es $\geq 25 \%$.

RESULTADOS DE CONSULTA DE ALTA RESOLUCIÓN DE PATOLOGÍA NODULAR TIROIDEA A TRAVÉS DE PAAF ECOGUIADA A CARGO DE ENDOCRINOLOGÍA EN EL ÁREA DE GESTIÓN SANITARIA SUR DE SEVILLA

RESULTS OF ULTRASOUND GUIDED FINE NEEDLE ASPIRATION FOR EVALUATION OF NODULAR THYROID DISEASE IN A HIGH RESOLUTION CONSULTATION OF ENDOCRINOLOGY IN SOUTHERN SEVILLE HEALTH AREA

\section{José Antonio Ariza Jiménez ${ }^{1 / 1}$; Manuel $\mathbf{J}$ Caballero Segura ${ }^{1 / 1}$; Guillermo Martínez de Pinillos Gordillo ${ }^{1 / 1}$; María Victoria Cózar León ${ }^{1 / 1}$}

(1) Hospital Universitario Virgen de Valme

(1) Endocrinología y Nutrición

\section{TIROIDES-PARATIROIDES (GENERAL)}

\section{INTRODUCCIÓN}

La punción aspiración con aguja fina (PAAF) ecoguiada es una herramienta que ayuda a valorar el riesgo de malignidad de los nódulos tiroideos. Su baja tasa de complicaciones y la valiosa información que aporta la convierten en una técnica fundamental para el estudio de la patología nodular tiroidea.

\section{OBJETIVOS}

Evaluar los resultados obtenidos en una consulta de alta resolución de nódulo tiroideo (CARNT) con realización de ecografía y PAAF ecoguiada en acto único a cargo del endocrinólogo.

\section{MATERIAL Y MÉTODOS}

Análisis descriptivo retrospectivo de los pacientes a los que se le realizó PAAF ecoguiada en CARNT entre mayo de 2017 y junio de 2021. Las citologías se informaron siguiendo el sistema Bethesda. Se analizó la actitud diagnóstico-terapéutica final en todos los casos.

\section{RESULTADOS}

Se realizaron 479 punciones (449 nódulos, 22 adenopatías, 8 otras estructuras) en 439 pacientes $(77,7 \%$ mujeres, edad media 51,35 \pm 14,01 años). La demora media desde la derivación a CARNT hasta la realización de la primera PAAF fue de 15,28 \pm 11,69 días.
La procedencia de los pacientes fue: $44,2 \%$ Atención Primaria, 30,3\% Endocrinología, 19,2\% interconsultas de otra especialidad y $6,2 \%$ Urgencias. El tamaño medio de nódulos punzados fue 27,47 $\pm 13,76 \mathrm{~mm}$ (6$87 \mathrm{~mm}$ ). El resultado citológico fue: 14,1\% "no diagnóstica", 60,2\% "benigna”, 15,2\% "atipia de significado incierto", 3,6\% "proliferación folicular", 2,7\% "sospechosa de malignidad" y 4,2\% "maligna”. El 58,6\% de los pacientes punzados se derivó para seguimiento en consultas generales de Endocrinología y el 37,4\% fue remitido a cirugía por sospecha de malignidad o presencia de clínica compresiva. De las biopsias realizadas tras derivación a cirugía, un $53 \%$ presentaron carcinoma tiroideo.

\section{CONCLUSIONES}

La combinación de la valoración clínica junto con la realización de ecografía y PAAF en el mismo acto por parte del endocrinólogo permite realizar un manejo más eficiente de la patología nodular tiroidea, reduciendo significativamente el tiempo de demora para la PAAF y secundariamente el tiempo hasta la intervención quirúrgica en los casos indicados.

Consideramos que la tasa de malignidad observada en los casos remitidos a cirugía refleja un funcionamiento óptimo de la consulta.

\section{DISFUNCIÓN TIROIDEA EN PACIENTES CON ESCLEROSIS MÚLTIPLE TRATADOS CON ALEMTUZUMAB}

THYROID DYSFUNCTION IN PATIENTS WITH MULTIPLE SCLEROSIS TREATED WITH ALEMTUZUMAB

Juan Jesús García González ${ }^{1 / 1}$; Pablo Rodríguez de Vera Gómez ${ }^{1 / 1}$; Reyes Ravé García ${ }^{1 / 1}$; Rocío López Ruiz $^{1 / 2}$; María Asunción Martínez Brocca ${ }^{1 / 1}$; Tomás Martín Hernández ${ }^{1 / 1}$

(1) Hospital Universitario Virgen Macarena, Sevilla

(1) Servicio de Endocrinología y Nutrición, (2) Servicio de Neurología

TIROIDES-PARATIROIDES (GENERAL)

\section{INTRODUCCIÓN}

La disfunción tiroidea se presenta como una complicación frecuente en individuos con esclerosis múltiple tratados con Alemtuzumab, un anticuerpo monoclonal humanizado aprobado en adultos con esclerosis múltiple remitente recurrente (EMRR).

\section{OBJETIVOS}

Descripción de alteraciones tiroideas presentadas en pacientes con esclerosis múltiple tratados con Alemtuzumab durante los años 2015-2019 en el Hospital Universitario Virgen Macarena. 


\section{MATERIAL Y MÉTODOS}

Estudio descriptivo en pacientes con EMRR tratados con Alemtuzumab en el Hospital Universitario Virgen Macarena entre los años 2015 y 2019 que desarrollaron alteraciones tiroideas. Las variables analizadas fueron: sexo, edad, años EM, ciclos de alemtuzumab, tipo de primera alteración tiroidea, actitud inicial y final y número de fluctuaciones hiper/hipo de la función tiroidea.

\section{RESULTADOS}

La incidencia de alteraciones tiroideas en pacientes tratados con alentuzumab fue del $33,84 \%$ en nuestra serie. Se identificaron 44 pacientes ( 35 mujeres y 9 varones), con una edad media de 42,58 años (DE $7,411)$. Los años de evolución de esclerosis múltiple fue de: 10,76 $\pm 6,35$. Ciclos de alemtuzumab recibidos (1: $11,6 \% ; 2: 76,7 \% ; 3: 9,3 \% ; 4: 2,3 \%)$. La alteración tiroidea más frecuente fue hipertiroidismo $(79,5 \%$, con 21 pacientes presentaban antiTSH positivos), seguido de hipotiroidismo (20,5\%). En el 31,7\% de los casos se tomó una actitud expectante, iniciando tratamiento farmacológico en el $68,3 \%$ de los casos (70\% antitiroideos, $23,3 \%$ levotiroxina y $6,7 \%$ terapia dual). Como actitud final, el $55,6 \%$ se mantuvo con el mismo tratamiento farmacológico, 22,2\% fue retirado, $11,1 \%$ se modificó tratamiento, $5,6 \%$ recibió radioyodo y otro $5,6 \%$ fue derivado a cirugía. Se describieron marcadas fluctuaciones en la función tiroidea, con inversiones del tipo de alteración en el $72,4 \%$ de los casos ( 1 inversión en el $28,6 \%, 2$ en el $33,3 \%, 3$ en el $7,1 \%$ y 5 en el $2,4 \%)$.

\section{CONCLUSIONES}

El tratamiento con Alentuzumab se asocia con alteraciones tiroideas, siendo el hipertiroidismo la más frecuente. Por su curso fluctuante, se recomienda vigilancia estrecha del estado tiroideo en pacientes tratados con alentuzumab.

\section{ANATOMÍA PATOLÓGICA DE TIROIDES EN PACIENTES CON ESCLEROSIS MÚLTIPLE TRATADOS CON ALEMTUZUMAB E INTER- VENIDOS POR ALTERACIONES TIROIDEAS REFRACTARIAS}

PATHOLOGICAL THYROID ANATOMY IN PATIENTS WITH MULTIPLE SCLEROSIS TREATED WITH ALEMTUZUMAB AND OPERATED ON FOR REFRACTORY THYROID DISORDERS

\section{Juan Jesús García González ${ }^{1 / 1}$; Pablo Rodríguez de Vera Gómez ${ }^{1 / 1}$; Reyes Ravé García ${ }^{1 / 1}$; Rocío López Ruiz $^{1 / 2}$; María Asunción Martínez Brocca ${ }^{1 / 1}$; Tomás Martín Hernández ${ }^{1 / 1}$}

(1) Hospital Universitario Virgen Macarena, Sevilla

(1) Servicio de Endocrinología y Nutrición, (2) Servicio de Neurología

TIROIDES-PARATIROIDES (GENERAL)

\section{INTRODUCCIÓN}

La disfunción tiroidea se presenta como una complicación frecuente en individuos con esclerosis múltiple tratados con Alemtuzumab, un anticuerpo monoclonal humanizado aprobado en adultos con esclerosis múltiple remitente recurrente (EMRR).

\section{OBJETIVOS}

Descripción anatomopatológica de glándula tiroidea en pacientes con esclerosis múltiple tratados con alemtuzumab durante los años 2015-2019 en el Hospital Universitario Virgen Macarena e intervenidos por alteraciones tiroideas refractarias a tratamiento médico.

\section{MATERIAL Y MÉTODOS}

Estudio descriptivo en pacientes con EMRR tratados con Alemtuzumab en el Hospital Universitario Virgen Macarena entre los años 2015 y 2019 que desarrollaron alteraciones tiroideas. Las variable analizada fue la anatomía patológica de la glándula tiroides en aquellos pacientes que se indició tiroidectomía (total o subtotal) por alteraciones tiroideas refractarias a tratamiento médico.

\section{RESULTADOS}

Durante los años 2015 y 2019, 133 pacientes con esclerosis múltiple recibieron tratamiento con Alemtuzumab. 52 pacientes (39\%) presentaron algún tipo de alteración en la función tiroidea (hiper o hipotiroidismo). En 8 pacientes $(15,38 \%)$ de los 52 que presentaron algún tipo de alteración tiroidea, se indicó tratamiento quirúrgico por mal control en la función a pesar de tratamiento médico. En los 8 pacientes se realizó tiroidectomía total (100\%). Los informes anatomopatológicos de la pieza quirúrgica (tiroides) arrojó los siguientes resultados: 6 piezas fueron informadas como hiperplasia difusa (75\%), 2 de las 6 con focos de tiroiditis linfocitaria y 1 de las 6 con cambios oncocíticos.

Las 2 piezas restantes se informaron como hiperplasia nodular (25\%), una de ellas con focos de tiroiditis linfocitaria. Ninguna pieza fue notificada con sospecha de malignidad.

\section{CONCLUSIONES}

El tratamiento con Alentuzumab se asocia con alteraciones tiroideas. En algunos casos, el tratamiento médico con antiroideos de síntesis o tratamiento sustitutivo con hormona tiroidea no es suficiente para controlar las alteraciones en la función que se presentan. La cirugía se muestra como una opción efectiva e indicada para la resolución en estos casos seleccionados. En nuestra serie, todas las piezas tiroideas intervenidas mostraron resultados benignos.

\section{REESTADIFICACIÓN DEL CÁNCER DIFE- RENCIADO DE TIROIDES SEGÚN LA NUE- VA EDICIÓN DE LA AJCC/TNM}


RE-STAGING OF DIFFERENTIATED THYROID CANCER ACCORDING TO THE NEW EDITION OF THE AJCC / TNM

Soraya León Idougourram ${ }^{1 / 1}$; Ana María Moyano Sánchez $^{1 / 1}$; Carlos Manuel Alzás Teomiro ${ }^{1 / 1}$; Mireia Isabel García Ramírez ${ }^{1 / 1}$; Paloma Moreno Moreno ${ }^{2 / 1}$; María Ángeles Gálvez Moreno ${ }^{2 / 1}$

(1) Médico residente Hospital Reina Sofía de Córdoba, (2) Facultativo Especialista de Área

(1) Endocrinología y Nutrición

\section{TIROIDES-PARATIROIDES (GENERAL)}

\section{INTRODUCCIÓN}

La incidencia del cáncer diferenciado de tiroides (CDT) está aumentando de forma significativa en los últimos años sin que esto se acompañe de un incremento de la mortalidad, lo que sugiere mayor detección de enfermedad subclínica.

\section{OBJETIVOS}

El objetivo de este estudio consiste en comprobar si la nueva edición de la clasificación American Joint Committe on Cancer (AJCC/TNM) predice las tasas mortalidad y morbilidad mejor que la antigua edición; evaluar la respuesta al tratamiento mediante la clasificación dinámica del riesgo (CDR) en pacientes diagnosticados de CDT y tratados quirúrgicamente, y describir si los pacientes cumplían el objetivo de TSH según estadiaje y toleraban adecuadamente el tratamiento supresor con levotiroxina.

\section{MATERIAL Y MÉTODOS}

Estudio retrospectivo de pacientes con CDT diagnosticados entre 2014 y 2019 en el Hospital Universitario Reina Sofía (HURS) de Córdoba. Se compararon las estadificaciones por la séptima y octava clasificación AJCC/TNM para cada paciente y se evaluó la predicción de morbi-mortalidad de dichas clasificaciones.

Se clasificaron a los pacientes en función de la respuesta al tratamiento para determinar si cumplían el objetivo de TSH: respuesta excelente TSH 0.5-2 $\mathrm{mU} / \mathrm{L}$; respuesta indeterminada y bioquímica incompleta TSH 0.1-0.5 $\mathrm{mU} / \mathrm{L}$; respuesta estructural incompleta TSH menor o igual a $0.1 \mathrm{mU} / \mathrm{L}$.

\section{RESULTADOS}

Un total de 184 pacientes cumplieron criterios de inclusión, de los cuales, el $26,1 \%$ fueron reestadiados al aplicar la nueva edición. El número de pacientes clasificados como estadio avanzado cayó del 21,7\% al $4,3 \%$. Las causas más frecuentes de reestadificación fueron el tamaño tumoral y la edad comprendida entre 45-55 años, factores presentes en el 90\% de los reestadificados.

El 57,5\% de la muestra presentaba una respuesta excelente al tratamiento según la CDR, y el 59,5\% de estos pacientes presentaban niveles de TSH dentro de objetivo, con adecuada tolerancia al tratamiento supresor con levotiroxina.

\section{CONCLUSIONES}

Con la implementación de la $8^{\text {a }}$ edición del sistema de clasificación AJCC/TNM para el CDT se espera que la gran mayoría de pacientes se clasifiquen en estadios bajos. Este nuevo modelo de estadificación refleja mejor la excelente supervivencia que conlleva el CDT. En nuestra serie, la mayoría de los pacientes cumplían objetivos de TSH según estadiaje y toleraban el tratamiento supresor con levotiroxina.

\section{ANÁLISIS RETROSPECTIVO DEL CÁNCER DE TIROIDES EN EL ÁREA SANITARIA SUR DE SEVILLA DE 2012 A 2020}

\section{THYROID CANCER IN SOUTH SEVILLE HEAL- TH MANAGEMENT AREA: RETROSPECTIVE ANALYSIS OF THE PERIOD 2012 - 2020}

\author{
Manuel J. Caballero Segura ${ }^{1 / 1}$; Guillermo Martínez de \\ Pinillos Gordillo ${ }^{1 / 1}$; Francisco Sosa Moreno ${ }^{1 / 2}$; María \\ Victoria Cózar León ${ }^{1 / 1}$ \\ (1) H. U. Virgen de Valme, Sevilla \\ (1) UGC Endocrinología y Nutrición, (2) UGC Anatomía \\ Patológica
}

\section{TIROIDES-PARATIROIDES (GENERAL)}

\section{INTRODUCCIÓN}

La incidencia del cáncer de tiroides ha aumentado en gran medida en las últimas décadas. Estudiar sus características histológicas y pronósticas puede ayudar a mejorar el proceso diagnóstico y terapéutico, motivando la realización de este trabajo.

\section{OBJETIVOS}

Analizar de forma descriptiva las características clínicas, histológicas y pronósticas del carcinoma tiroideo en nuestra área sanitaria.

\section{MATERIAL Y MÉTODOS}

Recogida de datos retrospectiva de todos los casos diagnosticados de carcinoma tiroideo en el Área Sanitaria Sur de Sevilla entre los años 2012 y 2020.

\section{RESULTADOS}

Se diagnosticaron 416 casos: 81 en 2012-2014, 139 en 2015-2017 y 196 en 2018-2020. El 78,6\% de los pacientes fueron mujeres, con una edad media de 49,8 $\pm 15,2$ años. El tamaño medio fue $1,6 \pm 1,5 \mathrm{~cm}$ y no se modificó de forma significativa en los diferentes intervalos temporales $(\mathrm{p}=0,47)$. El $97 \%$ de los casos fueron carcinomas diferenciados, el $2 \%$ carcinomas medulares, el $0,5 \%$ carcinomas desdiferenciados / anaplásicos y el $0,5 \%$ linfomas tiroideos. De los CDT, el $44 \%$ fueron 
carcinomas papilares clásicos, el $42 \%$ carcinomas papilares variante folicular y el $14 \%$ carcinomas foliculares. De ellos, el estadio AJCC fue 83,3\% estadio I, 6,9\% estadio II, 4,9\% estadio III y 4,9\% estadio IV ( $8^{\text {a }}$ Ed. desde enero 2018 , previos $7^{\mathrm{a}} \mathrm{Ed}$.) y el riesgo inicial de persistencia de enfermedad fue $65 \%$ riesgo bajo, $27,3 \%$ intermedio y 7,7\% alto (ATA 2015).

\section{CONCLUSIONES}

Se ha incrementado de forma progresiva el diagnóstico de carcinomas tiroideos a lo largo de nuestra serie sin que se justifique por el diagnóstico de neoplasias de menor tamaño. Algunos factores que podrían explicarlo son: el aumento de pacientes estudiados por nódulos tiroideos incidentales en pruebas de imagen, el uso de nuevos sistemas de estratificación de riesgo ecográfico para indicación de PAAF, la creación de un comité multidisciplinar con valoración conjunta de la indicación quirúrgica de patología nodular tiroidea y la incorporación progresiva de Endocrinología en la realización de ecografía y PAAF. La distribución de estadios AJCC y del riesgo inicial de persistencia de los CDT se ha mostrado acorde con lo publicado en la literatura, reflejando el buen pronóstico en un alto porcentaje de casos.

\section{PREVALENCIA DE CARCINOMAS DIFE- RENCIADOS DE TIROIDES (CDT) SOBRE NÓDULOS TIROIDEOS HIPERFUNCIONAN- TES O TÓXICOS}

\section{PREVALENCE OF DIFFERENTIATED THYROID CARCINOMAS (DTC) ON HYPERFUNCTIO- NING OR TOXIC THYROID NODULES}

Sandra Amuedo Domínguez ${ }^{1 / 1}$; Irene De Lara Rodríguez $^{1 / 1}$; Ana Romero Lluch $^{1 / 1}$; Suset Dueñas Disotuar $^{1 / 1}$; Juan Luis Tirado Hospital ${ }^{1 / 2}$; Elena Navarro González $^{1 / 1}$

(1) Hospital Universitario Virgen del Rocío

(1) Endocrinología y Nutrición, (2) Medicina Nuclear

TIROIDES-PARATIROIDES (GENERAL)

\section{INTRODUCCIÓN}

Los nódulos tiroideos con hiperfuncionamiento autónomo representan aproximadamente del 5 al $10 \%$ de todos los nódulos tiroideos. En comparación con los nódulos no tóxicos, tradicionalmente se cree que los nódulos calientes tienen una tasa de malignidad excepcionalmente baja y esto ha dado lugar a recomendaciones de no realizar punciones por aspiración con aguja fina (PAAF) en estas lesiones, independientemente de su tamaño. Sin embargo, estudios recientes han cuestionado el presunto bajo riesgo de malignidad en los nódulos calientes, lo que sugiere que se ha subestimado la incidencia de cáncer y la necesidad de más estudios que arrojen mayor evidencia al respecto.

\section{OBJETIVOS}

1) Valorar la prevalencia de CDT en el examen histológico definitivo, en pacientes sometidos a tiroidectomía total o hemitiroidectomía con nódulos tóxicos en un hospital de tercer nivel. 2) Comprobar la existencia de predictores ecográficos de malignidad sobre nódulos tóxicos.

\section{MATERIAL Y MÉTODOS}

Estudio descriptivo retrospectivo. Criterios de inclusión: nódulos calientes únicos gammagráficamente de 2017 a 2020. Criterios de exclusión: bocios multinodulares tóxicos. Se analizaron datos demográficos, realización o no de PAAF, características ecográficas de los nódulos y registro de función tiroidea al diagnóstico.

\section{RESULTADOS}

(Pendiente de incluir n total): 65 nódulos tóxicos ( $80 \%$ mujeres, edad media $62,3 \pm 13,3$ años, tamaño medio nodular $31,1 \mathrm{~mm}$ ), de los cuales 34 fueron sometidos a intervención quirúrgica $(52,3 \%)$, resultando corresponder al estudio anatomopatológico 2 carcinomas papilares sobre 2 nódulos tóxicos. Los patrones ecográficos de estos nódulos disponían de una clasificación de riesgo en las escalas ACR TI-RADS de TR 4 y 5, respectivamente $\mathrm{y}$, riesgo intermedio y alto en la American Thyroid Association (ATA). La clasificación ecográfica por ACR TI-RADS de los 32 nódulos benignos restantes fue: 9,4\% TR1, 15,6\% TR2, 25\% TR3, 12,5\% TR4, $3,1 \%$ TR5 y $34,4 \%$ no conocida.

\section{CONCLUSIONES}

La prevalencia preliminar de malignidad sobre los nódulos intervenidos fue del 5,8\% (similar a la descrita en la literatura para los nódulos no tóxicos). Puntuaciones más elevadas en las escalas de riesgo de malignidad sobre nódulos tóxicos solitarios, podrían sugerir la necesidad de realizar PAAF sobre los mismos. 
C O MUN I C A C IONES

DEL 44 CONGRESO DE LA SOCIEDAD ANDALUZA DE ENDOCRINOLOGÍA, DIABETES Y NUTRICIÓN

(SAEDYN) 2021 


\section{INFORMACIÓN PARA LOS AUTORES DE ACTUALIDAD MÉDICA}

NORMAS GENERALES

ACTUALIDAD MÉDICA es una revista centenaria (www.actualidadmedica.es) de ámbito científico nacional e internacional que publica artículos de investigación clínica o básica, artículos de docencia y de opinión, cartas al editor, editoriales y comentarios en relación con las enfermedades y patologías que afectan al ser humano fundamentalmente en el ámbito de la medicina interna y otras especialidades médico-quirúrgicas.

Es la revista oficial de la Real Academia de Medicina de Andalucía Oriental, edita 3 números al año, y acepta manuscritos en español e inglés. Tiene una versión impresa (español) y otra versión on line (español o inglés).

\section{RESPONSABILIDADES Y ASPECTOS ÉTICOS EN LA PUBLICACIÓN}

ACTUALIDAD MÉDICA considera que la negligencia en investigación o en publicación es una infracción ética seria y tratará este tipo de situaciones de la manera necesaria para que sean consideradas como negligencia. Es recomendable que los autores revisen el Committee on Publication Ethics (COPE) y el International Committee of Medical Journal Editors para mayor información a este respecto.

La revista ACTUALIDAD MÉDICA no acepta material previamente publicado. El plagio y el envío de documentos a dos revistas por duplicado se consideran actos serios de negligencia. El plagio puede tomar muchas formas, desde tratar de publicar trabajos ajenos como si fueran propios, copiar o parafrasear partes sustanciales de otro trabajo (sin atribución), hasta reclamar resultados de una investigación realizada por otros autores. El plagio, en todas sus formas posibles, constituye un comportamiento editorial no ético y, por tanto, se considera inaceptable. El envío/publicación duplicada ocurre cuando dos o más trabajos comparten la misma hipótesis, datos, puntos de discusión y conclusiones, sin que estos trabajos hayan sido citados mutuamente uno a otro.

\section{INVESTIGACIÓN HUMANA Y ANIMAL}

Toda información identificativa no deberá ser publicada en declaraciones escritas, fotografías o genealogías. Asimismo, no se podrán revelar nombres de pacientes, iniciales o números de historia clínica en materiales ilustrativos. Las fotografías de seres humanos deberá ir acompañadas de un consentimiento informado de la persona y que dicha persona revise el manuscrito previo a su publicación, en el caso de que dicho paciente pueda ser identificado por las imágenes o los datos clínicos añadidos en dicho manuscrito. Los rasgos faciales no deben ser reconocibles. El Comité Editorial puede requerir a los autores añadir una copia (PDF o papel) de la aprobación de un Comité de Ética en el caso de trabajos con experimentación animal o ensayos clínicos (pacientes, material de pacientes o datos médicos), incluyendo una traducción oficial y verificada de dicho documento. Se debe especificar en la sección ética que todos los procedimientos del estudio recibieron aprobación ética de los comités de ética relevantes correspondientes a nivel nacional, regional o institucional con responsabilidad en la investigación animal/humana. Se debe añadir igualmente la fecha de aprobación y número de registro. En caso de que no se hubiera recibido la aprobación ética, los autores deberán explicar el motive, incluyendo una explicación sobre la adherencia del estudio a los criterios propuestos en la Declaración de Helsinki. (http://www.wma.net/en/30publications/10policies/b3/index.html).

\section{AUTORÍA}

Todos los datos incluidos en la presentación de un manuscrito deben ser reales y auténticos. Todos los autores incluidos deben haber contribuido de forma significativa a la elaboración del documento, así como tiene la obligación de facilitar retracciones o correcciones, si fuera necesario, cuando se encuentren errores en el texto.

En el caso de artículos de investigación original y artículos docentes, se recomienda un máximo de 6 autores, aunque se aceptan sugerencias concretas para más de 6 autores. Para otros tipos de manuscritos, 4 autores será considerado un número aceptable. Cada autor deberá especificar cómo desea que se cite su nombre (i.e., solo el primer apellido, los dos apellidos o unir ambos apellidos con guión). En caso de ser necesario, se requerirá que cada autor especifique el tipo y grado de implicación en el documento. 


\section{REVISIÓN CIEGA POR PARES}

ACTUALIDAD MÉDICA publica documentos que han sido aceptados después de un proceso de revisión por pares. Los documentos enviados serán revisados por revisores ciegos que no tendrán ningún tipo de conflicto de interés con respecto a la investigación, a los autores y/o a las entidades financiadoras. Los documentos serán tratados por estos revisores de forma confidencial y objetiva. Los revisores podrán indicar algunos trabajos relevantes previamente publicados que no hayan sido citados en el texto. Tras las sugerencias de los revisores y su decisión, los editores de la revista tienen la autoridad para rechazar, aceptar o solicitar la participación de los autores en el proceso de revisión. Tanto los revisores como los editores no tendrán conflicto de interés con respecto a los manuscritos que acepten o rechacen.

\section{LICENCIAS}

En el caso de que un autor desee presentar una imagen, tabla o datos previamente publicados, deberá obtener el permiso de la tercera parte para hacerlo. Este permiso deberá estar reflejado por escrito y dirigido a la atención del editor de la revista ACTUALIDAD MÉDICA. En caso de que una institución o patrocinador participe en un estudio, se requiere de forma explícita su permiso para publicar los resultados de dicha investigación. En caso de presentar información sobre un paciente que pueda revelar su identidad, se requiere el consentimiento informado de dicho paciente por escrito.

\section{CONFLICTO DE INTERESES}

Los autores de un manuscrito son responsables de reconocer y revelar cualquier conflicto de intereses, o potencial conflicto de intereses, que pueda sesgar su trabajo, o pudiera ser percibido como un sesgo en su trabajo, así como agradecer todo el apoyo financiero y colaboraciones personales. ACTUALIDAD MÉDICA se adhiere a las directrices del International Committee of Medical Journal Editors, que está disponible en http://www.icmje.org, incluyendo aquellas de conflicto de intereses y de autoría. Cuando exista conflicto de intereses, deberá ser especificado en la Página de Título. De igual forma, el impreso de Conflicto de Intereses (ver impreso) deberá ser rellenado, firmado por todos los autores y remitido al editor ACTUALIDAD MÉDICA. Los autores deberán mencionar el tipo de relación e implicación de las Fuentes financiadoras. Si no existe conflicto de intereses, deberá especificarse igualmente. Cualquier posible conflicto de intereses, financiero o de cualquier otro tipo, relacionado con el trabajo enviado, deberá ser indicado de forma clara en el documento o en una carta de presentación que acompañe al envío.

\section{CONSENTIMIENTO INFORMADO}

En el último párrafo de la sección Material y Métodos, los autores deberán comentar que los pacientes incluidos en el estudio dieron su consentimiento a participar después de haber sido informados de forma concienzuda acerca del estudio. El editor de ACTUALIDAD MÉDICA, si lo considera necesario, puede requerir la presentación de este consentimiento informado a los autores.

\section{ENVÍO DE MANUSCRITOS}

Los manuscritos deberán ser remitidos por internet a través de la dirección www.actualidadmedica.es en el enlace de Envío de Manuscritos, debiéndose previamente registrar en dicha página y siguiendo las normas e instrucciones que aparecen en la misma. El texto del manuscrito (incluyendo primera página o página de título, resumen, cuerpo del artículo, agradecimientos y referencias) deberán incluirse en un único archivo. Las figuras y tablas deberán adjuntarse en archivos separados, usando un archivo para cada tabla o figura.

El envío de manuscritos a la revista a través de la plataforma disponible no conlleva ningún tipo de cargo de envío. La eventual aceptación de un manuscrito no conlleva ningún cargo por parte del autor para justificar la edición del mismo. 
NORMAS ESPECÍFICAS PARA CADA TIPO DE ARTÍCULO

\section{ARTÍCULO ORIGINAL DE INVESTIGACIÓN}

Se considerarán trabajos de investigación clínica o básica todos aquellos relacionados con la medicina interna y con aquellas especialidades médico-quirúrgicas que representen interés para la comunidad científica. Los tipos de estudios que se estiman oportunos son los estudios de casos controles, estudios de cohortes, series de casos, estudios transversales y ensayos controlados. En el caso de ensayos controlados deberán seguirse las instrucciones y normativas expresadas en CONSORT disponible en http:// www.consort-statement.org, o en otros similares disponibles en la web.

La extensión máxima del texto será de 3000 palabras que deberán dividirse en las siguientes secciones: Introducción, Material y Métodos, Resultados, Discusión y Conclusiones. Además deberá incluir un resumen de una extensión máxima de 300 palabras estructurado en Objetivos, Métodos, Resultados, Conclusiones. Se acompañará de 3 a 6 palabras clave, recomendándose para las mismas el uso de términos MeSH (Medical Subject Headings de Index Medicus/Medline disponible en: http://www.ncbi.nlm.nih.gov/ entrez/meshbrowser.cgi.) y de términos del Índice Médico Español. Para la redacción de los manuscritos y una correcta definición de palabras médicas le recomendamos consulten el Diccionario de Términos Médicos editado por la Real Academia Nacional de Medicina. En total se admitirán hasta 40 referencias bibliográficas siguiendo los criterios Vancouver (ver más adelante). El número máximo de tablas y figuras permitidas será de 6 . Una figura podrá estar a su vez formada por una composición de varias.

El manuscrito deberá enviarse en formato Word (.doc o .docx), las tablas en formato (.doc o .docx) y las figuras en formato.jpg o .tiff y con una calidad de al menos $300 \mathrm{dpi}$.

\section{ARTÍCULO ORIGINAL DE DOCENCIA}

Se considerarán artículos docentes originales aquellos encaminados a mejorar y aportar nuevos datos sobre un enfoque práctico y didáctico de los aspectos docentes más importantes en las Ciencias de la Salud que ayuden a mejorar la práctica docente diaria.

La extensión máxima del texto será de 2500 palabras que deberá dividirse en los mismos apartados descritos con anterioridad para los Artículos Originales. Se acompañará de un resumen no estructurado de hasta 250 palabras. Se incluirán de 3 a 6 palabras clave. El número máximo de referencias será de 20 . Se podrá acompañar de hasta 3 tablas o figuras en los casos precisos.

El manuscrito deberá enviarse en formato Word (.doc o .docx), las tablas en formato (.doc o .docx) y las figuras en formato.jpg o .tiff y con una calidad de al menos $300 \mathrm{dpi}$.

\section{ARTíCULO DE REVISIÓN}

Son artículos que de forma sistemática intentan mostrar las evidencias más actuales sobre un tema de interés médico o médico-quirúrgico, tratando de establecer una serie de pautas a seguir en determinadas patologías. Los artículos de revisión podrán ser solicitados al autor de forma directa por parte del Comité Editorial (Editor y Editores Asociados) o bien remitidos de forma voluntaria por los autores. Los artículos de este tipo serán revisados por el Comité Editorial, por algún miembro del Comité Asesor/Científico y por Revisores externos.

La extensión máxima del artículo será de 4000 palabras divididas en una Introducción, Cuerpo o Síntesis de la revisión (podrán usarse los apartados y subapartados que se estimen oportunos) y Conclusiones. El resumen no tendrá que ser estructurado, con un máximo de 300 palabras; Se añadirán de 3 a 6 palabras clave. Se permitirán hasta 50 referencias bibliográficas y hasta 10 tablas o figuras.

El manuscrito deberá enviarse en formato Word (.doc o .docx), las tablas en formato (.doc o .docx) y las figuras en formato.jpg o .tiff y con una calidad de al menos $300 \mathrm{dpi}$. 


\section{INFORMACIÓN PARA LOS AUTORES DE ACTUALIDAD MÉDICA}

\section{CASOS CLínICOS}

Se permitirá la elaboración y envío de casos clínicos interesantes y que tengan un mensaje que transmitir al lector. No se contemplarán casos clínicos habituales sin interés para la comunidad científica. La longitud máxima de los casos será de 1500 palabras distribuidas en una Introducción, Caso Clínico y Discusión. El resumen tendrá una extensión máxima de 150 palabras y no necesitará ser estructurado. Se permitirá un máximo de 3 figuras o tablas. El número máximo de referencias bibliográficas será de 10

El manuscrito deberá enviarse en formato Word (.doc o .docx), las tablas en formato (.doc o .docx) y las figuras en formato .jpg o .tiff y con una calidad de al menos $300 \mathrm{dpi}$.

\section{CARTAS AL EDITOR}

Los artículos incluidos en esta sección podrán ser comentarios libres sobre algún tema de interés médico o bien críticas a artículos recientemente publicados (últimos 6 meses) en la revista ACTUALIDAD MÉDICA. Se aceptarán de manera excepcional críticas o comentarios publicados en otras Revistas si tienen un interés médico evidente. La extensión máxima del texto enviado serán 500 palabras sin estructurar.

No es necesario incluir resumen ni palabras clave. Se podrá incluir 1 figura o tabla acompañando a la carta. Como máximo se permiten 5 citas bibliográficas.

El manuscrito deberá enviarse en formato Word (.doc o .docx), las tablas en formato (.doc o .docx) y las figuras en formato .jpg o .tiff y con una calidad de al menos $300 \mathrm{dpi}$.

\section{CRÍTICA DE LIBROS}

En esta sección se permitirá la crítica y comentarios sobre un libro de ámbito médico o médico-quirúrgico en el que se destacarán los aspectos formales y científicos más importantes, así como las aportaciones fundamentales del mismo a la práctica clínica. Su extensión máxima será de 500 palabras. No es necesario resumen, palabras clave y no se permitirán tablas ni figuras, salvo la portada del libro.

El manuscrito deberá enviarse en formato Word (.doc o .docx), las tablas en formato (.doc o .docx)

\section{CARACTERÍSTICAS FORMALES} EN LA REDACCIÓN DEL MANUSCRITO

Cada trabajo, en función del tipo de artículo anteriormente expresado, deberá estar estructurado según se ha comentado anteriormente. De forma general los trabajos deberán ir escritos en folios tamaño DIN A4 con una letra 10, tipo Times New Roman, con unos márgenes de $2.5 \mathrm{~cm}$ y un interlineado de 1.5 con una justificación completa. Los artículos podrán enviarse en Español o Inglés, que son los dos idiomas oficiales de la revista.

Durante la elaboración del manuscrito podrán realizarse abreviaturas, previamenteespecificadas y aclaradas durante la primera aparición de la misma. Se recomienda uso de abreviaturas comunes en el lenguaje científico. No se permitirá el uso de abreviaturas en el título ni el resumen, únicamente en el cuerpo principal del manuscrito. Se deberá hacer especial hincapié en la expresión correcta y adecuada de las unidades de medida.

Se considera fundamental y norma editorial la elaboración de un manuscrito que siga las instrucciones anteriormente mencionadas en cuanto a la estructura de cada uno de los tipos de artículos. 


\title{
INFORMACIÓN PARA LOS AUTORES DEACTUALIDAD MÉDICA
}

La estructura general de envío de los artículos será la siguiente:

\author{
- Página inicial o Página de Título \\ - Deberá incluirse un Título sin más de 90 caracteres que sea lo suficientemente claro y descriptivo \\ - Nombre y Apellidos de los autores \\ - Indicar las Instituciones en las que Trabajan o proceden los autores \\ - Incluir el nombre completo, dirección, e-mail y teléfono del Autor para la Correspondencia \\ - Título breve: Sin superar los 50 caracteres \\ - Añadir el número de palabras sin incluir el resumen y el número de tablas y figuras si procede
}

\begin{abstract}
- Segunda página o Página de Resumen y palabras clave
Se deberá incluir un Resumen si procede según el tipo de manuscrito elegido, en el que deberá incluirse unos Objetivos (indicar el propósito del estudio de forma clara y breve), Métodos (indicando el diseño del estudio, pruebas realizadas, tipo de estudio, selección de pacientes y estudio estadístico), Resultados (los más significativos con su estudio estadístico correspondiente) y Conclusiones (énfasis en lo más importante de lo obtenido en el estudio). A continuación se incluirán de 3 a 6 palabras clave.
\end{abstract}

\section{- Tercera página o Página de Resumen y palabras clave en Inglés}

Siguiendo las mismas recomendaciones anteriormente descritas pero en Inglés.

\section{- Texto y Cuerpo del manuscrito con sus diferentes apartados}

- Introducción: Se incluirán los antecedentes más importantes, así como los objetivos del estudio a realizar.

- Material y Métodos: Es la parte fundamental y más crítica del manuscrito. Es conveniente especificar el periodo de estudio, el tipo de población, el diseño del estudio, los procedimientos e instrumentos utilizados en el estudio, así como especificar los criterios de inclusión y de exclusión en el estudio. Deberá incluirse el tipo de estudio estadístico realizado según las características de las variables analizadas y estudiadas. Además se añadirá si cumple con los requisitos éticos del comité del centro donde se ha llevado a cabo el estudio.

- Resultados: Deben ser claros, concisos y bien explicados. Se intentará resumir parte de ellos en tablas para evitar confusión durante su lectura. Se recomienda no repetir información de las tablas o gráficos en el texto.

- Discusión: Deberán discutirse los resultados obtenidos con respecto a los datos existentes en la literatura de una forma clara y científicamente adecuada. Se evitará repetir comentarios o datos contemplados en los apartados anteriores en la medida de lo posible.

- Conclusiones: Se deberán destacar los aspectos más importantes de los datos obtenidos de forma breve y con mensajes directos

- Agradecimientos

- Referencias o Bibliografía: Se incluirán las citas que el autor o autores hayan utilizado en la elaboración del manuscrito y quede constancia de ellas en el texto. Deberán ser ordenadas según su aparición en el texto y ser incluidas dentro del mismo entre paréntesis y con números arábigos. En general, se deberán referenciar siguiendo las normas Vancouver. Se expresan diferentes ejemplos a continuación para facilitar la labor de los autores. En caso de que su tipo de cita no aparezca entre los ejemplos le rogamos revise las normas Vancouver.

Artículo: Deberán incluirse todos, a menos que haya más de 6, en cuyo caso se pondrán los tres primeros y et al. Ej: Nisengard R, Bascones A. Invasión bacteriana en la enfermedad periodontal. Avodontotoestomatol. 1987; 3: 119-33

Suplemento de un volumen: Shen HM, Zhang KF. Risk assesment of nickel carcinogenicity and occupational lung cancer. Environ Health Perspect. 1994; 102 Supl 1: 275-82.

Suplemento de un número: Ozben T, Nacitarhan S, Tuncer N. Plasma and urine sialic acid in non-insulin dependent diabetes mellitus. Ann ClinBiochem. 1995; 32 (Pt 3): 303-6.

Artículo en prensa: Deberá referenciarse igual que un artículo, pero añadiendo en la medida de lo posible el doi del artículo. Ej: Arrabal-Polo MA, Arias-Santiago S, Arrabal-Martin M. What is the value of boneremodeling markers in patients with calcium stones? Urol Res. doi: 10.1007/s00240-012-0511-1 
Libros: Carranza FA Jr. Glickman'sclinicalperiodontology. Saunders: Philadelphia; 1984

Capítulo de libros: Takey H, Carranza FA Jr. Treatment of furcation involvement and combined periodontal endodontic therapy. En Carranza FA Jr. Glickman's clinical periodontology. Saunders: Philadelphia; 1984. Editores o compiladores como autores: Norman JJ, Redfern SJ, editores. Mental health care for elderly people. Nueva York: Churchill Livingstone; 1996.

Documento de Internet:Donaldsom L, May, R. Healthimplications of geneticallymodifiedfoods [citado 1 de enero. 2013]. www.doh.gov.uk/gmfood.htm

- Tablas. Deberán realizarse siguiendo los mismos criterios en cuanto a tamaño y tipo de letra, así como interlineado. Cada tabla será incluida en una página en solitario y deberá ser numerada de forma correlativa a su aparición en el texto con números arábigos. Deberá llevar un título explicativo del contenido de la misma de manera clara y concisa. El formato de realización de las tablas será .doc o .docx.

- Figuras. Tanto gráficos como fotografías, dibujos o esquemas se consideran figuras. Deberán numerarse según el orden de aparición en el texto. Cada una de las figuras llevará un título explicativo de las mismas, que deberá incluirse en el cuerpo principal del manuscrito tras las Referencias o Bibliografía. Cada figura deberá enviarse en un archivo individual principalmente en formato .tiff o .jpg con una calidad de al menos 300 dpi.Se añadirá además un pie de figura explicativo

\section{DERECHOS DE PROPIEDAD INTELECTUAL Y PROCESO EDITORIAL}

\section{COPYRIGHT}

La Real Academia de Medicina de Andalucía Oriental, como propietaria de la revista ACTUALIDAD MÉDICA será responsable de custodiar los derechos de autoría de cada manuscrito. Los autores serán requeridos a completar un documento en lo que concierne a derechos de autoría y la transferencia de estos derechos a la revista ACTUALIDAD MÉDICA (mirar documento). El autor corresponsal está obligado a declarar si alguno de los autores es empleado del Gobierno de Reino Unido, Canadá, Australia o Estados Unidos de América o si tiene algún tipo de relación contractual con estas instituciones. En el caso de que un autor sea empleado de Estados Unidos de América, deberá especificar el número de contrato, así como si la investigación ha recibido fondos de Estados Unidos.

La firma y acuerdo de copyright incluye:

- Responsabilidad y garantía del autor: El autor garantiza que todo el material enviado a ACTUALIDAD MÉDICA es original y no ha sido publicado por otra revista o en otro formato. Si alguna parte del trabajo presentado ha sido previamente publicada, deberá especificarse en el manuscrito. El autor garantiza que ninguno de los datos presentados infringe los derechos de terceras partes y autoriza a ACTUALIDAD MÉDICA a usar el trabajo si fuera necesario.

- Transferencia de derechos de uso: El autor transfiere a la Real Academia de Medicina de Andalucía Oriental todos los derechos concernientes al uso de cualquier material derivado del trabajo aceptado para publicación en ACTUALIDAD MÉDICA, así como cualquier producto derivado respecto a la distribución, transformación, adaptación y traducción, tal y como figura en el texto revisado de la Ley de Propiedad Intelectual.

Por tanto, los autores no estarán autorizados a publicar o difundir trabajos aceptados para publicación en $A C$ TUALIDAD MÉDICA sin la expresa autorización escrita de la Real Academia de Medicina de Andalucía Oriental.

\section{PROCESO EDITORIAL Y REVISIÓN}

Los manuscritos enviados son recibidos a través de un sistema de envío mediante página web y, una vez recibidos, ACTUALIDAD MÉDICA informará a los autores si el manuscrito es aceptado, rechazado o requiere de un proceso de revisión. El proceso de revisión comienza tras la recepción y una evaluación formal del Editor o Editores Asociados. Posteriormente, el manuscrito sera enviado a un mínimo de dos revisores externos o miembros del Consejo Rector o del Comité Científico sin que aparezca el nombre de los autores, datos personales ni filiación de los mismos para asegurar un proceso de revisión apropiado y objetivo. Una vez que el informe del revisor externo se ha recibido, el Comité Editorial emitirá una decisión que será comunicada a los autores. El primer proceso de revisión no durará más de dos meses. Si un manuscrito requiere cambios, modificaciones o revisiones, será notificado a los autores y se les dará un tiempo para que realicen dichos cambios. La cantidad de tiempo dependerá del número de cambios que se requieran. Una vez que la versión revisada sea enviada, los autores deberán resaltar los cambios 
realizados en un color diferente y adjuntar una carta de respuesta a los revisores donde se argumentan de forma clara dichos cambios realizados en el manuscrito.

El Comité Editorial de ACTUALIDAD MÉDICA se reserve el derecho de hacer cambios o modificaciones al manuscrito con el consentimiento y aprobación de los autores sin hacer cambios en el contenido. El objetivo de estos cambios será mejorar la calidad de los manuscritos publicados en la revista.

Tras la aceptación de un artículo, este será enviado a prensa y las pruebas serán enviadas al autor. El autor deberá revisar las pruebas y dar su aprobación, así como indicar cualquier error o modificación en un plazo de 48 horas. Pasado este tiempo, no se admitirán cambios en el contenido científico, el número o el orden de los autores.

En caso de que aparezca errores tipográficos u otros errores en la publicación final, el Comité Editorial junto con los autores publicarán una aclaración apropiada en el siguiente número de la revista.

En el caso extremo en que los autores insistieran en hacer cambios no autorizados antes de la publicación final del artículo o violar los principios previamente mencionados, el Comité Editorial de ACTUALIDAD MÉDICA se reserva el derecho de no publicar el artículo.

\section{AGRADECIMIENTOS}

En agradecimiento, los revisores recibirán un diploma reconociendo su contribución a ACTUALIDAD MÉDICA (requiere solicitud al Editor). El Comité Editorial y Científico añadirán nuevos revisores cada año y están siempre abiertos a las sugerencias de los revisores para mejorar la calidad científica de la revista.

\section{POLÍTICA EDITORIAL Y PUBLICIDAD}

La revista ACTUALIDAD MÉDICA se reserva el derecho de admitir publicidad comercial relacionada con el mundo de las Ciencias de la Salud si lo cree oportuno.

ACTUALIDAD MÉDICA, su Consejo Editorial y Científico y la Real Academia de Medicina de Andalucía Oriental no se hacen responsables de los comentarios expresados en el contenido de los manuscritos por parte de los autores.

El Comité Editorial.

4 de junio de 2018. 


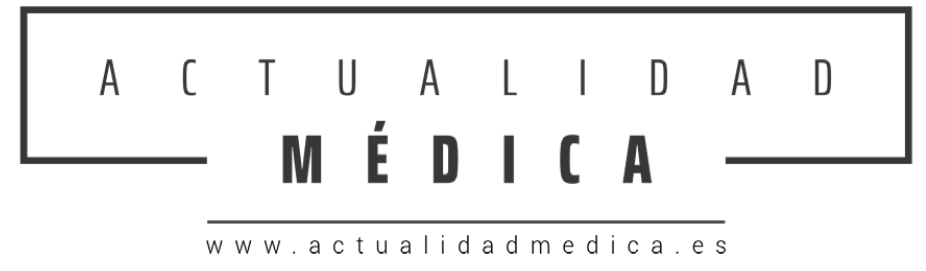




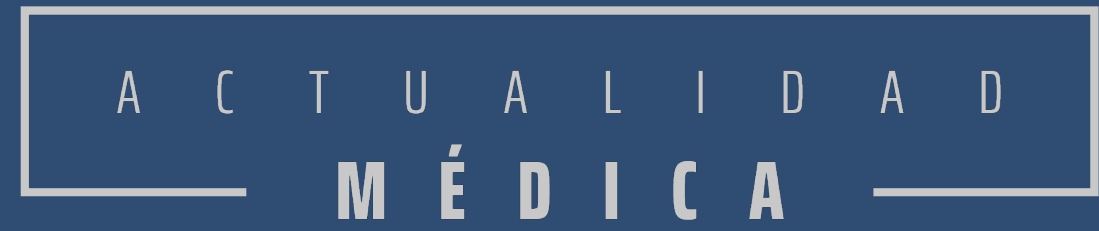

$\overline{\text { ww w a c t u alidad medica.es }}$

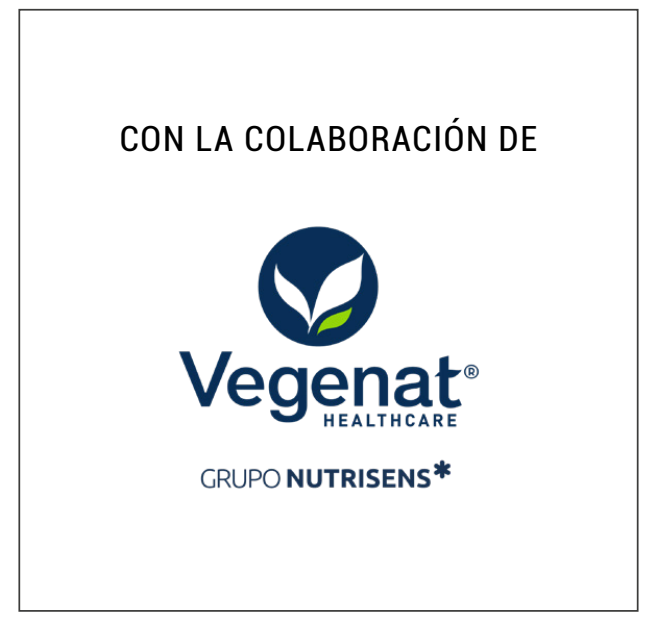

Real Academia de Medicina

y Cirugía de Andalucía Oriental

Real Academia de Medicina de Sevilla

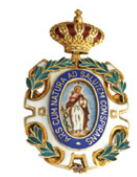

Publicación coordinada por:

FUNDACIÓN

Real Academia de Medicina de Cádiz

\section{ते}

